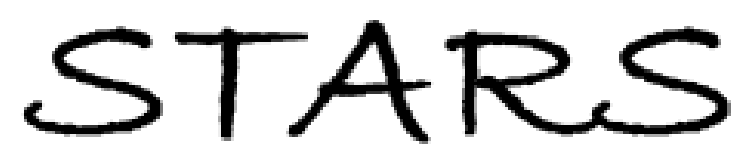

University of Central Florida

STARS

\title{
An Improved Thermoregulatory Model For Cooling Garment Applications With Transient Metabolic Rates
}

Johan Westin

University of Central Florida

Part of the Mechanical Engineering Commons

Find similar works at: https://stars.library.ucf.edu/etd

University of Central Florida Libraries http://library.ucf.edu

This Doctoral Dissertation (Open Access) is brought to you for free and open access by STARS. It has been accepted for inclusion in Electronic Theses and Dissertations, 2004-2019 by an authorized administrator of STARS. For more information, please contact STARS@ucf.edu.

\section{STARS Citation}

Westin, Johan, "An Improved Thermoregulatory Model For Cooling Garment Applications With Transient Metabolic Rates" (2008). Electronic Theses and Dissertations, 2004-2019. 3704.

https://stars.library.ucf.edu/etd/3704

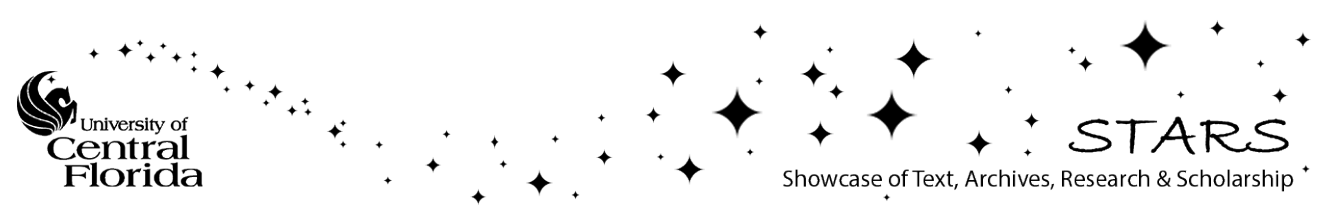




\section{AN IMPROVED THERMOREGULATORY MODEL FOR COOLING GARMENT APPLICATIONS WITH TRANSIENT METABOLIC RATES}

by

\section{JOHAN K. WESTIN}

B.S. University of Central Florida, 2002

M.S. University of Central Florida, 2005

A dissertation submitted in partial fulfillment of the requirements

for the degree of Doctor of Philosophy

in the Department of Mechanical, Materials and Aerospace Engineering

in the College of Engineering \& Computer Science

at the University of Central Florida

Orlando, Florida

\section{Fall Term}

2008

Major Professors:

Jayanta S. Kapat

Louis C. Chow 
(C) 2008 Johan K. Westin 


\begin{abstract}
Current state-of-the-art thermoregulatory models do not predict body temperatures with the accuracies that are required for the development of automatic cooling control in liquid cooling garment (LCG) systems. Automatic cooling control would be beneficial in a variety of space, aviation, military, and industrial environments for optimizing cooling efficiency, for making LCGs as portable and practical as possible, for alleviating the individual from manual cooling control, and for improving thermal comfort and cognitive performance. In this study, we adopt the Fiala thermoregulatory model, which has previously demonstrated state-of-the-art predictive abilities in air environments, for use in LCG environments. We validate the numerical formulation with analytical solutions to the bioheat equation, and find our model to be accurate and stable with a variety of different grid configurations. We then compare the thermoregulatory model's tissue temperature predictions with experimental data where individuals, equipped with an LCG, exercise according to a $700 \mathrm{~W}$ rectangular type activity schedule. The root mean square (RMS) deviation between the model response and the mean experimental group response is $0.16^{\circ} \mathrm{C}$ for the rectal temperature and $0.70^{\circ} \mathrm{C}$ for the mean skin temperature, which is within state-of-the-art variations. However, with a mean absolute body heat storage error $\bar{\varepsilon}_{B H S}$ of 9.7 $\mathrm{W} \cdot \mathrm{h}$, the model fails to satisfy the $\pm 6.5 \mathrm{~W} \cdot \mathrm{h}$ accuracy that is required for the automatic LCG cooling control development.

In order to improve model predictions, we modify the blood flow dynamics of the thermoregulatory model. Instead of using step responses to changing requirements, we introduce exponential responses to the muscle blood flow and the vasoconstriction command. We find that such modifications have an insignificant effect on temperature predictions. However, a new
\end{abstract}


vasoconstriction dependency, i.e. the rate of change of hypothalamus temperature weighted by the hypothalamus error signal $\left(\Delta T_{h y} \cdot d T_{h y} / d t\right)$, proves to be an important signal that governs the thermoregulatory response during conditions of simultaneously increasing core and decreasing skin temperatures, which is a common scenario in LCG environments. With the new $\Delta T_{h y} \cdot d T_{h y} / d t$ dependency in the vasoconstriction command, the $\bar{\varepsilon}_{B H S}$ for the exercise period is reduced by $59 \%$ (from $12.9 \mathrm{~W} \cdot \mathrm{h}$ to $5.2 \mathrm{~W} \cdot \mathrm{h}$ ). Even though the new $\bar{\varepsilon}_{B H S}$ of $5.8 \mathrm{~W} \cdot \mathrm{h}$ for the total activity schedule is within the target accuracy of $\pm 6.5 \mathrm{~W} \cdot \mathrm{h}, \varepsilon_{B H S}$ fails to stay within the target accuracy during the entire activity schedule. With additional improvements to the central blood pool formulation, the LCG boundary condition, and the agreement between model set-points and actual experimental initial conditions, it seems possible to achieve the strict accuracy that is needed for automatic cooling control development. 


\section{ACKNOWLEDGMENTS}

I would like to express my deepest gratitude to my advisors Dr. Jayanta Kapat and Dr.

Louis Chow for their inspiration, support, and guidance throughout the dissertation process and the graduate program. I would also like to thank my committee members Dr. Quanfang Chen, Dr. Gene Lee, and Dr. Xin Li for their advice and helpful comments. 


\section{TABLE OF CONTENTS}

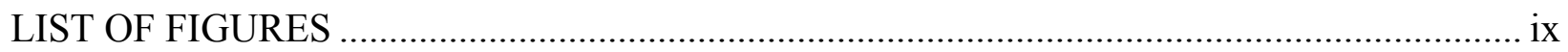

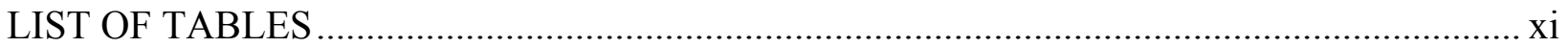

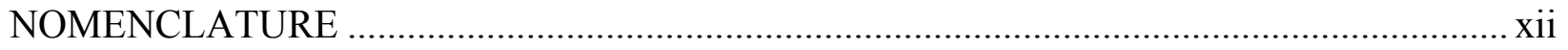

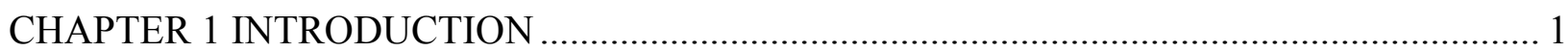

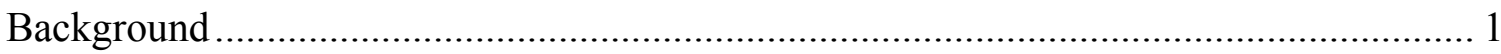

Purpose of Present Study ……………………………............................................... 3

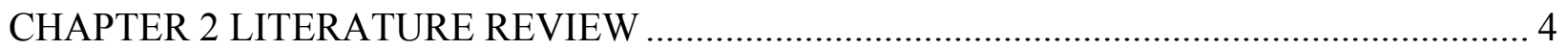

The Human Thermoregulatory System......................................................................... 4

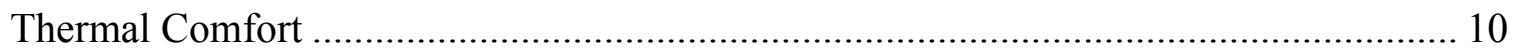

The Cooling Garment ………………………………................................................ 12

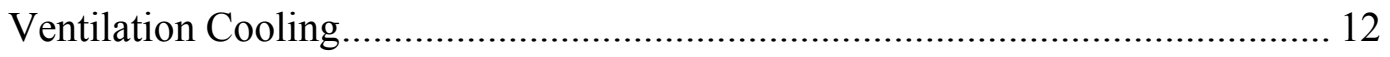

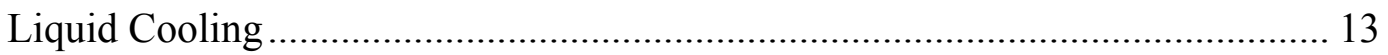

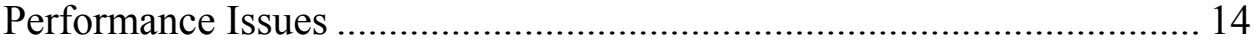

Experimental Investigations................................................................ 17

Human Thermoregulatory Modeling .......................................................................... 19

Early Passive System Development.................................................................. 23

One-Dimensional Thermoregulatory Models …………………………………... 25

Multi-Dimensional Thermoregulatory Models....................................................... 31

Applications to Cooling Garment Environments................................................... 34

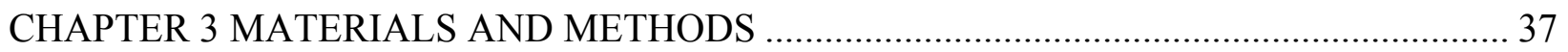

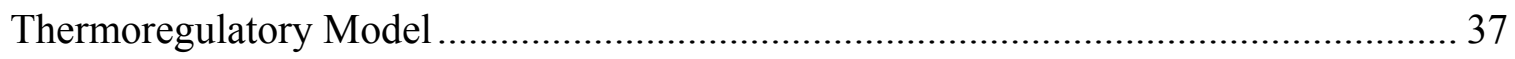

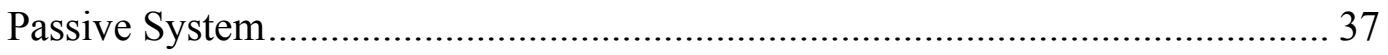

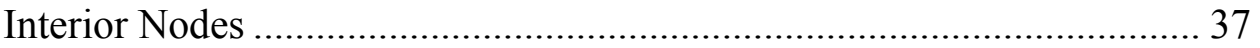

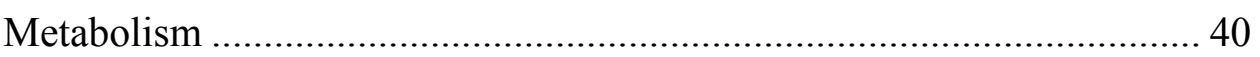

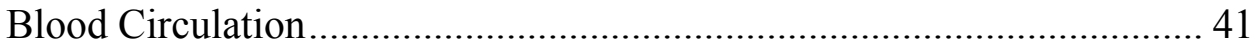




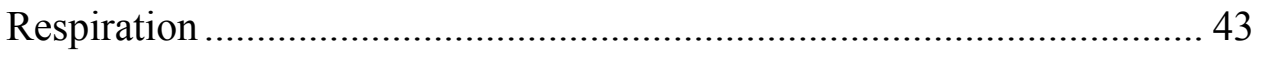

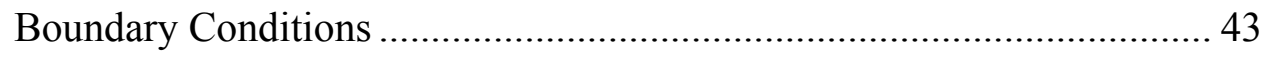

Interface between Two Different Tissue Compartments ............... 43

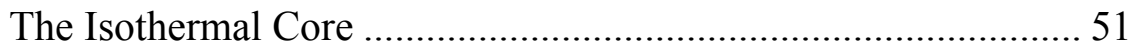

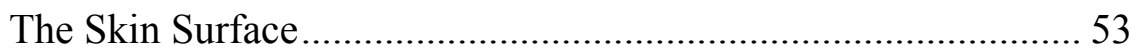

Whole-Body Matrix Equation.................................................................. 56

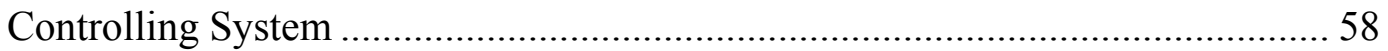

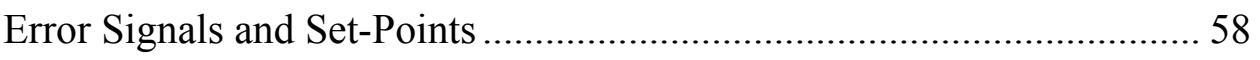

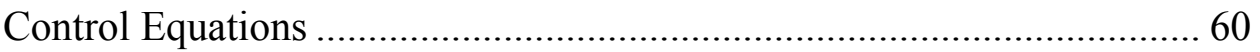

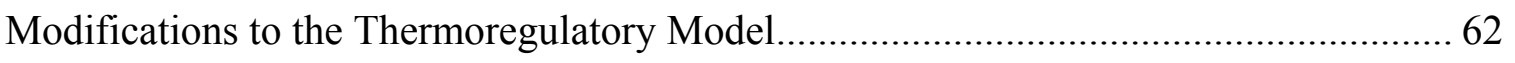

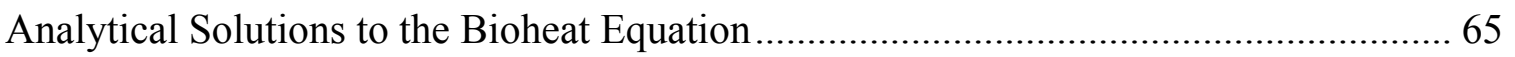

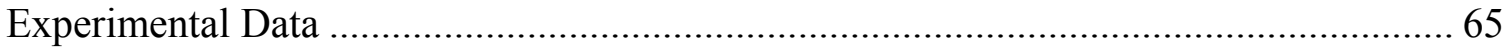

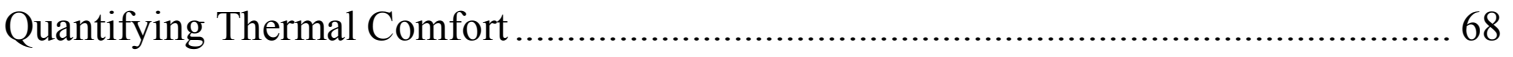

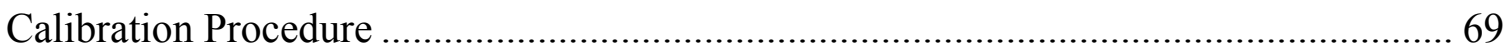

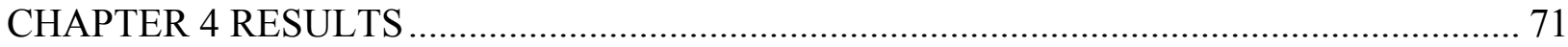

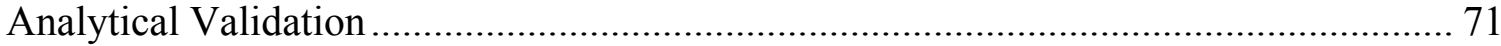

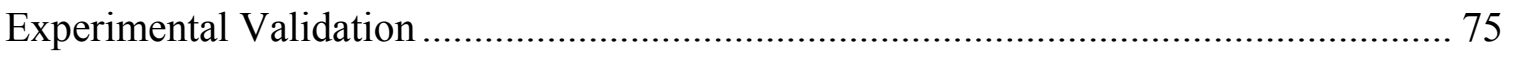

Old Model Response ..................................................................................... 76

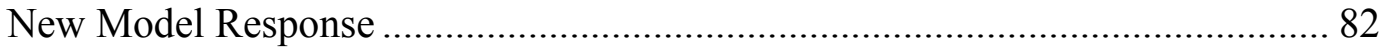

Exponential Delay of Muscle Blood Flow................................................. 82

Exponential Delay of Vasoconstriction …………………....................... 87

Modifying the Vasoconstriction Command............................................... 91

Investigating Dependency on Work Efficiency and LCG Water Temperature.... 99

Assuming a 20\% Instead of a 40\% Work Efficiency ................................. 99

Using Average Instead of Inlet LCG Water Temperature ....................... 102 
CHAPTER 5 CONCLUSIONS AND RECOMMENDATIONS ....................................... 106 APPENDIX A THERMOREGULATORY MODEL PARAMETERS .................................. 109 APPENDIX B AN ANALYTICAL SOLUTION TO PENNES’ BIOHEAT EQUATION....... 113

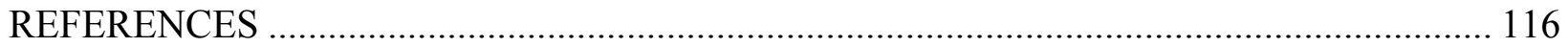




\section{LIST OF FIGURES}

Figure 1: Kuznetz' thermal comfort band [42] .............................................................. 12

Figure 2: Simplified representation of the thermoregulatory system [85] ............................ 21

Figure 3: Body segmentation of the Stolwijk thermoregulatory model [11] ........................... 26

Figure 4: Body segmentation of the Fiala thermoregulatory model [15] .............................. 30

Figure 5: Pairs of regular and fictitious nodes adjacent to the interface between two physiologically distinct tissue compartments (modified from [112]) ........................... 45

Figure 6: Structure of the whole body matrix equation ................................................. 57

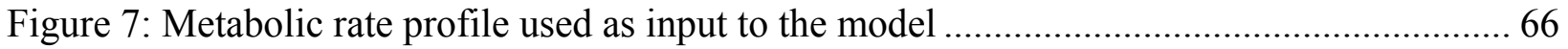

Figure 8: LCG inlet water temperature (mean \pm standard deviation) used as input to the model 67

Figure 9: Comparing model response with exact analytically derived temperatures after a sudden supply of blood perfusion and metabolic heat in a homogeneous cylinder .................... 72

Figure 10: Investigating model response dependency on time step ................................... 73

Figure 11: Investigating model response dependency on radial node spacing ......................... 74

Figure 12: Comparing model response with exact analytically derived temperature profiles in a sphere with eight physiologically distinct compartments ......................................... 75

Figure 13: Predicted sweat production rate and sweat evaporation rate during the activity schedule 77

Figure 14: Comparing predicted rectal and mean skin temperature responses with experimental data and recommended accuracy limits . 78

Figure 15: Predicted variation of body heat storage during the activity schedule 80

Figure 16: Comparing absolute body heat storage error of the old model with comfort band and target accuracy 
Figure 17: Comparing instantaneous versus exponential blood flow response to working muscles in the leg segment 82

Figure 18: Investigating effect of muscle blood flow delay on blood pool temperature response 84

Figure 19: Investigating effect of muscle blood flow delay on rectal temperature response ....... 86

Figure 20: Investigating effect of muscle blood flow delay on mean skin temperature response 87

Figure 21: Investigating effect of vasoconstriction delay on vasoconstriction, vasodilation, and skin blood flow responses. 89

Figure 22: Investigating effect of vasoconstriction delay on rectal and mean skin temperature responses 90

Figure 23: Investigating effect of new vasoconstriction command on vasoconstriction, vasodilation, and skin blood flow responses 92

Figure 24: Investigating effect of new vasoconstriction command on rectal and mean skin temperature responses 94

Figure 25: Comparing absolute body heat storage errors of the old and new models with comfort band and target accuracy..... 97

Figure 26: Rectal and mean skin temperature responses of the old and new models with $20 \%$ work efficiencies 101

Figure 27: Inlet, outlet, and average LCG water temperatures during the activity schedule ..... 103 Figure 28: Rectal and mean skin temperature responses of the old model when using inlet and average LCG water temperatures. 105 


\section{LIST OF TABLES}

Table 1: Set-points obtained when exposing the passive basal model to thermal neutrality........ 76

Table 2: Calibration parameters of the old and the new models............................................ 91

Table 3: Comparing old and new rectal temperature RMS deviations for the different activity

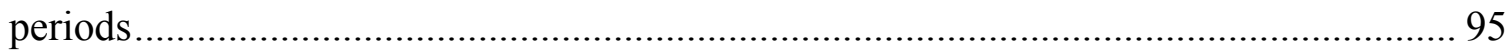

Table 4: Comparing old and new mean skin temperature RMS deviations for the different

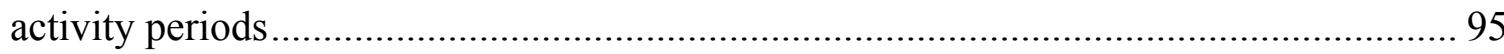

Table 5: Comparing root mean square deviations between measured and predicted temperatures

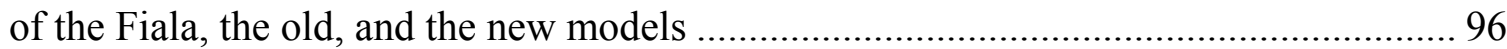

Table 6: Comparing old and new mean absolute BHS errors for the different activity periods... 97

Table 7: Modified calibration parameters of the old and the new models with $20 \%$ work efficiencies 100

Table 8: Comparing old and new mean absolute BHS errors for the different activity periods when using $20 \%$ work efficiencies

Table 9: Calibration parameters of the old model when using inlet and average LCG water temperatures. 104

Table 10: Geometric data of the human body model [15] ................................................. 110

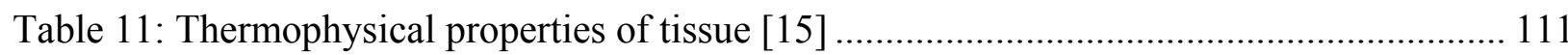

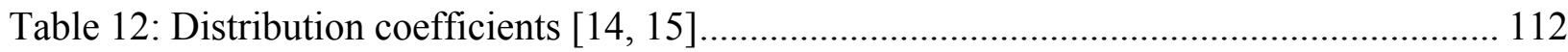




\section{NOMENCLATURE}

\begin{tabular}{|c|c|}
\hline$a$ & distribution coefficient \\
\hline$A$ & interface coefficient; area, $\mathrm{m}^{2}$ \\
\hline ADI & alternating direction implicit finite difference scheme \\
\hline$b$ & calibrated constant in the vasoconstriction command, $\mathrm{h} \cdot \mathrm{K}^{-2}$ \\
\hline BHS & body heat storage, $\mathrm{W} \cdot \mathrm{h}$ \\
\hline$B i$ & Biot number \\
\hline$B P C$ & blood pool column coefficient \\
\hline$B P R$ & blood pool row coefficient, $\mathrm{W} \cdot \mathrm{K}^{-1}$ \\
\hline$c$ & specific heat, $\mathrm{J} \cdot \mathrm{kg}^{-1} \cdot \mathrm{K}^{-1}$ \\
\hline CplC & coupling coefficient, $\mathrm{W} \cdot \mathrm{K}^{-1}$ \\
\hline Cs & vasoconstriction command \\
\hline$D$ & interface coefficient parameter \\
\hline$D l$ & vasodilation command, $\mathrm{W} \cdot \mathrm{K}^{-1}$ \\
\hline Ds & interface coefficient parameter \\
\hline Env & environmental interface coefficient, $\mathrm{K}$ \\
\hline EVA & extravehicular activity \\
\hline$h$ & heat transfer coefficient, $\mathrm{W} \cdot \mathrm{m}^{-2} \cdot \mathrm{K}^{-1}$ \\
\hline$H$ & internal whole body heat load due to work, W \\
\hline$h_{x}$ & countercurrent heat exchange coefficient, $\mathrm{W} \cdot \mathrm{K}^{-1}$ \\
\hline$I_{0}$ & modified Bessel function of the first kind and zero order \\
\hline$I_{1}$ & modified Bessel function of the first kind and first order \\
\hline$J_{0}$ & Bessel function of the first kind and zero order \\
\hline
\end{tabular}




\begin{tabular}{|c|c|}
\hline$J_{1}$ & Bessel function of the first kind and first order \\
\hline$k$ & thermal conductivity, $\mathrm{W} \cdot \mathrm{m}^{-1} \cdot \mathrm{K}^{-1}$ \\
\hline LCG & liquid cooling garment \\
\hline LHS & left hand side \\
\hline$m$ & mass, $\mathrm{kg}, \mathrm{g}$ \\
\hline$M$ & metabolic rate, $\mathrm{W}$ \\
\hline NASA & national aeronautics and space administration \\
\hline$p$ & partial vapor pressure, $\mathrm{Pa}$ \\
\hline PLSS & portable life support system \\
\hline PMV & predicted mean vote \\
\hline PPD & predicted percentage dissatisfied \\
\hline$Q$ & heat transfer rate, $\mathrm{W}$ \\
\hline$q$ & volumetric heat generation rate, $\mathrm{W} \cdot \mathrm{m}^{-3}$ \\
\hline$q^{\prime \prime}$ & heat flux, $\mathrm{W} \cdot \mathrm{m}^{-2}$ \\
\hline$R$ & non-dimensional radius \\
\hline$r$ & radius, $m$ \\
\hline$r h$ & relative humidity, $\%$ \\
\hline RMS & root mean square deviation \\
\hline$r_{o}$ & outer radius, $\mathrm{m}$ \\
\hline$S$ & rate of whole body heat storage, $\mathrm{W}$ \\
\hline SBF & skin blood flow, $\mathrm{L} \cdot \mathrm{min}^{-1}$ \\
\hline$S h$ & shivering command, $\mathrm{W}$ \\
\hline Sw & sweating command, $\mathrm{g} \cdot \mathrm{min}^{-1}$ \\
\hline
\end{tabular}




$\begin{array}{ll}S w_{C A P} & \text { maximum allowable sweat evaporation rate, } \mathrm{g} \cdot \mathrm{min}^{-1} \\ T & \text { temperature, } \mathrm{K},{ }^{\circ} \mathrm{C} \\ t & \text { time, } \mathrm{s}, \mathrm{min}, \mathrm{h} \\ \text { tanh } & \text { hyperbolic tangent function } \\ U & \text { overall heat transfer coefficient, } \mathrm{W} \cdot \mathrm{m}^{-2} \cdot \mathrm{K}^{-1} \\ u_{n} & n \text {-th root of the transcendental equation } \\ V & \text { volume, } \mathrm{m}^{3} \\ \dot{V} & \text { volumetric flow rate, } \mathrm{m}^{3} \cdot \mathrm{s}^{-1} \\ \mathrm{VCG} & \text { ventilation cooling garment } \\ w & \text { perfusion rate, } \mathrm{s}^{-1} \\ W & \text { work rate, } \mathrm{W}\end{array}$

Greek symbols

$\begin{array}{ll}\alpha & \text { thermal diffusivity, } \mathrm{m}^{2} \cdot \mathrm{s}^{-1} \\ \beta & \text { blood perfusion rate factor, } \mathrm{W} \cdot \mathrm{m}^{-3} \cdot \mathrm{K}^{-1} \\ \beta & \text { volume weighted blood perfusion rate factor, } \mathrm{W} \cdot \mathrm{K}^{-1} \\ \gamma & \text { coefficient in the finite difference formulation of the bioheat equation } \\ \delta & \text { coefficient in the finite difference formulation of the bioheat equation, } \mathrm{m}^{3} \cdot \mathrm{K} \cdot \mathrm{W}^{-1} \\ \Delta & \text { difference } \\ \Delta r & \text { radial node spacing, } \mathrm{m} \\ \Delta T & \text { temperature error signal, } \mathrm{K} \\ \Delta t & \text { time step, } \mathrm{s} \\ \varepsilon & \text { absolute error }\end{array}$




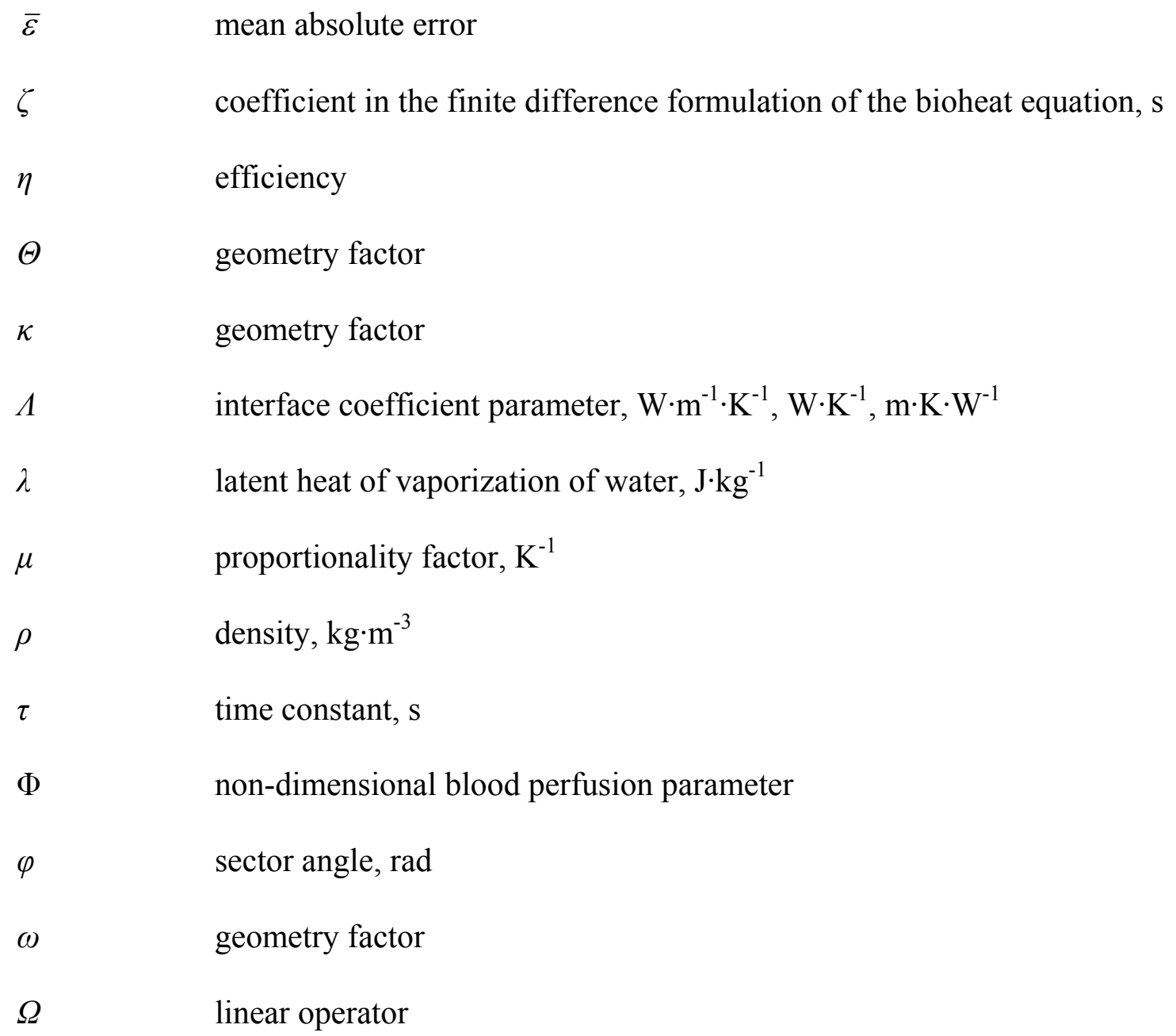




\begin{tabular}{|c|c|}
\hline comp & compartment \\
\hline cond & conduction \\
\hline conv & convection \\
\hline$c S$ & vasoconstriction \\
\hline$c y l$ & cylindrical \\
\hline$d l$ & vasodilation \\
\hline evap & evaporation \\
\hline $\operatorname{expl}$ & explicit \\
\hline$F$ & forward \\
\hline hy & hypothalamus \\
\hline$i$ & initial \\
\hline ifc & interface \\
\hline impl & implicit \\
\hline in & inlet \\
\hline iso & isothermal core compartment \\
\hline$j$ & body segment number \\
\hline lat & latent \\
\hline$L C G$ & liquid cooling garment \\
\hline$m$ & mean; metabolic \\
\hline $\max$ & maximum \\
\hline $\bmod$ & modified \\
\hline$m s c$ & muscle \\
\hline out & outlet \\
\hline
\end{tabular}




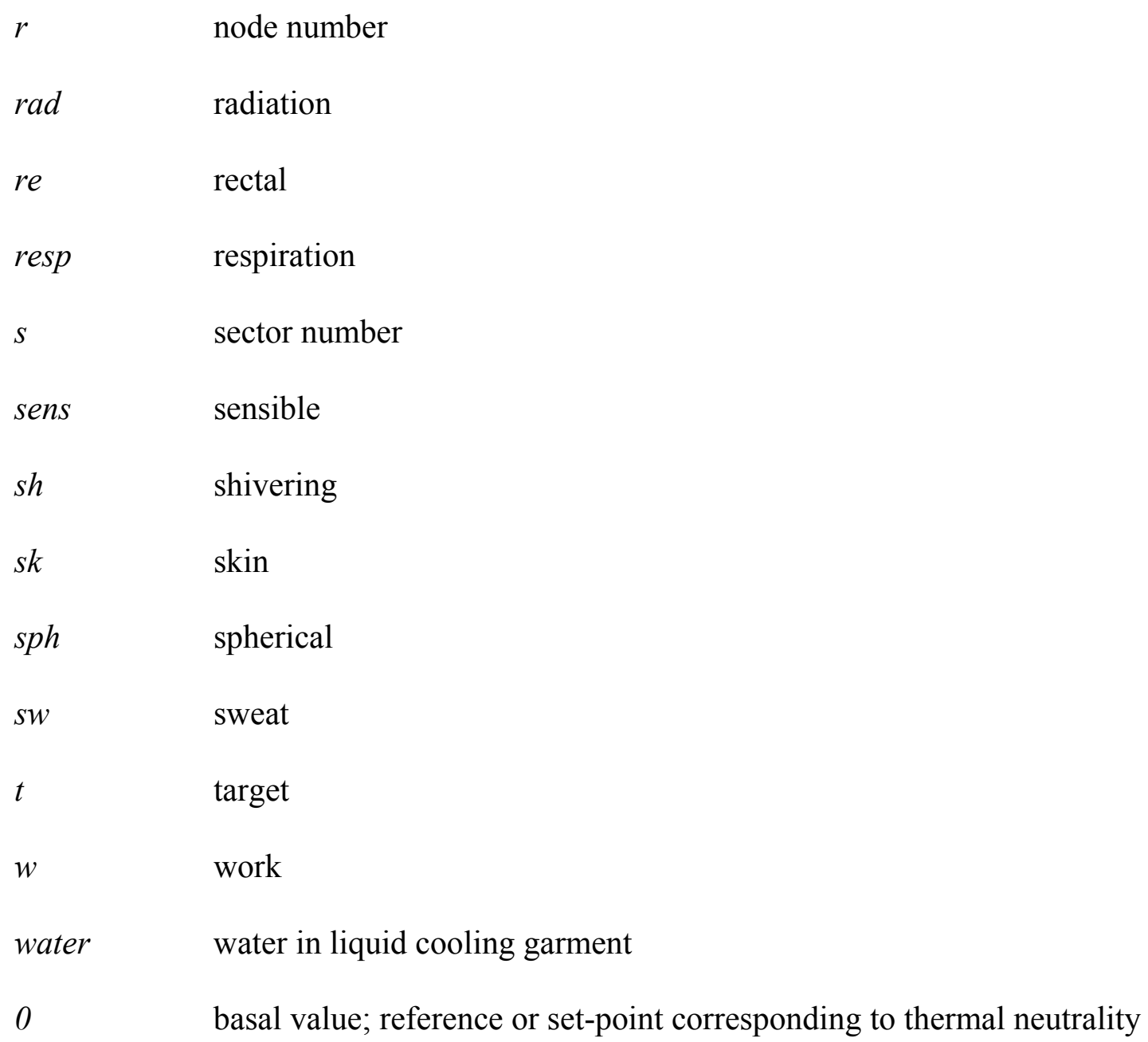




\section{CHAPTER 1 \\ INTRODUCTION}

\section{Background}

There are numerous space, aviation, military, and industrial environments in which individuals need to wear protective clothing. Although such clothing is necessary for human tolerance to hostile environments, its insulative properties impair the body's ability to reject metabolic heat to the surroundings. In order to prevent heat stress and extend tolerance time, a cooling garment needs to be worn under the protective clothing. Cooling garments use circulating liquid and/or gas, or a phase changing substance, and can be used by astronauts, aircrew pilots, military personnel, miners, fire fighters, hazardous material workers, racecar drivers, and furnace workers in metal, glass, and ceramic industries. Liquid cooling garments (LCGs) can also be used for heating deep sea divers, and as a calorimeter for direct determination of metabolic heat production. The LCG can also be used in medical applications to control core and skin temperatures, cutaneous blood flow, and sweat rates during certain procedures.

The individual wearing an LCG usually controls the cooling rate manually, but this is not optimal because perceptual sensation of thermal strain is poor in cooling garment environments, and cooling rate adjustments are usually done too late and too vigorously [1]. This leads to thermal discomfort and stress which not only reduces the individual's cognitive functioning [2], but also leads to inefficient use of coolant and power sources [1]. Automatic cooling control would resolve these problems by matching cooling to actual needs, and relieve the individual 
from a distracting task [1]. Several attempts have been made to develop an automatic controller for inlet coolant temperature, but such a controller has not found widespread implementation [3].

An accurate thermoregulatory model simulating the heat transport within the human body and between the body and the environment would be a useful tool for optimizing automatic cooling control and cooling garment design [4]. Thermoregulatory models can also be used for predicting response and tolerance to hostile environments, for designing climate control in work and living spaces, and for predicting the impact of accidents, diseases, and medical treatments [5, 6]. In addition, thermoregulatory models are valuable tools for gaining insight into the complex non-linear thermoregulatory system. Several thermoregulatory models have been developed over the last four decades including one-dimensional lumped parameter models [7-13], onedimensional finite difference models [14-18], two-dimensional finite difference models [19-21], and three-dimensional finite element models [22, 23]. Despite the development, thermoregulatory models have not found widespread use potentially due to questionable predictive abilities. According to Smith et al. [24] and French et al. [25], state-of-the-art thermoregulatory models do not predict body temperatures with the accuracies that are needed for automatic cooling control development. The deficiencies may be attributed to an incomplete understanding of the complex thermoregulatory system and difficulties obtaining key parameters such as local blood perfusion from experiments. In addition, thermoregulatory models have usually been postulated on a limited number of experiments, and extensive experimental validations have rarely been done.

The Fiala thermoregulatory model has been validated extensively for a wide range of steady and transient air environments and exercise intensities [14], and has shown state-of-the-art predictive abilities in such environments. However, it has not been validated in cooling garment 
environments which may include high and varying metabolic heat loads with limited sweat evaporation. Thermoregulation is therefore mainly achieved by the vasomotor response which would otherwise be overshadowed by sweat evaporation. In order to accurately predict body temperatures in such environments, the thermoregulatory model needs to simulate the vasomotor response well.

\section{Purpose of Present Study}

It has been stated in the literature that a body heat storage accuracy of $\pm 6.5 \mathrm{~W} \cdot \mathrm{h}$ is required for the automatic LCG cooling control development [24]. Is this accuracy attainable with current state-of-the-art thermoregulatory models? In order to answer this question, we will implement Fiala's state-of-the-art thermoregulatory model within an LCG environment and benchmark model predictions with available experimental data for a rectangular type activity schedule where individuals, initially at rest, exercise in LCGs for one hour at a high and constant metabolic rate and thereafter rest for one hour. Even though this simple activity schedule is not typical for real world scenarios, it highlights our model's ability to predict the dynamic thermoregulatory responses after the onset and the cessation of exercise. If the target BHS accuracy is not attainable with the current model formulation, we will identify and correct weaknesses with the model in an effort to attain the target accuracy. 


\section{CHAPTER 2 LITERATURE REVIEW}

\section{The Human Thermoregulatory System}

Energy is liberated when foods such as carbohydrates, fat, and protein react with oxygen to form mainly carbon dioxide and water. These oxidation processes continuously take place in the human body to provide the energy needed for basic physiological functions such as breathing, blood circulation, and the biochemical reactions that sustain life. The rate of energy

utilized by the body is called metabolic rate, and the necessary rate of energy required to support the life sustaining processes is called basal metabolic rate. The metabolic rate increases with muscular activity, food intake, and increasing or decreasing body temperatures. Hence, the basal metabolic rate is determined at rest in a comfortable environment 12-14 hours after food intake [26]. The average man has a basal metabolic rate of about $2000 \mathrm{kcal} /$ day $(97 \mathrm{~W}$ ) [26], but individual differences exists due to factors such as height, weight, body surface area, body fat content, age, and gender.

Muscles have the ability to convert chemical energy into mechanical work. When activated, the muscles increase oxidation rates and metabolic energy production. During strenuous exercise, the average person can increase the metabolic rate up to 10 times the basal rate, while trained athletes may be able to achieve a 20 -fold increase [26]. The mechanical work generated by the muscles can be divided into internal and external components. Internal mechanical work includes that required for respiration, blood circulation, and body movements such as acceleration, deceleration, and stabilization of body parts [27, 28]. External mechanical work is the net work done on the environment including lifting something to a higher level, 
running uphill, and cycling on an ergometer [2]. Internal mechanical work is always converted into heat within the body, while external mechanical work done by the body appears as an energy loss to the environment. However, when external mechanical work is done on the body, it will appear as heat. An example of this is downhill running where potential energy is converted into heat in muscles and joints [2]. The work efficiency $\eta_{w}$ is defined as

$$
\eta_{w}=\frac{W}{M}
$$

where $W(\mathrm{~W})$ is the external mechanical work rate and $M(\mathrm{~W})$ is the metabolic rate. The work efficiency is usually zero or close to zero, because the external mechanical work rate is insignificant for many activities [2]. The maximum work efficiency rarely exceeds $30 \%$ [28], but $40 \%$ work efficiencies have been recorded when individuals walk on treadmills with positive slopes [27]. Due to the mechanical inefficiency of the human musculature, the majority of the metabolic energy will appear as heat during muscular activities. When no external mechanical work is done, the entire metabolic energy will appear as heat within the body.

The human body exchanges heat with the environment at the skin surface by radiation, conduction, convection, and evaporation of water. Breathing also results in small amounts of sensible and latent heat exchanges with the environment. The balance between heat production and environmental heat and work exchanges determines the energy storage and body temperature. Applying an energy balance to the body results in

$$
S=M-\left(W+Q_{\text {cond }}+Q_{\text {conv }}+Q_{\text {rad }}+Q_{\text {evap }}+Q_{\text {resp }}\right)
$$

where $S$ is the rate of heat storage within the body, $M$ is the metabolic rate, $W$ is the rate of external mechanical work done by the body, $Q_{\text {cond }}$ is the rate of conduction heat loss at the skin 
surface, $Q_{\text {conv }}$ is the rate of convection heat loss at the skin surface, $Q_{\text {rad }}$ is the rate of radiation heat loss at the skin surface, $Q_{\text {evap }}$ is the rate of evaporation at the skin surface, and $Q_{\text {resp }}$ is the rate of sensible and latent heat losses from respiration. The external mechanical work done by the body and heat transfer from the body to the environment are considered positive quantities in Equation ( 2 ). The mean body temperature increases when $S$ is positive, it decreases when $S$ is negative, and it remains constant when $S$ is zero and the body is in thermal equilibrium with the environment.

The thermoregulatory system employs different methods to control heat production and heat exchange with the environment including variation of skin blood flow, sweating, and shivering. In addition to fulfilling the metabolic needs of tissue, blood also transports large amounts of heat. The amount of heat reaching the body surface from the core is controlled by varying the blood flow to the skin. When exposed to cold, cutaneous blood vessels constrict to minimize blood flow to the skin. Hence, vasoconstriction increases the thermal resistance of the cutaneous tissue and reduces the skin temperature, which reduces the heat loss rate to a cold environment [29]. Another heat conserving mechanism in the cold is the countercurrent heat exchange between deep arteries and veins in the extremities. This mechanism allows heat transfer from warm arterial blood to the cold venous blood, which reduces heat loss to a cold environment. If vasoconstriction and countercurrent heat exchange are not sufficient to maintain a heat balance in the cold, muscles start shivering to generate heat. Shivering can increase the metabolic rate fivefold [30]. In addition to low core temperature, shivering can also be activated by a rapid decrease in skin temperature [31]. 
When exposed to heat, either from a hot environment or from internal heat production during for instance exercise, cutaneous blood vessels dilate to increase blood flow to the skin. Vasodilation decreases the thermal resistance of the cutaneous tissue and increases the skin temperature [29], which increases body heat loss to a colder environment or decreases body heat gain in a warmer environment. However, the main defense against heat stress is the evaporation of water (or sweat). If permitted by the environment, a certain amount of water is constantly evaporated at the skin surface and via respiration. This amount is normally around $50 \mathrm{~mL} / \mathrm{h}$ and is not under physiological control [26]. During heat stress, sweat is secreted onto the skin surface to increase the evaporation rate. Even though there are large individual differences, the maximum sweat rate is about $2 \mathrm{~L} / \mathrm{h}$, which corresponds to a heat loss of about $1400 \mathrm{~W}$ if the sweat is evaporated on the skin [32]. Acclimatization, which is the physiological adjustment to a particular environment, can increase the maximum sweat rate to $3 \mathrm{~L} / \mathrm{h}$ [33]. However, the maximum sweat rate can only be sustained for a short period of time. For longer periods, the average maximum sweat rate is about $1 \mathrm{~L} / \mathrm{h}$ for an acclimatized individual [31]. Some amount of sweat is usually absorbed by clothing and dripped off or wiped off the skin, and hence does not contribute to body cooling. These losses of latent cooling potential can be significant in humid environments, where evaporation rates are lower than in dry environments.

The thermoregulatory system maintains core temperature within a narrow range despite large variations in environmental conditions. Core temperature is normally said to be $37^{\circ} \mathrm{C}$, but it varies slightly throughout the day, from individual to individual, and with the site of measurement. Since it is not possible to measure the temperature of the hypothalamus, core temperature is usually represented by oral, ear canal, rectal, or esophageal temperature. The oral temperature is the least accurate [31] since it is affected by factors such as mouth breathing, and 
ingestion of hot and cold fluids [26]. The ear canal temperature normally reflects hypothalamic temperature well [31], but it is sensitive to head skin temperature [34] and may be inappropriate during for example active head cooling. The rectal temperature is frequently used as an approximation of hypothalamus temperature, but it is not very responsive and hence unsuitable during thermal transients [34]. Of the above temperatures, the esophageal temperature is the most accurate approximation of hypothalamus temperature since it reflects the temperature of the blood flowing through the heart, it is independent of environmental temperature, and it responds quickly to thermal transients [34]. The core temperature may vary from $35^{\circ} \mathrm{C}$ during sleep to $40^{\circ} \mathrm{C}$ during exercise [35].

Skin temperature is allowed to fluctuate more than core temperature. The average skin temperature of a resting individual in thermal comfort is about $33^{\circ} \mathrm{C}$ with a $6^{\circ} \mathrm{C}$ gradient from the warmer head to the colder hands and feet [36]. When ambient temperature increases, the skin temperatures approaches core temperature, while the skin temperature variation between different body regions decreases. However, the mean skin temperature will always be at least $1{ }^{\circ} \mathrm{C}$ lower than the core temperature if a heat balance is established [32]. When ambient temperature decreases, mean skin temperature decreases while the skin temperature variation between different body regions increases. Mean skin temperature may be as low as $20^{\circ} \mathrm{C}$ in a cold environment [32], where head temperature remains high and skin temperatures of extremities can be very low due to intense vasoconstriction and countercurrent heat exchange between arteries and veins.

When the thermoregulatory system is unable to maintain a thermal balance between the body and the environment, the core temperature will become abnormally high (hyperthermia) or abnormally low (hypothermia). In addition to extreme thermal environments, extensive 
exposures to less severe environments pose a threat as well. Prolonged sweating depletes body water and salts which leads to dehydration, reduced sweat rates, increases in body temperatures, and eventual collapse [29]. A core temperature above $40^{\circ} \mathrm{C}$, can lead to impairment of the central nervous system and circulatory failure [34]. Permanent brain damage may occur at core temperatures above $41^{\circ} \mathrm{C}$ [31], while heat stroke and death are imminent at $43^{\circ} \mathrm{C}$ [26]. Shivering, on the other hand, cannot be sustained indefinitely because of muscle fatigue. A core temperature below $35^{\circ} \mathrm{C}$ is associated with intense shivering and numbness of the skin, a core temperature below $32^{\circ} \mathrm{C}$ is life threatening, and when the core temperature goes below $28^{\circ} \mathrm{C}$, the individual needs to be warmed by external means to return to a normal state [26].

Two different theories exist regarding the objective of the thermoregulatory system. The prevailing theory is that of core temperature regulation, where the objective is to keep the hypothalamic temperature within a narrow range for optimum body function [26]. In this theory, the thermoregulatory center is located in the hypothalamus, which integrates information mainly from temperature sensors in the skin and the hypothalamus itself [34]. The thermoregulatory responses are activated when certain threshold core temperatures are reached [26]. The alternative theory is that of heat regulation, where the objectives are to maintain a body heat balance and to keep body heat content within a narrow range [35]. This theory is based on the existence of temperature sensors at several different depths in the skin, enabling the body to sense heat flow to and from the body [35]. Thermoregulatory responses strive to conserve body heat content (instead of core temperature), so the core temperature is merely a result of the heat content [35]. Regardless of the thermoregulatory objective, the observed responses to heat and cold exposures are consistent. 
During exercise, there is an obligatory rise in the steady state core temperature. According to Webb [35], this rise is due to a time lag between heat production and body heat loss, and not due to a shift in the set-point of the internal thermostat. Both heat production and heat loss respond exponentially to exercise, but their time constants differ significantly [35]. Heat production (or metabolic rate) reaches the new plateau within 2 to 3 min after the onset of exercise, while the corresponding time for body heat loss is 50 to $60 \mathrm{~min}$ [35]. At the onset of exercise, the time lag between heat production and heat loss results in a mandatory period of heat storage and increasing core temperature [35]. Similarly, when exercise stops, heat production quickly returns to normal levels while heat loss responds slower and there is a period of negative heat storage with decreasing core temperature. If exercise is sustained long enough to establish equilibrium, the elevation of core temperature is proportional to the exercise intensity [37].

\section{$\underline{\text { Thermal Comfort }}$}

The thermoregulatory responses discussed so far have been physiological responses that are controlled by the hypothalamus, and not deliberately controlled by the individual. Thermoregulation also includes behavioral responses that are consciously controlled by the individual including adjustment of clothing, voluntary muscular activity that controls heat production, escape from thermally stressful environments, and posture changes that controls exposed surface area. Behavioral thermoregulatory responses are associated with conscious temperature sensation and thermal comfort.

Thermal comfort can be defined as "that condition of mind which expresses satisfaction with the thermal environment" [38]. This is an ambiguous definition since the comfort sensation in a specific thermal environment varies from individual to individual. A more objective 
definition is "thermal neutrality", which refers to the absence of heat storage [29]. This implies that during sedentary activity none of the thermoregulatory responses are activated. However, an exercising subject can be sweating and still be thermally comfortable [2].

Thermal comfort is mainly dependent on activity level, thermal resistance of clothing, ambient air temperature, mean radiant temperature, relative air velocity, and ambient relative humidity [2]. Fanger's "Comfort Equation" and his concepts of "Predicted Mean Vote" (PMV) and "Predicted Percentage Dissatisfied" (PPD) are widely accepted tools for thermal comfort estimations [39]. Fanger's comfort equation [2], which is an extension of Equation ( 2 ) with $S=$ 0 , predicts the combination of environmental factors necessary for optimum thermal comfort for any combination of clothing and activity. The effects of deviations from the optimum conditions are indicated by the PMV scale, which is the predicted mean vote of a large group of people. The PMV scale range from $-3=$ cold $;-2=$ cool $;-1=$ slightly cool; $0=$ neutral $;+1=$ slightly warm; $+2=$ warm; to $+3=$ hot [2]. The PPD predicts the percentage of a large group of people that will be thermally uncomfortable (i.e., a PMV value of $-3,-2,+2$, or +3 ) in a particular environment [2]. The comfort equation, PMV, and PPD are based on steady state conditions and are therefore limited to exposures exceeding one hour with only minor fluctuations in the comfort variables [40]. Hence, these tools are not applicable to situations involving large thermal transients.

Another method to quantify thermal comfort is to relate it to body heat storage. Kuznetz' thermal comfort band, which is frequently used by NASA [41], is based on steady state body heat storage and varies linearly from $0 \pm 19 \mathrm{~W} \cdot \mathrm{hr}$ at a metabolic rate of $146 \mathrm{~W}$ to $40 \pm 19 \mathrm{~W} \cdot \mathrm{hr}$ at a metabolic rate of $586 \mathrm{~W}[42]$. Hence, the cold and hot thresholds for a $146 \mathrm{~W}$ metabolic rate are $-19 \mathrm{~W} \cdot \mathrm{h}$ and $19 \mathrm{~W} \cdot \mathrm{h}$, respectively. The corresponding cold and hot thresholds for a $586 \mathrm{~W}$ 
metabolic rate are $21 \mathrm{~W} \cdot \mathrm{h}$ and $59 \mathrm{~W} \cdot \mathrm{h}$, respectively. Kuznetz' thermal comfort band is illustrated in Figure 1.

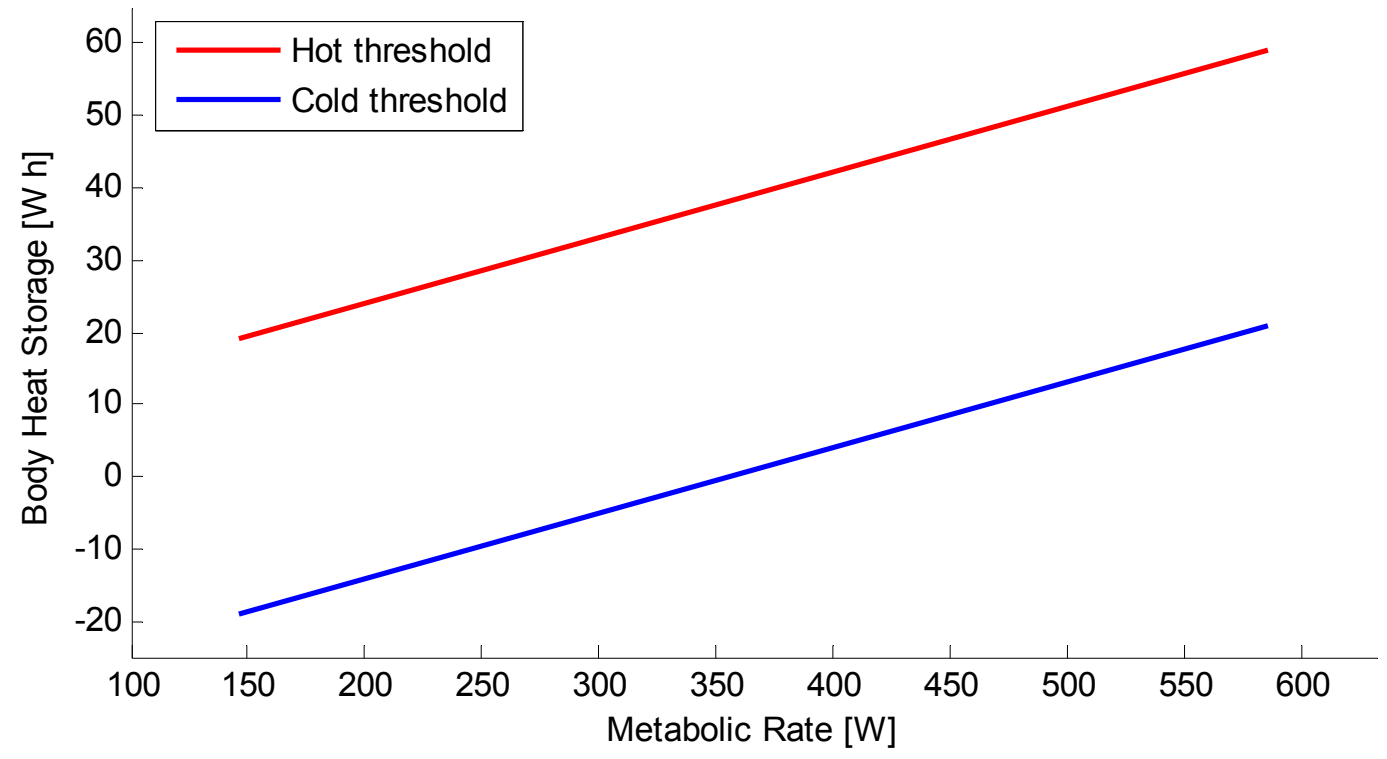

Figure 1: Kuznetz' thermal comfort band [42]

\section{The Cooling Garment}

\section{Ventilation Cooling}

The first major applications of the cooling garment appear to have been for crewmen in hot aircraft cockpits and extravehicular activities [29, 43]. Extravehicular activity (EVA) was one of the main objectives during the Gemini space program in 1963-1966 [44]. The space suit used during these EVAs utilized a flow of gaseous oxygen as the cooling medium, and body heat was removed by both convection and evaporation of sweat [45]. However, at any practical inlet temperature and flow rate, nearly all of the heat removed was by sweat evaporation rather than convection [46], which eventually lead to dehydration and body heat storage. Ventilation cooling 
has also been shown to be inadequate for work rates exceeding $350 \mathrm{~W}[47,48]$. Even though simple tasks were performed, astronauts during the Gemini program overloaded the cooling and carbon dioxide removal capacities of their space suits, and experienced visor fogging, high heart and respiration rates, extreme sweating, and exhaustion, which lead to early termination of the EVAs $[44,45]$. Attempts to increase the capacity of ventilation cooling resulted in unacceptable increases in flow rate, noise level, system weight, and power consumption [49].

\section{Liquid Cooling}

Billingham [50] proposed an improved technique for metabolic heat removal by using water as the cooling medium. The first liquid cooling garment (LCG) was developed in the early 1960's by the Royal Aircraft Establishment [51], and consequently NASA implemented the LCG in the Apollo space suit [29]. However, oxygen ventilation was still required for breathing, suit pressurization, and for elimination of moisture, carbon dioxide and other contaminants. The LCG removes metabolic heat by circulating cold water in flexible tubes that are in contact with the skin. Heat conducts from the skin to the circulating water and is rejected to the environment in an external heat sink. The high heat capacity of water significantly reduces the power consumption of the space suit cooling system compared to ventilation cooling, and decreases garment bulk [51]. The system weight is also drastically reduced for long periods of activity and high cooling loads [52]. The utilization of sensible rather than latent heat transport significantly reduces sweat rate and risk of dehydration and performance reductions. Compared to ventilation cooling, water cooling is considerably more effective in reducing heat strain and improving thermal comfort [29]. 


\section{Performance Issues}

Factors influencing the performance of the liquid cooling garment include specific heat, mass flow rate, and inlet temperature of the fluid, as well as heat sink capacity and supplementary ventilation cooling [29]. There is a non-linear relationship between heat removal and flow rate since increasing the flow rate above $1 \mathrm{~L} / \mathrm{min}$ produces little increase in heat removal rate [53-55]. The fluid inlet temperature has to be such that local skin temperatures are maintained between the absolute limits of $17^{\circ} \mathrm{C}$ and $45^{\circ} \mathrm{C}$, which correspond to the thresholds for cold and heat pain, respectively [56]. However, the practical limits of local skin temperatures are well within these limits and dictated by subjective comfort and heat transfer efficiency. It is desirable to maintain cutaneous circulation during cooling and suppress sweating during heating [57]. According to Chambers [45], skin temperatures during LCG cooling should be maintained between $32.5^{\circ} \mathrm{C}$ and $34.5^{\circ} \mathrm{C}$ for very low activity levels, and between $22^{\circ} \mathrm{C}$ and $28^{\circ} \mathrm{C}$ for extremely high activity levels.

The performance of the liquid cooling garment also depends on design factors such as tubing characteristics, total tubing area in contact with skin, tubing distribution, flow pattern, and fit [29]. Tubing characteristics that influence heat transfer rates include material, wall thickness, and diameter [29]. Furthermore, different body segments prefer different skin temperatures. Hence, if a single inlet temperature is used for the entire body, the lowest inlet temperature is limited by comfort sensations from the most sensitive body regions. For optimum performance, the cooling rate for different body segments should be controlled independently. However, many garments allow only one controlled inlet temperature and flow rate. Since the total tube length is restricted by weight and mobility issues, attention must be given to the tubing distribution. Even though the optimum tubing distribution depends on the environmental conditions and the type of 
physical work being performed [29], various general recommendations have been given for different garments [49, 52, 58-61]. Flow patterns include one-way flow in which the water enters at the extremities and exits at the torso, and loop flow in which the water both enters and exits at the torso [29]. The flow pattern dictates the length of individual tubes, which affects the inletoutlet temperature gradient of the fluid [55]. Another important factor for performance is that the cooling garment fits tightly onto the body since it increases tubing contact area and reduces air gaps that deteriorate heat transfer rates. In addition, flow interruptions such as compressed or kinked tubing can deteriorate heat transfer rates [29].

Furthermore, cooling garment performance is also affected by the associated clothing worn by the individual, environmental factors, and physiological factors. Unless an outer insulation garment is worn, the LCG will also remove heat from a warm environment which will decrease the LCG body heat removal ability. A thin fabric layer may be worn between the skin and the LCG for comfort, but this can deteriorate heat transfer rates significantly [52]. Environmental factors include air temperature and humidity, wind speed, and radiation heat loads. Humidity originating from sweat or from the environment will increase the cooling load on the cooling garment if the moisture is allowed to condense on the cooling tubes. However, superimposing gas ventilation will mitigate this problem. Furthermore, cooling garment performance is also dependent on physiological factors such as metabolic rate, acclimatization, subjective comfort, and tissue conductivity, which depends on blood circulation and fat content [29].

Cooling control is a major concern since the main objective of the cooling garment is to maintain the individual in thermal comfort despite large fluctuations in environmental conditions and exercise rates. Thermal comfort typically refers to a state of thermal neutrality, but for 
optimum heat transfer rates, the individual should be in a vasodilated state [1]. The cooling rate is controlled by regulating the flow rate and inlet temperature of the fluid. However, many investigators have found it more practical to set a reasonable flow rate and vary the inlet temperature alone [1]. Cooling control can be either subjective or objective. Subjective control is based on the individual's sensation of comfort, while objective control is based on physiological variables such as oxygen uptake, heart rate, sweat rate, and skin temperature [29] and/or LCG variables such as inlet temperature and inlet-outlet temperature difference [62]. Objective control can be either manual or automatic. One of the difficulties with cooling control is associated with the time lag between metabolic heat production and body heat loss, which makes it hard to match the required cooling rate following a change in exercise intensity [29].

The individual wearing an LCG usually controls the cooling rate manually, but this is not optimal because perceptual sensation of thermal strain is poor in cooling garment environments, and cooling rate adjustments are usually done too late and too vigorously [1]. This leads to thermal discomfort and stress which not only reduces the individual's cognitive functioning [2], but also leads to inefficient use of coolant and power sources [1]. Automatic cooling control would resolve these problems by matching cooling to actual needs, and relieve the individual from a distracting task [1]. Several attempts have been made to develop an automatic inlet temperature controller based on various inputs such as oxygen consumption rate, heart rate, skin temperature, sweat rate, ear canal temperature, carbon dioxide production, LCG inlet temperature, temperature change across LCG, and LCG heat removal rate [29, 63]. Even though these controllers work for certain conditions, they do not work well over the wide range of conditions experienced by the astronaut [63] and have not found widespread implementation [3]. For improved control design, a complete computer simulation of the astronaut's portable life 
support system (PLSS), controller, space suit, cooling garment, and human body is needed [4, 24]. A critical component of this simulation test bed is the human thermoregulatory model $[4$, 24], but according to [24] and [25], state-of-the-art thermoregulatory models do not predict body temperatures with the accuracies that are needed for automatic cooling control development.

\section{Experimental Investigations}

Several studies demonstrate the powerful cooling capacity of whole body liquid cooling garments. A whole body liquid cooling garment covers the entire body except (a) face, hands and feet, or (b) head, neck, hands and feet [61].

Webb and Annis [64] use whole body liquid cooling garments to remove metabolic heat from individuals during a variety of different exercise programs lasting 3 to 6 hours and consisting of grade walking on a treadmill. The clothing assembly includes a water cooled garment, an insulating suit with air ventilation, an impermeable coverall, and an outer insulation garment. The air ventilation is included to detect sweating and not to remove any significant amounts of latent heat, so the majority of the metabolic heat is removed by the liquid cooling garment. The impermeable coverall and the outer insulation garment are used to prevent latent and sensible heat exchange with the environment. To further minimize environmental heat exchange, the test subjects perform the exercise schedules in an environmental chamber with fast and accurate control of its air temperature. Temperature gradients between the suit and the chamber air can therefore be kept to a minimum. The test subjects are cooled with a network of water tubes that is applied directly onto the skin. It covers the entire body, except the face, hands, and feet, with a contact area of $22 \%$. Water with a constant flow rate of $1.5 \mathrm{~L} / \mathrm{min}$ enters through a common inlet manifold and flows through the suit in five parallel circuits, and exits through a 
common outlet manifold. The common water inlet temperature is continuously adjusted to maintain thermal comfort with minimal sweating. Despite severe metabolic rates up to $1047 \mathrm{~W}$, the cooling scheme achieves complete heat strain reduction, and the test subjects feel comfortable throughout the activity schedules.

In another study by Shvartz and Benor [65], test subjects wearing impermeable clothing walk for two hours on a treadmill in environments ranging from $25^{\circ} \mathrm{C}$ to $50^{\circ} \mathrm{C}$. Cooling is provided with a liquid cooling garment covering the entire body except face, hands, and feet. Water inlet temperature and flow rate are adjusted according to subjective comfort. Without the cooling garment, heat strain increases rapidly in the warm environments and shortens tolerance time. However, when wearing the cooling garment, heat strain is completely eliminated in all environments under consideration.

Waligora and Michel [66] investigate the cooling performance of a garment that excludes the head, neck, hands and feet. The cooling tube coverage is about $17 \%$ [61] and the cooling rate is adjusted according to subjective comfort. The subjects are thermally isolated from the environment, and exercise on a treadmill at varying work rates. The cooling garment, which does not cover the head and neck, can only maintain subjective comfort up to a work rate of $582 \mathrm{~W}$. Even though a whole body LCG that does not cover the head and neck can eliminate about $90 \%$ of the heat strain in extreme environments [61], the individual may still be thermally uncomfortable because of a warm head and facial sweating [61, 67]. For complete heat strain elimination and thermal comfort in severe environments, the whole body LCG needs to include the head and neck [61].

Several experiments have been done where only parts of the body are being cooled. Examples of such partial cooling garment coverage include torso only [68-71]; torso and arms 
[72]; torso, upper arms, and thighs [73]; torso, upper arms, thighs, and head [74]; and head and neck $[58,59,74-80]$. Even though partial cooling does not completely eliminate heat strain in these experiments, substantial reductions in heat strain and increased comfort are achieved. Partial cooling can therefore be feasible in situations where one is willing to accept some heat strain (compared to whole body cooling), in order to improve mobility, reduce weight, and reduce power consumption.

The thermoregulatory characteristics of different body regions differ. The important characteristics for the heat removal rate from a specific region include surface area, local heat production, tissue insulation, vascularity, and ability to maintain thermal exchange when exposed to cold [29]. Due to the local heat production, skin areas covering working muscles are excellent sites for heat removal $[81,82]$, and low skin temperatures can be accepted without discomfort [59]. Except for skin areas covering working muscles, cutaneous blood vessels in the limbs constrict when exposed to cold, which reduces heat removal rates [83]. In contrast, when cooling is applied to the head and neck, cutaneous circulation and high heat transfer rates remain high $[83,84]$. Hence, the head and neck are excellent sites for heat removal, as indicated by numerous studies [58, 59, 61, 74-80, 84].

\section{Human Thermoregulatory Modeling}

Thermoregulatory models simulate human thermal responses to different environments and activities. They are based on thermodynamic theories and transport processes, and include physiological responses such as respiration, shivering, vasoconstriction, vasodilation, and sweating [5]. A thermoregulatory model consists of a controlled passive system and a controlling system. The passive system simulates the heat transport within the body, and between the body 
and the environment. The controlling system controls the thermal state of the body by invoking thermoregulatory responses that regulate heat rejection to the environment and metabolic heat production. The controlling system of most thermoregulatory models is based on the StolwijkHardy error function concept [85]. The interaction between the passive and the controlling system is described in Figure 2. When the passive system is exposed to a thermal disturbance from the environment and/or from metabolic heat, it produces changes in the controlled temperature variables. Thermal receptors sense these changes and generate feedback information, which is integrated in the thermoregulatory center (hypothalamus) and compared to some reference information. The hypothalamus develops error signals and activates control actions that oppose the effect of the disturbance. Vasodilation and sweating are control actions that are activated by positive error signals (heat stress) and serve to increase heat rejection to the environment. Vasoconstriction and shivering are control actions that are activated by negative error signals (cold stress) and serve to reduce heat rejection and increase metabolic heat production, respectively. 


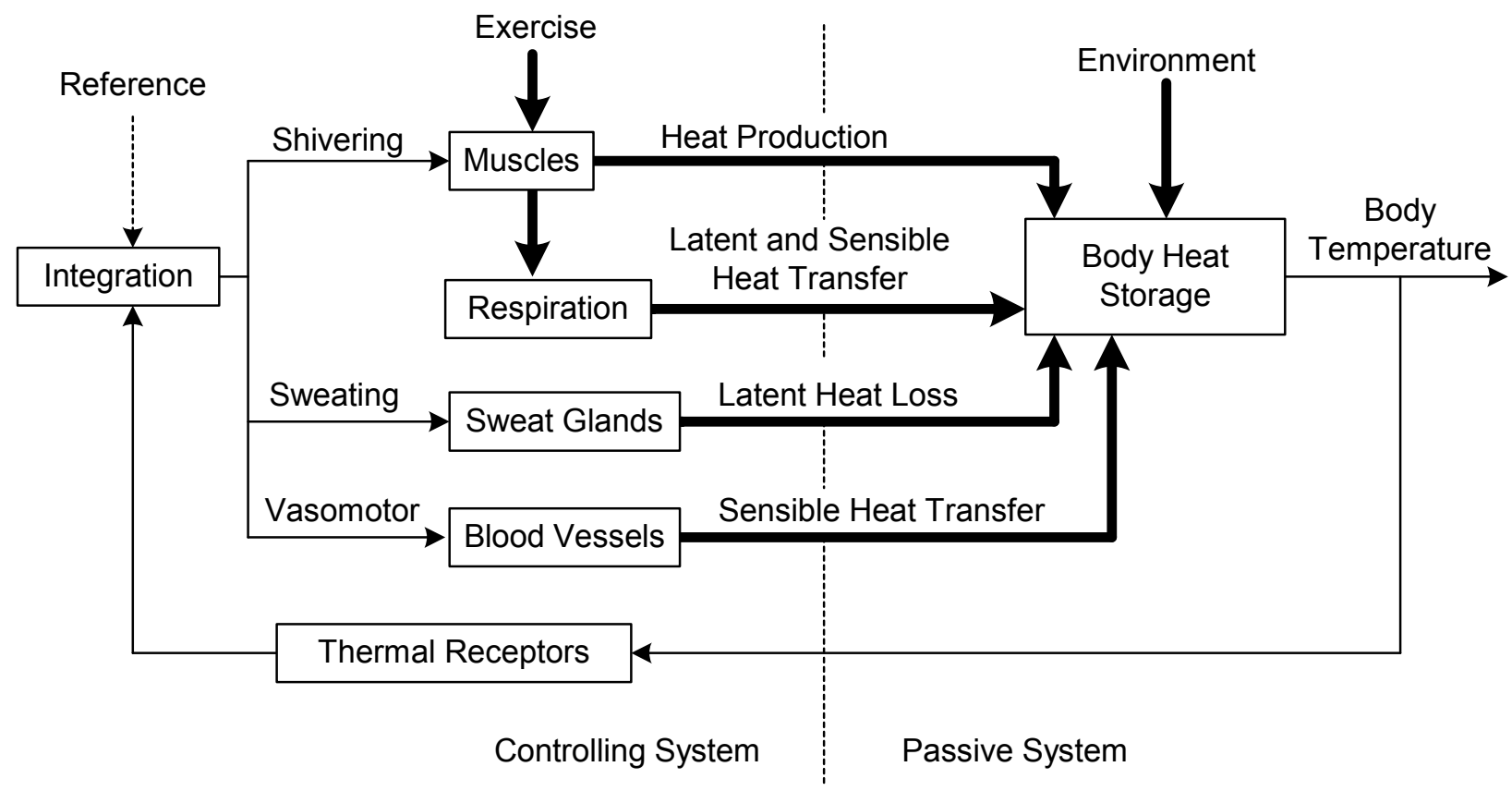

Figure 2: Simplified representation of the thermoregulatory system [85]

The passive system of thermoregulatory models is typically based on the Pennes bioheat equation [86], which quantifies heat transport in living tissue. This equation is an alteration of the regular heat diffusion equation, in which an additional isotropic source term has been added to account for the blood perfusion in the tissue. The Pennes bioheat equation can be expressed as

$$
\nabla \cdot k \nabla T+\rho_{b l} w_{b l} c_{b l}\left(T_{b l, a}-T\right)+q_{m}=\rho c \frac{\partial T}{\partial t}
$$

where $k$ is the thermal conductivity of the tissue, $T$ is the tissue temperature, $\rho_{b l}$ is the blood density, $w_{b l}$ is the volumetric rate of blood perfusion to the tissue per unit volume, $c_{b l}$ is the blood specific heat, $T_{b l, a}$ is the arterial blood temperature of the tissue, $q_{m}$ is the rate of metabolic heat production per unit volume, $\rho$ is the tissue density, $c$ is the tissue specific heat, and $t$ is time.

The blood perfusion source term in Pennes' bioheat equation essentially assumes that all heat exchange between blood and tissue takes place in the capillary bed, and hence neglects the 
heat exchange between larger blood vessels and tissue. This perfusion term lacks directionality and ignores details of the vascular system, such as the branching, tapering, and countercurrent characteristics of the blood vessels. Pennes' perfusion term has been critically discussed in the literature, and several alternative formulations have been suggested [87]. Of these, the Weinbaum-Jiji bioheat equation [88] has received much attention. This equation considers the physical details of the vascular system and models heat transport in tissue containing blood vessels of various sizes. However, it was developed for peripheral tissue and is therefore not suitable for deep tissue containing larger blood vessels [87]. A hybrid model, which applies Pennes' bioheat equation to deep tissue and the Weinbaum-Jiji bioheat equation to peripheral tissue, is suggested in [89]. However, the Weinbaum-Jiji bioheat equation requires detailed information about the vascular architecture, which makes it difficult to use for whole body thermoregulatory models. The Pennes bioheat equation does not require such details, but still produces tissue temperature profiles with comparable accuracy [89].

Numerous thermoregulatory models have been developed throughout the years, and their complexity range from one-dimensional models that represent the body with one or several cylinders to complex three-dimensional finite element models. All thermoregulatory models are population based, and hence predict the average response of a group of people. The models are usually based on a standard man, but some of them can be adapted to account for individual differences such as body surface area, mass, fat content, maximal oxygen uptake, and acclimatization [90]. A brief overview of the existing thermoregulatory models is presented in the following sections. The reader is referred to [5, 6, 91-96], for more comprehensive reviews. 


\section{Early Passive System Development}

The first human thermal models considered only the passive system, and physiological parameters were specified as input data to the models. One of the first passive thermal models assumed the body to be a cylinder with uniform properties throughout [97]. With this model, Burton [97] computed radial temperature profiles within the body following a step increase in water bath temperature, by assuming that vasodilation rapidly increases the effective thermal conductivity by fourfold. He concluded that the thermal capacitance of the body is significant, and that it will take hours to reach thermal equilibrium.

In 1960, Wyndham and Atkins [98] approximated the human body with a single cylinder consisting of several concentric cylindrical compartments. The heat diffusion equation was applied to each compartment, and the effect of peripheral blood perfusion was implicitly taken into account by letting the effective thermal conductivity vary as a function of temperature. By assuming that the rate of heat transfer between adjacent compartments is proportional to the temperature difference between the compartments, a set of first order differential equations was obtained and solved on an analog computer. Although this one-segmental model considers the characteristics of different tissue layers to some extent, it does not account for regional differences between body parts, or non-uniform environments.

Wissler [99] introduced a more realistic multi-segmental passive model by modeling the

body with six cylindrical segments representing head, torso, arms, and legs, which allowed parameters such as metabolic heat generation and blood perfusion to vary between segments. The one dimensional (radial direction) Pennes bioheat equation was applied to each segment, which was assumed to have uniform thermophysical properties, blood perfusion rate, and metabolic heat generation. The model also considered heat transfer through respiration, and 
countercurrent heat exchange between large arteries and veins. Wissler's first model [99] was for steady state applications only, but his second model [100] was extended to transient conditions. In addition, his second model [100] partitioned each segment into two concentric cylindrical compartments. The inner compartment represented bone, tissue, and viscera, while the outer compartment represented fat and skin. Hence, parameters were allowed to vary between the compartments within each segment.

Wissler [101] later increased the number of segments to 15 , which represented head, thorax, abdomen, and the proximal, medial, and distal segments of arms and legs. Each segment contained an arterial and a venous blood pool that perfused the tissue, connected the different segments, and accounted for countercurrent heat exchange between large arteries and veins. Each segment was partitioned into different tissue compartments with different tissue parameters. Each segment contained 15 nodes, which were spaced closer together near the skin surface, where the temperature gradients are the largest. Wissler also added two more terms in the Pennes bioheat equation that account for heat transfer between large arteries and tissue, and between large veins and tissue. A finite difference technique was used to solve the bioheat equation.

Wissler's multi-segmental model [101] was the first complete one-dimensional passive model. However, at the time this model was presented, a rather sophisticated computer was required for managing the computations, especially when integrating the model with the controlling system [95]. Hence, many of the following thermoregulatory models used a simplified passive system. 


\section{One-Dimensional Thermoregulatory Models}

One of the first thermoregulatory models was developed in 1963 by Crosbie and coworkers [102]. Physiological variables such as effective thermal conductivity, metabolic rate, and evaporation rate, were allowed to vary as functions of the mean body temperature. The human body was modeled as an infinite slab, which was partitioned into three compartments that represented core, muscle, and skin. The core compartment was the source of basal metabolism; the muscle compartment was the source of increased metabolism caused by shivering and exercise; and the skin compartment was the heat exchanger between the body and the environment.

One-segmental thermoregulatory models using a cylindrical configuration include the four compartment model developed by Wyndham and Atkins [103] and the two compartment model developed by Gagge and coworkers $[13,104]$. The Gagge model is one of the simplest thermoregulatory models available, but it is limited to moderate activity levels and uniform environments [22]. It has been used to predict thermal comfort [105].

Stolwijk and Hardy developed a series of thermoregulatory models $[11,85,106]$ based on Wissler's multi-segmental approach. Their latest model [11] is from 1977 and represents the trunk, arms, hands, legs, and feet as cylinders, and the head as a sphere (see Figure 3). Each of these six segments is divided into four concentric cylindrical compartments with different thermophysical properties representing core, muscle, fat, and skin. The temperature within each tissue compartment is assumed to be constant throughout its volume, and hence varies with time only. The discontinuous temperature distribution defines the model as a lumped-parameter model. Heat conducts radially between the adjacent tissue compartments, while heat is exchanged between blood and tissue by convection. However, countercurrent heat exchange 
between large arteries and veins is not accounted for in the model, and hence all compartments are supplied with blood at the same temperature. Metabolic heat production is distributed over the different tissue compartments according to their tissue composition. In addition, the skin compartments exchange heat with the environment by conduction, convection, radiation, and evaporation. The controlling system is based on a set point theory, in which the drives for sweating, shivering, vasoconstriction, and vasodilation are functions of error signals. An error signal, which is a measure of heat strain, is the difference between the actual temperature and the set-point temperature for a specific node or quantity. The set-point is the reference state corresponding to thermal neutrality.

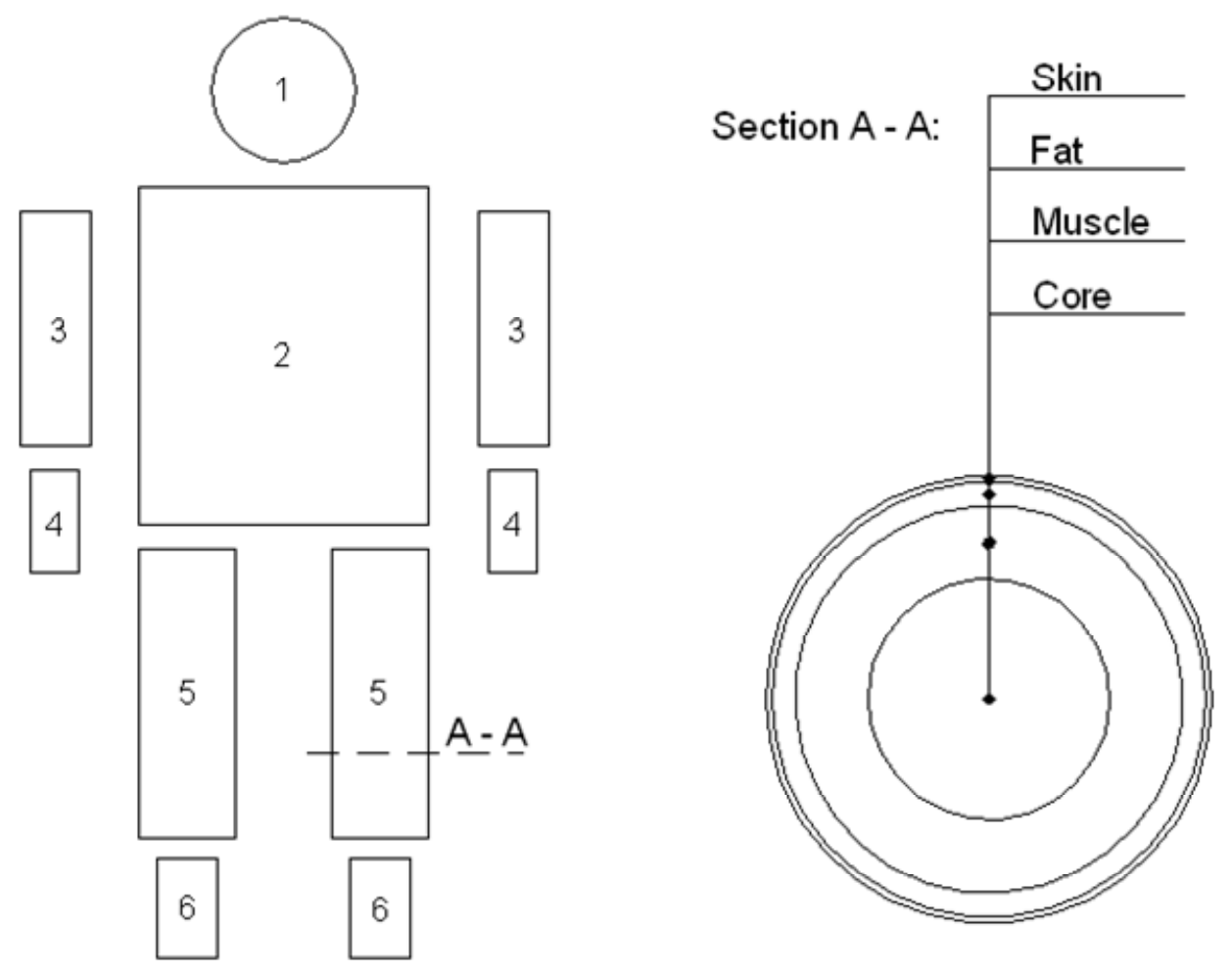

Figure 3: Body segmentation of the Stolwijk thermoregulatory model [11] 
The Stolwijk model is well validated in hot environments, but it has limited capabilities in cold exposures [107], and it is inappropriate for situations involving large and frequent changes in the metabolic rate [4]. The discrepancy in cold exposure is considered to be due to the large temperature gradients between compartments, which introduce errors in the heat flow calculations [11]. One of the reasons for the discrepancy following a step change in metabolic rate is due to the simplified cardiovascular system that immediately supplies the required blood flow to working muscles, and does not allow for the development or repayment of oxygen debts in the working muscles [11]. Hence, when there is a change in metabolic rate, there is a step change in muscle blood perfusion, which induces abrupt changes (sometimes in the wrong direction) in the central blood pool and core temperatures.

In order to improve the model response in cold exposures, Montgomery [12] increased the number of concentric compartments in the Stolwijk model from four to eleven. The model was validated for cold water immersion of nude and wet suited resting individuals. However, some discrepancies exist in the rectal temperature and metabolic rate responses [10].

Gordon and coworkers [18] developed a model to predict thermoregulatory responses to transient cold exposure. In this model, the human body is approximated by 14 cylindrical and spherical segments representing head, forehead, face, neck, thorax, abdomen, arms, hands, legs, and feet. The segments are divided into four or five concentric tissue compartments, and each compartment contains two or more nodes. Counter current heat exchange between large arteries and veins in the extremities is considered. Shivering and vasoconstriction responses are dependent on core temperature, skin temperatures, and skin heat flux. The model has been validated for sedentary subjects exposed to cold air. 
Based on his passive model [101], Wissler developed a thermoregulatory model that includes details on the respiratory and metabolic processes [17]. In addition to computing body temperatures, the model also computes oxygen, carbon dioxide, and lactate concentrations as they relate to the cardiovascular dynamics. This increases the complexity of the model and the computational requirements, but it also provides a more realistic exponential response of blood perfusion to activated or deactivated muscles [4]. The model has been validated for varying metabolic rates, and for hot, cold, atmospheric and hyperbaric environments [17].

Tikuisis and coworkers adapted the Montgomery model, in order to improve predictions of rectal temperature and metabolic rate responses in cold water immersion for nude [10] and clothed [108] subjects at rest, and at a steady work rate [109]. In order to match the rapid initial rise in metabolic rate after immersion, the skin temperature dependency in the shivering command was increased [10]. Furthermore, the onset of shivering in the limbs was exponentially delayed to counteract an unrealistic initial drop in core temperature induced by the increased blood flow to cold limb muscles [10]. For the same reason, the increase in blood flow to working muscles at the onset of exercise was delayed exponentially as well [109]. Furthermore, countercurrent heat exchange between arteries and veins in the extremities was accounted for [109]. In addition, instead of basing the set-point temperatures on a standard man as in the Stolwijk model, a procedure was developed to better match the set-points with the actual subjects $[10,110]$.

Werner and Webb [16] developed a thermoregulatory model based on the work of Wissler [101], and Stolwijk and Hardy [106]. Their model is composed of six cylindrical segments representing head, trunk, arms, hands, legs, and feet. Body tissue is separated into core and shell layers, and each segment contains 101 radial nodes. The Pennes bioheat equation, with an added countercurrent heat exchange factor, is solved using a finite difference scheme. Werner 
and Webb validated their model for sedentary nude subjects in transient air environments between $15^{\circ} \mathrm{C}$ and $45^{\circ} \mathrm{C}$. The model was further enhanced by $\mathrm{Xu}$ and Werner [111], who partitioned the tissue into core, muscle, fat, and skin layers, and added a clothing layer. They validated the model for sedentary and exercising subjects exposed to hot and cold environments with or without clothing. However, core temperature predictions in the cold were not very accurate.

In 1997, Wolf and Garner [9] developed a thermoregulatory model for a wide range of cold exposures. Their model, which is based on the Tikuisis model [10], simulates the transient responses of rectal temperature and metabolic heat production for subjects immersed in water at temperatures ranging from $0^{\circ} \mathrm{C}$ to $28^{\circ} \mathrm{C}$. The model also simulates the metabolic heat production in cold air exposures, but the model cannot accurately predict the rectal temperature response in these conditions.

In 2001, Huizenga and coworkers [8] made several improvements to the Stolwijk model. Their thermoregulatory model, referred to as "The Berkeley Comfort Model", models the human body with an arbitrary number of segments (the base model has 16 segments) to better account for non-uniform environments. As in the Stolwijk model, the tissue is partitioned into core, muscle, fat, and skin. An additional clothing layer may be added, and convection, conduction, and radiation between the body and the environment are treated separately. The circulatory system has been improved to account for the countercurrent heat exchange between large arteries and veins in the extremities. The Berkeley Comfort Model has been validated for sedentary subjects in transient air environments ranging from $5^{\circ} \mathrm{C}$ to $48^{\circ} \mathrm{C}$.

Fiala [112] and Fiala et al. [14, 15] developed a thermoregulatory model that consists of 15 cylindrical segments that represent head, face, neck, shoulders, thorax, abdomen, arms, hands, 
legs, and feet (see Figure 4). Each segment is divided into one, two, or three angular sections and four to five different tissue compartments. Figure 4 also shows the cross sectional view of the left leg segment, which consists of four distinct tissue compartments and three angular sections.

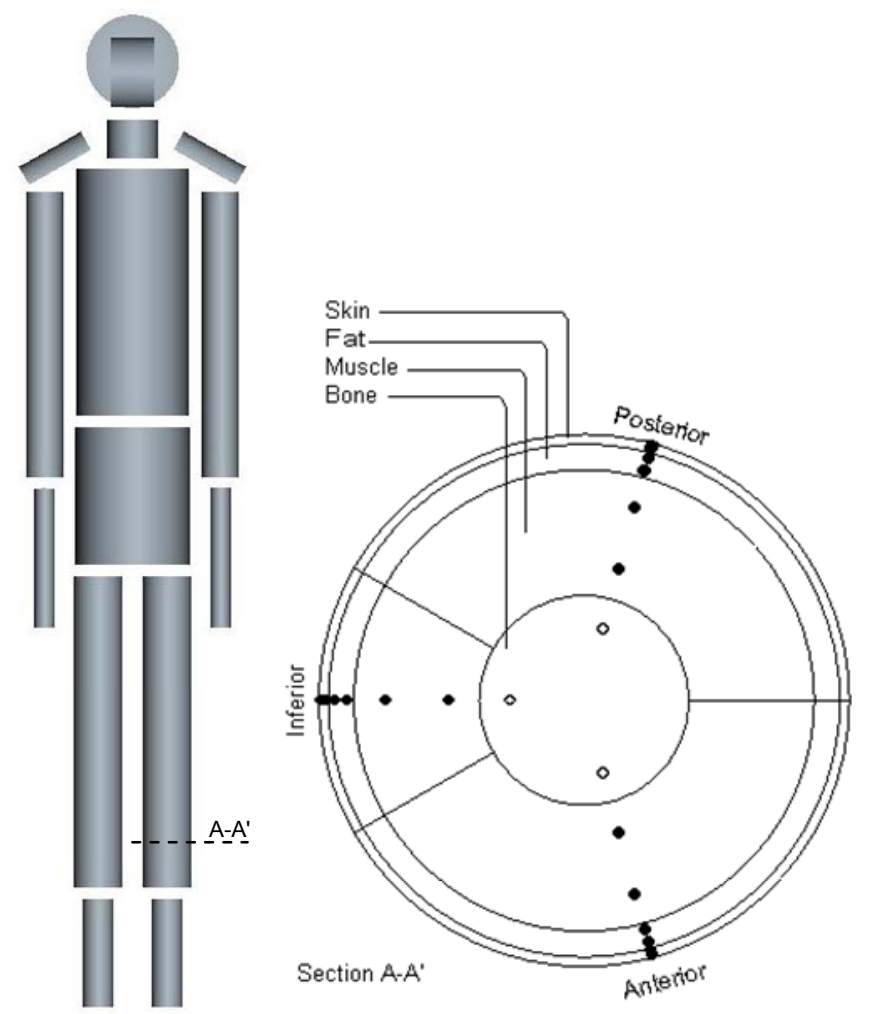

Figure 4: Body segmentation of the Fiala thermoregulatory model [15]

Pennes' one-dimensional bioheat equation is discretized and applied to each tissue node using a second order accurate finite difference scheme that is unconditionally stable. Special internal boundary conditions are applied to prevent numerical instabilities during transient conditions due to coupled physiologically distinct compartments [113]. Fiala's thermoregulatory model only considers radial conduction, but it still accounts for environmental asymmetries by allowing heat to conduct from one sector to another through the core compartment. The model accounts for countercurrent heat exchange between large arteries and veins in the extremities by 
employing a countercurrent heat exchange coefficient that is calibrated with experimental data. Fiala's model has been validated for a wide range of steady and transient air environments and exercise intensities [14].

Salloum and coworkers [7, 114] developed a thermoregulatory model consisting of 15 cylindrical segments. Each segment is divided into four nodes representing core, skin, arterial blood, and venous blood. The model includes a realistic representation of the arterial system, which calculates the circulation blood flow rates using physiological and anatomical data. The pulsatile blood flow in the largest arteries is taken into account as it relates to the convective heat transport. Unlike other thermoregulatory models that treat perfusion rate as an input variable, this model calculates perfusion rates in the core and skin tissue regions based on the arterial system and heart rate. The control equations are based on Smith's three-dimensional thermoregulatory model [22]. The thermoregulatory model simulates responses in transient air environments, and in a constant environment with a step change in metabolic rate.

All one-dimensional models that are based on cylindrical geometries consider only radial conduction, and hence neglect any axial or angular conduction. It seems reasonable to ignore axial conduction if an appropriate number of segments are used for a given situation. Hence, multi-segmental one-dimensional thermoregulatory models can be used for uniform environments and certain environments that are non-uniform in the axial direction.

\section{Multi-Dimensional Thermoregulatory Models}

The one dimensional thermoregulatory models discussed so far are inappropriate to use when the boundary conditions vary significantly around the body. Examples of such situations include the accidental cold immersion victim who is floating in a buoyant survival suit [17], and 
the nonuniform thermal environments experienced by astronauts during EVAs [63]. In addition, if one intends to compute very accurate temperature profiles within a body segment, one needs to consider the inhomogeneous and asymmetrical tissue composition [6].

In 1979, Kuznetz [21] extended his Stolwijk based "41-node man" [42] to account for circumferential heat conduction. This two-dimensional model consists of 10 cylindrical segments, which are divided into four concentric tissue regions and four angular quadrants. Each quadrant contains nine radial nodes, which are spaced progressively closer together towards the skin surface. Similar to the Stolwijk model [85], the central blood pool is represented by a single node and countercurrent heat exchange between arteries and veins is neglected. In contrast, blood perfusion rates, metabolic heat production, and tissue properties can be varied in an axially asymmetric manner. The two-dimensional Pennes bioheat equation is solved using an alternating direction implicit (ADI) finite difference scheme, and the controlling system is the same as the one used for the 41-node man. Kuznetz validated his model with data from two highly nonuniform exposures.

Based on detailed anatomical data, Werner and Buse [23] developed a very realistic three-dimensional finite element representation of the human body. The model considers 63 different tissue types and computes several hundred thousand temperatures on a 0.5 to $1 \mathrm{~cm}$ grid. A controlling system has not yet been included, and hence the model is restricted to steady state conditions. The model can be used to extrapolate temperature profiles that cannot be obtained experimentally [115].

In 1989, Mungcharoen [116] extended Wissler's one-dimensional thermoregulatory model to two dimensions, in order to allow radial and angular temperature variations. The segmentation and radial node distribution are the same as in Wissler's model, but each of the 15 
cylindrical body segments can be divided into 12 angular regions. Furthermore, the physiological properties, the circulatory system, and the controlling system remain unchanged from the onedimensional model. The model was validated for non-uniform thermal exposures $[20,116]$.

Smith [22] developed a three-dimensional finite element thermoregulatory model that is composed of 15 cylindrical segments representing head, neck, trunk, upper and lower arms and legs, hands, and feet. Each segment is radially, angularly, and axially divided into finite elements. The characteristics and number of elements vary between body segments to account for their different tissue composition. Furthermore, the circulatory system is approximated as a network of blood vessels running along the interior boundaries of the finite elements, and the blood flow is computed based on the pressure field in the tube network. Smith validated his model for sedentary conditions. However, due to deficiencies in the circulatory system, he experienced difficulties when simulating exercising conditions [22]. Takemori and coworkers [117] improved certain aspects of the circulatory system in the Smith model, but their model was only validated for sedentary exposures to transient thermal environments. Fu [118] added a clothing layer to Smith's model.

Based on the work of Wissler [17] and Mungcharoen [116], Qi [19] developed in 1994 a detailed two-dimensional thermoregulatory model based on published physiological and anatomical data. The model consists of 51 cylindrical body segments and 23,000 spatial nodes, and unlike Mungcharoen's model, Qi's model considers angular and radial variations in properties and physiological parameters. Hence, the model can be used to investigate the effects of large blood vessels and regional variations in properties and metabolic heat production on temperature profiles under various conditions. Due to the computational requirements, a supercomputer was needed to run the model. 


\section{Applications to Cooling Garment Environments}

Buchberg and Harrah [119] were first to mathematically describe the interaction between human tissue and a liquid cooling garment. They developed a relationship for computing the required coolant inlet temperature for thermal neutrality as a function of metabolic rate, skintubing contact area, and coolant flow rate. Shitzer, Chato, and Hertig [120, 121] investigated analytically the effects of variable LCG tube spacing, heat flux, metabolic rates, and peripheral blood perfusion on the temperature profile within the tissue. They concluded that peripheral blood flow significantly influences the local skin temperature, that increased tubing density yields a more uniform skin temperature, and that the highest body temperatures during exercise probably occur within working muscles. The above studies considered only a small tissue region, and did not take into account the dynamic effect of the thermoregulatory system.

In 1975, Kuznetz [42] integrated a Stolwijk based thermoregulatory model with a liquid cooling ventilation garment. In the literature, this model is referred to as the "41-node man". The LCG covered the whole body excluding head, neck, hands, and feet, while the VCG covered the entire body. The model predicted sweat rate, skin temperature, core temperature, and heat losses for a variety of different water inlet temperatures $\left(7^{\circ} \mathrm{C}-26^{\circ} \mathrm{C}\right)$, water flow rates, ventilation flow rates, metabolic rate profiles (up to $620 \mathrm{~W}$ ), and environmental conditions. Based on body heat storage and subjective comfort evaluations, Kuznetz introduced a comfort band that was used to quantify thermal comfort. Kuznetz' integrated thermoregulatory and cooling garment models have been used as design tools for an automatic control scheme for inlet coolant temperature [62].

Wissler [122] integrated his thermoregulatory model [17] with liquid and air cooled vests, and simulated rectal temperature, mean skin temperature, and sweat rate responses for 
intermittent exercise in hot and humid conditions. Wissler illustrated the different cooling mechanisms for the two cooling garments by demonstrating that an increase in inlet ventilation temperature from $15^{\circ} \mathrm{C}$ to $20^{\circ} \mathrm{C}$ has little effect on cooling garment performance, but a similar increase in inlet water temperature leads to a significant decrease in performance. Wissler's cooling garment models account for fluid flow path, sensible and latent heat transport, and garment property changes due to moisture accumulation.

Xiugan and Bin [123] simulated thermal responses of sedentary subjects wearing liquid cooled vests in hot nonuniform environments. Their thermoregulatory model is based on Stolwijk's model, but the cylindrical torso and head segments are divided into four quadrants (in addition to the four radial compartments) to allow both angular and radial heat conduction. The controller commands are modified for segments that are covered by the cooling garment, and they present a new sweating command.

In 1997, Nyberg and coworkers [124] adapted Wissler's thermoregulatory model for space suit applications with simultaneous liquid and ventilation cooling. The LCG covered the whole body excluding head, neck, hands, and feet, while the ventilation was applied to the entire body. The simulated thermal response was validated with experimental data for subjects wearing a space suit ensemble and exercising at transient metabolic rates up to $600 \mathrm{~W}$. The model was later used in the design of an automatic LCG inlet temperature controller $[125,126]$.

$\mathrm{Xu}$ et al. [81] adapted their thermoregulatory model $[16,111]$ with a triple-loop LCG in which the torso, arms, and legs were independently cooled. The model was used to predict heat storage in the three regions during steady exercise and various LCG inlet temperatures. They found that high cooling rates can be applied to skin surfaces over working muscles without thermal discomfort. Hence, the majority of the heat that is generated within working muscles can 
be removed by conduction to the adjacent skin. $\mathrm{Xu}$ et al. [127] extended the model for intermittent regional cooling where the coolant is circulated with an on/off cycle to reduce power consumption. The model simulated core and mean skin temperature responses for subjects exercising at a steady rate in warm environments while wearing an LCG covering head, torso, and legs.

$\mathrm{Pu}[128]$ integrated the Stolwijk thermoregulatory model with cooling garments that use either liquid, air, or ice as the cooling medium. The model was used to predict the core temperature response of subjects exercising at a constant rate in hot environments. 


\section{CHAPTER 3 \\ MATERIALS AND METHODS}

\section{Thermoregulatory Model}

We chose to adopt the Fiala thermoregulatory model for the present study. Even though this model has not been validated for LCG environments, it has been validated extensively for a wide range of steady and transient air environments and exercise intensities [14], and has shown state-of-the-art predictive abilities in such environments. A major advantage of the Fiala thermoregulatory model is that the details of the model are readily available in the literature. For completeness sake, we summarize the key equations of the Fiala thermoregulatory model in this section. The majority of the equations in this section are taken from $[14,15,112]$.

\section{Passive System}

As discussed earlier, the passive system simulates the heat transport within the body and between the body and the environment. The body construction of the Fiala thermoregulatory model (see Figure 4) is based on an average human with a weight of $73.5 \mathrm{~kg}$, body fat of $14 \%$, skin surface area of $1.86 \mathrm{~m}^{2}$, cardiac output of $4.9 \mathrm{~L} / \mathrm{min}$, and a basal metabolic rate of $87.1 \mathrm{~W}$. The model parameters are summarized in Appendix A.

\section{Interior Nodes}

The one-dimensional Pennes bioheat equation for cylindrical and spherical geometries is formulated as 


$$
k\left(\frac{\partial^{2} T}{\partial r^{2}}+\frac{\omega}{r} \frac{\partial T}{\partial r}\right)+\beta\left(T_{b l, a}-T\right)+q_{m}=\rho c \frac{\partial T}{\partial t}
$$

where $\beta$ is the blood perfusion rate factor (defined later), and $\omega$ is a dimensionless geometry factor; $\omega=1$ for cylindrical geometries and $\omega=2$ for spherical geometries. Equation ( 4 ) is discretized using the Crank-Nicolson finite difference method $\left(\Omega_{\mathrm{CN}} \mathrm{T}_{\mathrm{r}}\right)$, which is an average between the explicit $\left(\Omega_{\text {expl }} T_{r}\right)$ and the implicit $\left(\Omega_{\text {impl }} T_{r}\right)$ finite difference methods

$$
\Omega_{C N} T_{r}=\frac{1}{2}\left[\Omega_{\exp l} T_{r}+\Omega_{\text {impl }} T_{r}\right]
$$

When considering node $r$ in a cylindrical or spherical geometry, the explicit finite difference formulation of Equation ( 4 ) yields

$$
\begin{aligned}
\Omega_{\exp l} T_{r} & =\rho_{r} c_{r} \frac{T_{r}^{(t+1)}-T_{r}^{(t)}}{\Delta t} \\
& =k_{r}\left[\frac{T_{r+1}^{(t)}+T_{r-1}^{(t)}-2 T_{r}^{(t)}}{\Delta r^{2}}+\omega \frac{T_{r+1}^{(t)}-T_{r-1}^{(t)}}{2 r \Delta r}\right]+q_{m, r}^{(t)}+\beta_{r}^{(t)}\left[T_{b l, a}^{(t)}-T_{r}^{(t)}\right]
\end{aligned}
$$

The corresponding implicit finite difference formulation of Equation ( 4 ) is

$$
\begin{aligned}
\Omega_{\text {impl }} T_{r} & =\rho_{r} c_{r} \frac{T_{r}^{(t+1)}-T_{r}^{(t)}}{\Delta t} \\
& =k_{r}\left[\frac{T_{r+1}^{(t+1)}+T_{r-1}^{(t+1)}-2 T_{r}^{(t+1)}}{\Delta r^{2}}+\omega \frac{T_{r+1}^{(t+1)}-T_{r-1}^{(t+1)}}{2 r \Delta r}\right]+q_{m, r}^{(t+1)}+\beta_{r}^{(t+1)}\left[T_{b l, a}^{(t+1)}-T_{r}^{(t+1)}\right]
\end{aligned}
$$

By applying Equation ( 5 ) to Equation ( 4 ) and separating the future and current temperature terms, we obtain [15] 


$$
\begin{gathered}
\left(\gamma_{r}-1\right) T_{r-1}^{(t+1)}+\left[\frac{\zeta_{r}}{\Delta t}+2+\delta_{r} \beta_{r}^{(t+1)}\right] T_{r}^{(t+1)}-\left(1+\gamma_{r}\right) T_{r+1}^{(t+1)}-\delta_{r} \beta_{r}^{(t+1)} T_{b l, a}^{(t+1)} \\
= \\
\left(1-\gamma_{r}\right) T_{r-1}^{(t)}+\left[\frac{\zeta_{r}}{\Delta t}-2-\delta_{r} \beta_{r}^{(t)}\right] T_{r}^{(t)}+\left(1+\gamma_{r}\right) T_{r+1}^{(t)}+\delta_{r}\left[q_{m, r}^{(t+1)}+q_{m, r}^{(t)}\right]+\delta_{r} \beta_{r}^{(t)} T_{b l, a}^{(t)}
\end{gathered}
$$

where

$$
\begin{gathered}
\gamma_{r, c y l}=\frac{\Delta r}{2 r} \\
\gamma_{r, s p h}=\frac{\Delta r}{r} \\
\delta_{\mathrm{r}}=\frac{\Delta r^{2}}{k_{r}} \\
\zeta_{r}=2 \Delta r^{2} \frac{\rho_{r} c_{r}}{k_{r}}
\end{gathered}
$$

where $\Delta r$ is the local node spacing (constant within each tissue compartment) and $r$ is the local node radius. The node spacing and the node radiuses within a tissue compartment depend on the geometry and the number of nodes we use in the compartment. Table 10 in Appendix $A$ summarizes the geometry data that is used for the current model. The thermophysical properties $k, \rho$, and $c$ in Equation ( 11 ) and Equation ( 12 ) depend on the tissue type, as specified in Table 11 in Appendix A. Equation ( 8 ) is the governing equation for interior nodes with homogeneous tissue properties. Hence, it does not apply to nodes that are adjacent to compartment interfaces, to skin surface nodes, or to core nodes. 


\section{Metabolism}

The nodal metabolic heat generation rate $q_{m, r}$ in Equation ( 8 ) is computed as

$$
q_{m, r}=q_{m, 0, r}+\Delta q_{m, r}
$$

where $q_{m, 0}$ and $\Delta q_{m}$ are the basal and the variable components of the metabolic heat generation rate, respectively. The basal component $q_{m, 0}$ depends on tissue type, as specified in Table 11 in Appendix A. The variable component of the metabolic heat generation rate is defined by

$$
\Delta q_{m, r}=\Delta q_{m, 0, r}+q_{m, s h, j}+q_{m, w, j}
$$

where $\Delta q_{m, 0}$ is the temperature dependent van't Hoff $\mathrm{Q}_{10}$ effect

$$
\Delta q_{m, 0, r}=q_{m, 0, r}\left[2^{\frac{T_{r}-T_{0, r}}{10}}-1\right]
$$

where $T_{r}$ is the local tissue temperature and $T_{0, r}$ is the local reference or "set-point" temperature corresponding to thermal neutrality (see Controlling System). The shivering component $q_{m, s h, j}$ in Equation ( 14 ) is controlled by the controlling system (see Controlling System). The work component $q_{m, w, j}$ in Equation ( 14 ) is defined as

$$
q_{m, w, j}=\frac{a_{m, w, j} H}{V_{m s c, j}}
$$

where $a_{m, w, j}$ is the segmental workload distribution coefficient (see Table 12 in Appendix A), $V_{m s c, j}$ is the segmental muscle volume, and $H$ is the internal whole body heat load due to work 


$$
H=M\left(1-\eta_{w}\right)-M_{0}
$$

where $M$ is the metabolic rate, $M_{0}$ is the basal metabolic rate, and $\eta_{w}$ is the work efficiency. The shivering and work components of the metabolic heat generation rate $\left(q_{m, s h}\right.$ and $q_{m, w}$ in Equation ( 14 )) are only applicable to muscle tissue. Hence, the metabolic heat generation rate in nonmuscular tissue varies only with temperature according to van't Hoff $\mathrm{Q}_{10}$ effect (Equation ( 15 )).

\section{$\underline{\text { Blood Circulation }}$}

Similar to the metabolic heat generation rate, the blood perfusion rate factor $\beta_{r}$ in Equation ( 8 ) has a basal and a variable component. It is defined as

$$
\beta_{r}=\beta_{0, r}+\Delta \beta_{r}
$$

where

$$
\begin{gathered}
\beta_{0, r}=\rho_{b l} c_{b l} w_{b l, 0, r} \\
\Delta \beta_{r}=\mu \Delta q_{m, r}
\end{gathered}
$$

where $w_{b l, 0, r}$ is the local basal blood perfusion rate (see Table 11 in Appendix $A$ ), $\mu=0.932 \mathrm{~K}^{-1}$ is a proportionality factor [85], and $\Delta q_{m, r}$ is the sum of the three metabolic rate components in Equation ( 14 ).

The blood circulatory system is modeled with a central blood pool that supplies blood to the different body segments. Before perfusing a distant body segment (shoulder, arm, hand, leg, or foot), the arterial blood is cooled by countercurrent heat exchange with adjacent veins. The 
blood then flows through the capillaries where it is assumed that it reaches a thermal equilibrium with the surrounding tissue. Before returning to the central blood pool, the venous blood is heated by the warmer countercurrent arterial blood. The venous blood from all body segments are mixed to obtain the new central blood pool temperature. The arterial blood temperature of a body segment is a function of the central blood pool $\left(T_{b l, p}\right)$, the segmental countercurrent heat exchange coefficient $\left(h_{x}\right)$, and the nodal volumes $\left(V_{r}\right)$, the nodal perfusion rate factors $\left(\beta_{r}\right)$, and the nodal temperatures $\left(T_{r}\right)$ within the body segment (see [15] for derivation)

$$
T_{b l, a}=\frac{T_{b l, p} \sum_{r}^{n o d} \beta_{r} V_{r}}{h_{x}+\sum_{r}^{\text {nod }} \beta_{r} V_{r}}+\frac{\sum_{x} \frac{\sum_{r}^{\text {nod }} T_{r} \beta_{r} V_{r}}{\sum_{x}+\sum_{r} \beta_{r}}}{h_{r} \beta_{r} V_{r}}
$$

where the summation is over all nodes within the specific body segment under consideration. The central blood pool temperature $T_{b l, p}$ is defined as [15]

$$
T_{b l, p}=\frac{\sum_{j}\left[\frac{\sum_{r}^{\text {nod }} \beta_{j, r} V_{j, r}}{h_{x, j}+\sum_{r}^{n o d} \beta_{j, r} V_{j, r}} \times \sum_{r}^{n o d} \beta_{j, r} V_{j, r} T_{j, r}\right]}{\sum_{j}^{\operatorname{seg}}\left[\frac{\left(\sum_{r}^{n o d} \beta_{j, r} V_{j, r}\right)^{2}}{h_{x, j}+\sum_{r}^{n o d} \beta_{j, r} V_{j, r}}\right]}
$$

where the summation is over all nodes in all body segments. The countercurrent heat exchange coefficient $h_{x}$ in Equation ( 21 ) and Equation ( 22 ) depends on body segment as specified in Table 11 in Appendix A. 


\section{$\underline{\text { Respiration }}$}

As described by Fanger [2], the respiratory heat loss $Q_{r e s p}(\mathrm{~W})$ is a function of the metabolic rate $M(\mathrm{~W})$, the ambient air temperature $T_{\text {air }}\left({ }^{\circ} \mathrm{C}\right)$, and the partial vapor pressure of the ambient air $p_{\text {air }}(\mathrm{Pa})$

$$
\begin{aligned}
Q_{\text {resp }}= & Q_{\text {resp }, \text { lat }}+Q_{\text {resp }, \text { sens }} \\
= & 3.45 M\left(0.028+6.5 \times 10^{-5} T_{\text {air }}-4.98 \times 10^{-6} p_{\text {air }}\right) \\
& +1.44 \times 10^{-3} M\left(32.6-0.934 T_{\text {air }}+1.99 \times 10^{-4} p_{\text {air }}\right)
\end{aligned}
$$

The respiration heat loss $Q_{\text {resp }}$ is distributed to tissue associated with the pulmonary tract; the lung, and the muscle layers in face and neck. The respiration heat loss distribution coefficient $a_{r e s p}$ is 0.25 for the outer face muscle compartment, 0.2 for the inner face muscle compartment, 0.25 for the neck muscle compartment, and 0.3 for the lung compartment [15]. These four tissue compartments have an additional term in the nodal heat generation rate (Equation ( 13 ))

$$
q_{m, r}=q_{m, 0, r}+\Delta q_{m, r}-\frac{a_{r e s p} Q_{r e s p}}{V_{c o m p}}
$$

where $V_{\text {comp }}$ is the corresponding compartment volume.

\section{Boundary Conditions}

\section{Interface between Two Different Tissue Compartments}

A fictitious node concept is used to model the boundary conditions at the interface between two physiologically distinct compartments. Within a given tissue compartment, nodes are placed so that their spacing is constant and so that the first and last nodes are placed half a 
node spacing from the compartment interfaces. The first and last nodes in a tissue compartment are attached to fictitious nodes with identical thermophysical tissue properties. Figure 5 shows pairs of regular and fictitious nodes adjacent to a tissue interface for both the "forward configuration" and the "backward configuration". The "forward configuration" arises when the actual node $r$ is attached to a fictitious node $(r+1)^{\prime \prime}$ that has a greater radius than node $r$. Contrary, the "backward configuration" arises when the actual node $r$ is attached to a fictitious node $(r-1)$ " that has a smaller radius than node $r$. 


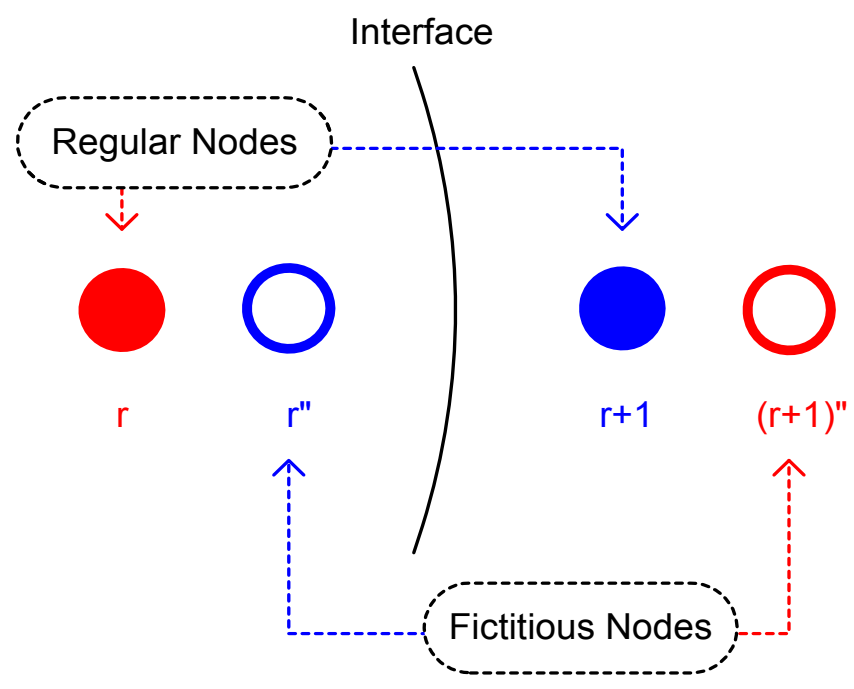

(a) Forward configuration

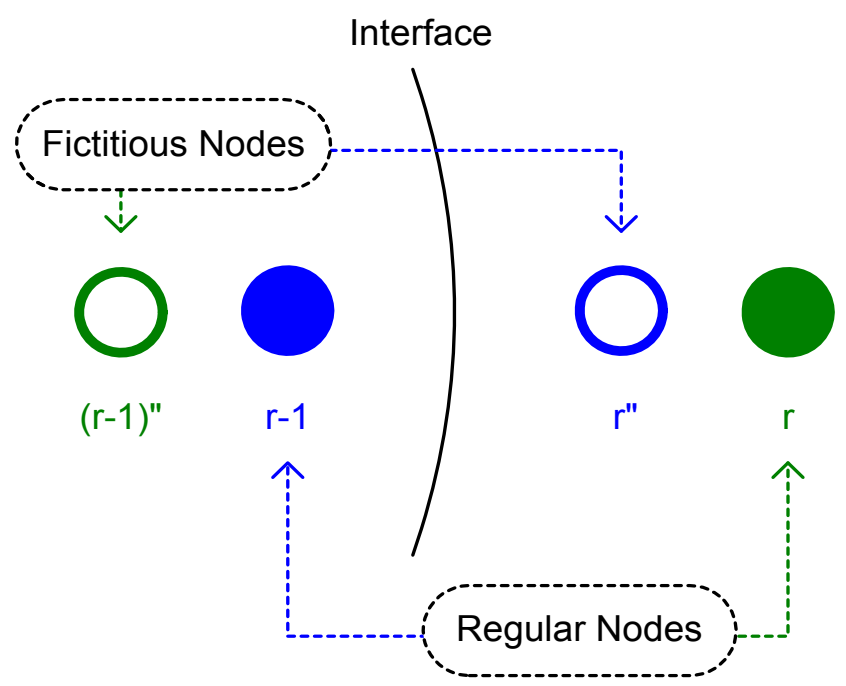

(b) Backward configuration

Figure 5: Pairs of regular and fictitious nodes adjacent to the interface between two physiologically distinct tissue compartments (modified from [112])

The boundary conditions at an interface are satisfied by equating the interface temperatures and the interface heat fluxes for the two adjacent pairs of regular and fictitious nodes. Considering the "forward configuration" in a cylindrical geometry, the interface temperature $T_{i f c}$ and the interface heat flux $q_{i f c}^{\prime \prime}$ are expressed as 


$$
\begin{gathered}
\frac{T_{r} \ln \left[\frac{r_{i f c}}{r_{(r+1)^{\prime \prime}}}\right]-T_{(r+1)^{\prime \prime}} \ln \left[\frac{r_{i f c}}{r_{r}}\right]}{\ln \left[\frac{r_{r}}{r_{(r+1)^{\prime \prime}}}\right]}=T_{i f c}=\frac{T_{r^{\prime \prime}} \ln \left[\frac{r_{i f c}}{r_{r+1}}\right]-T_{r+1} \ln \left[\frac{r_{i f c}}{r_{r^{\prime \prime}}}\right]}{\ln \left[\frac{r_{r^{\prime \prime}}}{r_{r+1}}\right]} \\
\frac{k_{r}\left(T_{r}-T_{(r+1)^{\prime \prime}}\right)}{r_{i f c} \ln \left[\frac{r_{(r+1)^{\prime \prime}}}{r_{r}}\right]}=q_{i f c}^{\prime \prime}=\frac{k_{r+1}\left(T_{r^{\prime \prime}}-T_{r+1}\right)}{r_{i f c} \ln \left[\frac{r_{r+1}}{r_{r^{\prime \prime}}}\right]}
\end{gathered}
$$

By separating $T_{r^{\prime \prime}}$ in Equation ( 25 ) and introducing it into Equation ( 26 ), the forward fictitious node temperature $T_{(r+1) \text { " }}$ can be expressed as

$$
T_{(r+1)^{n}}=A_{F, r, c y l} T_{r}+A_{F, r+1, c y l} T_{r+1}
$$

where $A_{F, r, c y l}$ and $A_{F, r+l, c y l}$ are the cylindrical forward interface coefficients [112]

$$
\begin{gathered}
A_{F, r, c y l}=\frac{D s_{F, r, c y l} \Lambda_{F, r+1, c y l}-D_{F, r+1, c y l} \Lambda_{F, r, c y l}}{D_{F, r, c y l} \Lambda_{F, r+1, c y l}-D_{F, r+1, c y l} \Lambda_{F, r, c y l}} \\
A_{F, r+1, c y l}=\frac{\Lambda_{F, r+1, c y l}}{D_{F, r, c y l} \Lambda_{F, r+1, c y l}-D_{F, r+1, c y l} \Lambda_{F, r, c y l}}
\end{gathered}
$$

where

$$
\Lambda_{F, r, c y l}=\frac{k_{r}}{\ln \left(\frac{r_{r}+\Delta r_{r}}{r_{r}}\right)}
$$




$$
\begin{gathered}
\Lambda_{F, r+1, c y l}=\frac{k_{r+1}}{\ln \left(\frac{r_{r+1}}{r_{r+1}-\Delta r_{r+1}}\right)} \\
D_{F, r, c y l}=\frac{\ln \left(\frac{r_{i j c}}{r_{r}}\right)}{\ln \left(\frac{r_{r}+\Delta r_{r}}{r_{r}}\right)} \\
D s_{F, r, c y l}=\frac{\ln \left(\frac{r_{i f c}}{r_{r}+\Delta r_{r}}\right)}{\ln \left(\frac{r_{r}+\Delta r_{r}}{r_{r}}\right)} \\
D_{F, r+1, c y l}=\frac{\ln \left(\frac{r_{i j c}}{r_{r+1}}\right)}{\ln \left(\frac{r_{r+1}}{r_{r+1}-\Delta r_{r+1}}\right)}
\end{gathered}
$$

For the "backward configuration" in cylindrical geometries, the interface temperature and the interface heat flux are expressed as

$$
\frac{T_{r-1} \ln \left[\frac{r_{i f c}}{r_{r " n}}\right]-T_{r^{\prime \prime}} \ln \left[\frac{r_{i f c}}{r_{r-1}}\right]}{\ln \left[\frac{r_{r-1}}{r_{r^{\prime \prime}}}\right]}=T_{i f c}=\frac{T_{(r-1)^{n}} \ln \left[\frac{r_{i f c}}{r_{r}}\right]-T_{r} \ln \left[\frac{r_{i f c}}{r_{(r-1)^{n}}}\right]}{\ln \left[\frac{r_{(r-1)^{\prime \prime}}}{r_{r}}\right]}
$$




$$
\frac{k_{r-1}\left(T_{r-1}-T_{r^{\prime \prime}}\right)}{r_{i f c} \ln \left[\frac{r_{r^{\prime \prime}}}{r_{r-1}}\right]}=q_{i j c}^{\prime \prime}=\frac{k_{r}\left(T_{(r-1)^{n}}-T_{r}\right)}{r_{i f c} \ln \left[\frac{r_{r}}{r_{(r-1)^{n}}}\right]}
$$

By separating $T_{r^{\prime \prime}}$ in Equation ( 35 ) and introducing it into Equation ( 36 ), the backward fictitious node temperature $T_{(r-1)^{\prime \prime}}$ is expressed as

$$
T_{(r-1)^{n}}=A_{B, r, c y l} T_{r}+A_{B, r-1, c y l} T_{r-1}
$$

where $A_{B, r, c y l}$ and $A_{B, r-1, c y l}$ are the cylindrical backward interface coefficients [112]

$$
\begin{gathered}
A_{B, r, c y l}=\frac{D_{B, r-1, c y l} \Lambda_{B, r, c y l}-D s_{B, r, c y l} \Lambda_{B, r-1, c y l}}{D_{B, r-1, c y l} \Lambda_{B, r, c y l}-D_{B, r, c y l} \Lambda_{B, r-1, c y l}} \\
A_{B, r-1, c y l}=\frac{\Lambda_{B, r-1, c y l}}{D_{B, r-1, c y l} \Lambda_{B, r, c y l}-D_{B, r, c y l} \Lambda_{B, r-1, c y l}}
\end{gathered}
$$

where

$$
\begin{aligned}
\Lambda_{B, r, c y l} & =\frac{k_{r}}{\ln \left(\frac{r_{r}}{r_{r}-\Delta r_{r}}\right)} \\
\Lambda_{B, r-1, c y l} & =\frac{k_{r-1}}{\ln \left(\frac{r_{r-1}+\Delta r_{r-1}}{r_{r-1}}\right)}
\end{aligned}
$$




$$
\begin{gathered}
D_{B, r, c y l}=\frac{\ln \left(\frac{r_{i f c}}{r_{r}}\right)}{\ln \left(\frac{r_{r}}{r_{r}-\Delta r_{r}}\right)} \\
D s_{B, r, c y l}=\frac{\ln \left(\frac{r_{i f c}}{r_{r}-\Delta r_{r}}\right)}{\ln \left(\frac{r_{r}}{r_{r}-\Delta r_{r}}\right)} \\
D_{B, r-1, c y l}=\frac{\ln \left(\frac{r_{i f c}}{r_{r-1}}\right)}{\ln \left(\frac{r_{r-1}+\Delta r_{r-1}}{r_{r-1}}\right)}
\end{gathered}
$$

A similar procedure is followed to formulate the fictitious node temperatures for spherical geometries. The resulting forward fictitious node temperature $T_{(r+1)^{\prime \prime}}$ for spherical geometries is of the same form as the forward fictitious temperature for cylindrical geometries

$$
T_{(r+1)^{n}}=A_{F, r, s p h} T_{r}+A_{F, r+1, s p h} T_{r+1}
$$

where $A_{F, r, s p h}$ and $A_{F, r+1, s p h}$ are the spherical forward interface coefficients [112]

$$
A_{F, r, s p h}=\frac{\Lambda_{F, r, s p h}-\Lambda_{F, r+1, s p h} \frac{r_{r}}{r_{r+1}-\Delta r_{r+1}}}{\Lambda_{F, r, s p h}+\Lambda_{F, r+1, s p h} \frac{r_{r}+\Delta r_{r}}{r_{r+1}-\Delta r_{r+1}}}
$$




$$
A_{F, r+1, s p h}=\frac{\Lambda_{F, r+1, s p h}\left(1+\frac{r_{r+1}}{r_{r+1}-\Delta r_{r+1}}\right)}{\Lambda_{F, r, s p h}+\Lambda_{F, r+1, s p h} \frac{r_{r}+\Delta r_{r}}{r_{r+1}-\Delta r_{r+1}}}
$$

where

$$
\begin{gathered}
\Lambda_{F, r, s p h}=\frac{k_{r}}{\frac{1}{r_{r}}-\frac{1}{r_{r}+\Delta r_{r}}} \\
\Lambda_{F, r+1, s p h}=\frac{k_{r+1}}{\frac{1}{r_{r+1}-\Delta r_{r+1}}-\frac{1}{r_{r+1}}}
\end{gathered}
$$

The resulting backward interface fictitious node temperature $T_{(r-1)}$ is expressed as

$$
T_{(r-1)^{\prime \prime}}=A_{B, r, s p h} T_{r}+A_{B, r-1, s p h} T_{r-1}
$$

where $A_{B, r, s p h}$ and $A_{B, r-1, s p h}$ are the spherical backward interface coefficients [112]

$$
\begin{gathered}
A_{B, r, s p h}=\frac{\Lambda_{B, r, s p h}-\Lambda_{B, r-1, s p h} \frac{r_{r}}{r_{r-1}+\Delta r_{r-1}}}{\Lambda_{B, r, s p h}+\Lambda_{B, r-1, s p h} \frac{r_{r}-\Delta r_{r}}{r_{r-1}+\Delta r_{r-1}}} \\
A_{B, r-1, s p h}=\frac{\Lambda_{B, r-1, s p h}\left(1+\frac{r_{r-1}}{r_{r-1}+\Delta r_{r-1}}\right)}{\Lambda_{B, r, s p h}+\Lambda_{B, r-1, s p h} \frac{r_{r}-\Delta r_{r}}{r_{r-1}+\Delta r_{r-1}}}
\end{gathered}
$$

where 


$$
\begin{gathered}
\Lambda_{B, r, s p h}=\frac{k_{r}}{\frac{1}{r_{r}-\Delta r_{r}}-\frac{1}{r_{r}}} \\
\Lambda_{B, r-1, s p h}=\frac{k_{r-1}}{\frac{1}{r_{r-1}}-\frac{1}{r_{r-1}+\Delta r_{r-1}}}
\end{gathered}
$$

By substituting $T_{r+1}$ and $T_{r-1}$ in Equation ( 8 ) with Equations ( 27 ) and ( 37 ) for cylindrical geometries or Equations ( 45 ) and ( 50 ) for spherical geometries, we obtain

$$
\begin{gathered}
\left(\gamma_{r}-1\right) A_{B, r-1} T_{r-1}^{(t+1)}+\left[\left(\gamma_{r}-1\right) A_{B, r}+\frac{\zeta_{r}}{\Delta t}+2+\delta_{r} \beta_{r}^{(t+1)}-\left(1+\gamma_{r}\right) A_{F, r}\right] T_{r}^{(t+1)} \\
-\left(1+\gamma_{r}\right) A_{F, r+1} T_{r+1}^{(t+1)}-\delta_{r} \beta_{r}^{(t+1)} T_{b l, a}^{(t+1)} \\
= \\
\left(1-\gamma_{r}\right) A_{B, r-1} T_{r-1}^{(t)}+\left[\left(1-\gamma_{r}\right) A_{B, r}+\frac{\zeta_{r}}{\Delta t}-2-\delta_{r} \beta_{r}^{(t)}+\left(1+\gamma_{r}\right) A_{F, r}\right] T_{r}^{(t)} \\
+\left(1+\gamma_{r}\right) A_{F, r+1} T_{r+1}^{(t)}+\delta_{r}\left[q_{m, r}^{(t)}+q_{m, r}^{(t+1)}\right]+\delta_{r} \beta_{r}^{(t)} T_{b l, a}^{(t)}
\end{gathered}
$$

For homogeneous tissue; $A_{F, r}=0, A_{B, r}=0, A_{F, r+1}=1$, and $A_{B, r-1}=1$, which reduce Equation ( 55 ) to Equation ( 8 ). Hence, Equation ( 55 ) is the governing equation for any interior node in both homogeneous and non-homogeneous tissue, and in both cylindrical and spherical geometries.

\section{The Isothermal Core}

Since the thermoregulatory model accounts for environmental asymmetries, heat is able to conduct from one sector to another through the core compartment of a body segment (see Figure 4). Therefore, an isothermal core compartment is assigned around the cylinder axis or the midpoint of the sphere of each body segment. Since there is no temperature gradient within this 
isothermal compartment, a lumped parameter representation of Equation ( 4 ) is used for the core governing equation

$$
-\frac{\kappa}{r_{i f c}} \frac{\sum_{s}^{\text {sec }} \phi_{s} q_{i f c, s}^{\prime \prime}}{\sum_{s}^{\text {sec }} \phi_{s}}+\beta_{i s o}\left(T_{b l, a}-T_{i s o}\right)+q_{m, i s o}=\rho_{i s o} c_{i s o} \frac{\partial T_{i s o}}{\partial t}
$$

The conduction term in Equation ( 56 ) arises from relating the sectorial interface heat flux $q_{i j, s}^{\prime \prime}$ with the sectorial interface area and the isothermal compartment volume. The geometry factor $\kappa$ is $\kappa=2$ for cylinders and $\kappa=3$ for spheres. We discretize Equation ( 56 ) with the CrankNicolson finite difference method and apply the fictitious node concept. However, only the "forward configuration" (Equation ( 27 )) is applicable because the core node is the node with the smallest radius. The resulting governing equation for the isothermal core node is

$$
\begin{gathered}
{\left[\frac{\zeta_{r}}{\Delta t}+\delta_{r} \beta_{r}^{(t+1)}+\theta\left(1-A_{F, r}\right) \sum_{s}^{\mathrm{sec}} \phi_{s}\right] T_{r}^{(t+1)}-\theta A_{F, r+1} \sum_{s}^{\mathrm{sec}} \phi_{s} T_{r+1, s}^{(t+1)}-\delta_{r} \beta_{r}^{(t+1)} T_{b l, a}^{(t+1)}} \\
= \\
{\left[\frac{\zeta_{r}}{\Delta t}-\delta_{r} \beta_{r}^{(t)}+\theta\left(A_{F, r}-1\right) \sum_{s}^{\mathrm{sec}} \phi_{s}\right] T_{r}^{(t)}+\theta A_{F, r+1} \sum_{s}^{\mathrm{sec}} \phi_{s} T_{r+1, s}^{(t)}+\delta_{r}\left[q_{m, r}^{(t)}+q_{m, r}^{(t+1)}\right]+\delta_{r} \beta_{r}^{(t)} T_{b l, a}^{(t)}}
\end{gathered}
$$

where the geometry dependent factor $\theta$ is defined as

$$
\theta_{c y l}=\frac{8\left(1-\frac{1}{\sqrt{2}}\right)^{2}}{\ln (2 \sqrt{2}-1) \sum_{s}^{\text {sec }} \phi_{s}}
$$

for cylindrical geometries and 


$$
\theta_{s p h}=\frac{12(\sqrt[3]{16}-1)\left(1-\frac{1}{\sqrt[3]{2}}\right)^{2}}{(\sqrt[3]{32}-\sqrt[3]{16}) \sum_{s}^{\sec } \phi_{s}}
$$

for spherical geometries.

\section{The Skin Surface}

When formulating the boundary condition at the skin surface, we made the following simplifying assumptions;

- the individual wears sufficient insulation so that environmental heat exchange can be neglected

- the dynamic effect of moisture accumulation, condensation, and evaporation within the garment is negligible, coolant flow rate is constant, and coolant temperature changes are small so that we can assume a constant overall heat transfer coefficient

- regional variations are small so that we can assume a uniform overall heat transfer coefficient

- the LCG coolant has a high flow rate and passes through the LCG in multiple parallel circuits so that the inlet-outlet temperature gradient is small

With these assumptions, the heat flux at the skin surface $q_{s k}^{\prime \prime}$ can be formulated as

$$
q_{s k}^{\prime \prime}=U\left(T_{s k}-T_{L C G}\right)+q_{s w}^{\prime \prime}
$$

where $U$ is the overall heat transfer coefficient, $T_{s k}$ is the local skin temperature, $T_{L C G}$ is the LCG inlet water temperature, and $q_{s w}^{\prime \prime}$ is the local latent heat flux due to sweat evaporation. Equation ( 
60 ) does not account for the rise in coolant temperature along the LCG tubes, but it has the advantage of being linear in the skin temperature $T_{s k}$, so there is no need to iterate at each time step or to assume a quasi steady state formulation.

By substituting $q_{s k}^{\prime \prime}$ and $T_{s k}$ in Equation ( 60 ) with the corresponding expressions for cylindrical (LHS of Equation ( 26 ) and LHS of Equation ( 25 )) or spherical geometries, we arrive at

$$
T_{(r+1)^{n}}=A_{F, s k} T_{r}+E n v
$$

where $A_{F, s k}$ and $E n v$ are the forward skin and environmental interface coefficients, respectively. For cylindrical geometries, they are defined as

$$
\begin{gathered}
A_{F, s k, c y l}=\frac{U \cdot \frac{\ln \left(\frac{r_{s k}}{r_{(r+1) "}}\right)}{\ln \left(\frac{r_{s k}}{r_{r}}\right)}+\frac{k_{r}}{r_{s k} \ln \left(\frac{r_{s k}}{r_{r}}\right)}}{U+\frac{k_{r}}{r_{s k} \ln \left(\frac{r_{s k}}{r_{r}}\right)}} \\
E n v_{c y l}=\frac{\left(U T_{L C G}-q_{s w}^{\prime \prime}\right) \cdot \frac{\ln \left(\frac{r_{(r+1)^{\prime \prime}}}{r_{r}}\right)}{\ln \left(\frac{r_{s k}}{r_{r}}\right)}}{U+\frac{k_{r}}{r_{s k} \ln \left(\frac{r_{s k}}{r_{r}}\right)}}
\end{gathered}
$$

For spherical geometries, the skin and environmental interface coefficients are expressed as 


$$
\begin{gathered}
A_{F, s k, s p h}=\frac{1-U \Lambda_{s k}\left(2 r_{s k}-r_{(r+1)^{\prime \prime}}\right)}{1+r_{(r+1)^{\prime \prime}} U \Lambda_{s k}} \\
E n v_{s p h}=\frac{2 r_{s k} \Lambda_{s k}\left(U T_{L C G}-q_{s w}^{\prime \prime}\right)}{1+r_{(r+1)^{\prime \prime}} U \Lambda_{s k}}
\end{gathered}
$$

where

$$
\Lambda_{s k}=\frac{r_{s k}}{2 k_{r}}\left[\frac{1}{r_{r}}-\frac{1}{r_{(r+1)^{n}}}\right]
$$

Since the environmental interface coefficient Env depends on the LCG water temperature $T_{L C G}$ and the latent heat flux $q_{s w}^{\prime \prime}$, it is time dependent and needs to be updated at each time interval. The latent heat flux at the skin surface of sector $s$ is computed as

$$
q_{s w, s}^{\prime \prime}=\frac{\lambda}{6 \times 10^{4} A_{s k, s}} \frac{d m_{s w, s}}{d t}
$$

where $\lambda$ is the latent heat of vaporization of water, $6 \times 10^{4}\left(\mathrm{~g} \cdot \mathrm{min}^{-1} \cdot \mathrm{s} \cdot \mathrm{kg}^{-1}\right)$ is a conversion constant, $A_{s k, s}$ is the area of skin sector $s$, and $d m_{s w, s} / d t\left(\mathrm{~g} \cdot \mathrm{min}^{-1}\right)$ is the local sweat rate (see Controlling System).

By substituting $T_{r+1}$ and $T_{r-1}$ in Equation ( 8 ) with Equation ( 61 ) and Equation ( 37 ) (or Equation ( 50 )), respectively, we obtain the governing equation for the skin node 


$$
\begin{gathered}
\left(\gamma_{r}-1\right) A_{B, r-1} T_{r-1}^{(t+1)} \\
+\left[\left(\gamma_{r}-1\right) A_{B, r}+\frac{\zeta_{r}}{\Delta t}+2+\delta_{r} \beta_{r}^{(t+1)}-\left(1+\gamma_{r}\right) A_{F, s k}\right] T_{r}^{(t+1)} \\
-\delta_{r} \beta_{r}^{(t+1)} T_{b l, a}^{(t+1)}=\left(1-\gamma_{r}\right) A_{B, r-1} T_{r-1}^{(t)} \\
+\left[\left(1-\gamma_{r}\right) A_{B, r}+\frac{\zeta_{r}}{\Delta t}-2-\delta_{r} \beta_{r}^{(t)}+\left(1+\gamma_{r}\right) A_{F, s k}\right] T_{r}^{(t)} \\
+\left(1+\gamma_{r}\right)\left[E n v^{(t)}+E n v^{(t+1)}\right]+\delta_{r}\left[q_{m, r}^{(t)}+q_{m, r}^{(t+1)}\right]+\delta_{r} \beta_{r}^{(t)} T_{b l, a}^{(t)}
\end{gathered}
$$

The variable skin blood perfusion term $\beta_{r}$ in Equation ( 68 ) is controlled by the controlling system (see Controlling System).

\section{Whole-Body Matrix Equation}

By applying Equation ( 57 ) to all core nodes, Equation ( 55 ) to all interior nodes, Equation ( 68 ) to all skin nodes, and Equation ( 22 ) to the central blood pool, we obtain the whole body matrix equation that is shown in Figure 6. 


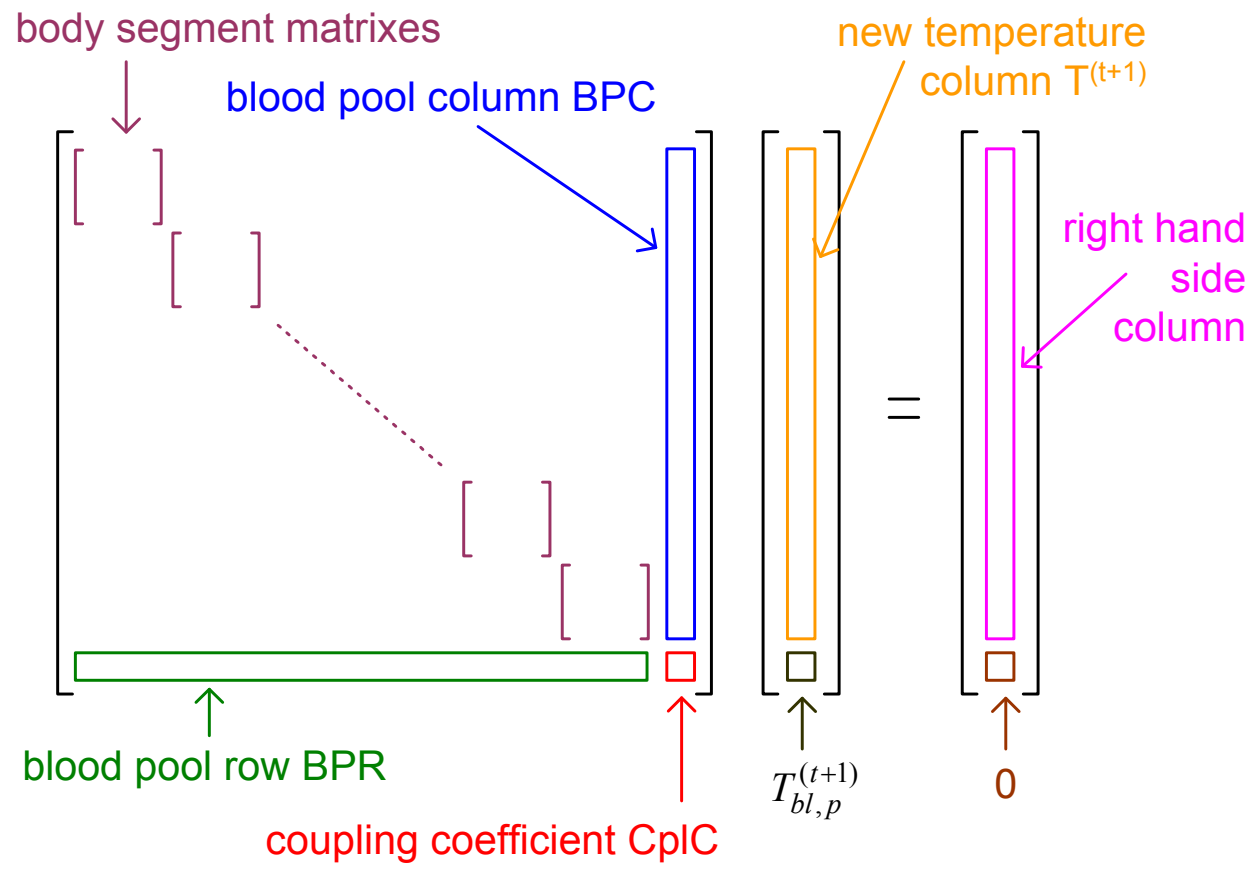

Figure 6: Structure of the whole body matrix equation

The coefficients in the blood pool column $(B P C)$ arise from substituting $T_{b l, a}^{(t+1)}$ in Equation ( 55 ), Equation ( 57 ), and Equation ( 68 ) with Equation ( 21 )

$$
B P C_{j, r}=-\frac{\sum_{r}^{\text {nod }} \beta_{j, r}^{(t+1)} V_{j, r}}{h_{x, j}+\sum_{r}^{n o d} \beta_{j, r}^{(t+1)} V_{j, r}} \times \delta_{j, r} \beta_{j, r}^{(t+1)}
$$

The blood pool row $(B P R)$ and coupling coefficient $(C p l C)$ in Figure 6 arise from Equation ( 22 ) and are defined as 


$$
\begin{gathered}
B P R_{j, r}=\frac{\sum_{r}^{n o d} \beta_{j, r}^{(t+1)} V_{j, r}}{h_{x, j}+\sum_{r}^{n o d} \beta_{j, r}^{(t+1)} V_{j, r}} \times \beta_{j, r}^{(t+1)} V_{j, r} \\
\text { CplC }=-\sum_{j}^{\operatorname{seg}}\left[\frac{\left(\sum_{r}^{\text {nod }} \beta_{j, r}^{(t+1)} V_{j, r}\right)^{2}}{h_{x, j}+\sum_{r}^{n o d} \beta_{j, r}^{(t+1)} V_{j, r}}\right]
\end{gathered}
$$

The whole body matrix equation in Figure 6 is updated and solved at each time interval to obtain the new tissue temperatures $\left(T_{r}^{(t+1)}\right)$ and the new blood pool temperature $\left(T_{b l, p}^{(t+1)}\right)$.

\section{Controlling System}

\section{Error Signals and Set-Points}

The controlling system operates with error signals that quantify the thermal strain on the body. An error signal $(\Delta T)$ is the difference between the actual temperature $(T)$ and the corresponding reference or "set-point" temperature $\left(T_{0}\right)$

$$
\Delta T=T-T_{0}
$$

The set-point temperatures correspond to tissue temperatures at thermal neutrality, which refers to a state where no thermoregulation is needed to maintain optimal body temperatures. The setpoint temperatures are obtained by exposing the thermoregulatory model in basal configuration (basal metabolic rate and thermoregulatory responses turned off) to a thermally neutral 
environment and solving for the steady state temperatures. The thermally neutral environment is defined as $T_{\text {air }}=30^{\circ} \mathrm{C}$ and $r h=40 \%$ (from [15]), $T_{L C G}=30.4^{\circ} \mathrm{C}$ (initial LCG inlet water temperature in Figure 8), and $U=11.175 \mathrm{~W} \cdot \mathrm{m}^{-2} \cdot \mathrm{K}^{-1}$ (calibrated so that set-points match with setpoints of the Fiala model).

The governing equations for steady state conditions are obtained by dropping the "transient" coefficient $\frac{\zeta_{r}}{\Delta t}$ in the left-hand-sides and removing all "current" terms in the righthand-sides of Equation ( 57 ), Equation ( 55 ), and Equation ( 68 ). Hence, the steady state equations for core, interior, and skin nodes, respectively, are

$$
\begin{gathered}
{\left[\delta_{r} \beta_{r}+\theta\left(1-A_{F, r}\right) \sum_{s}^{\mathrm{sec}} \phi_{s}\right] T_{r}-\theta A_{F, r+1} \sum_{s}^{\mathrm{sec}} \phi_{s} T_{r+1, s}-\delta_{r} \beta_{r} T_{b l, a}=\delta_{r} q_{m, r}} \\
\left(\gamma_{r}-1\right) A_{B, r-1} T_{r-1}+\left[\left(\gamma_{r}-1\right) A_{B, r}+2+\delta_{r} \beta_{r}-\left(1+\gamma_{r}\right) A_{F, r}\right] T_{r} \\
-\left(1+\gamma_{r}\right) A_{F, r+1} T_{r+1}-\delta_{r} \beta_{r} T_{b l, a}=\delta_{r} q_{m, r} \\
\left(\gamma_{r}-1\right) A_{B, r-1} T_{r-1}+\left[\left(\gamma_{r}-1\right) A_{B, r}+2+\delta_{r} \beta_{r}-\left(1+\gamma_{r}\right) A_{F, s k}\right] T_{r} \\
-\delta_{r} \beta_{r} T_{b l, a}=\left(1+\gamma_{r}\right) E n v+\delta_{r} q_{m, r}
\end{gathered}
$$

By applying Equation ( 73 ) to all core nodes, Equation ( 74 ) to all interior nodes, Equation ( 75 ) to all skin nodes, and Equation ( 22 ) to the central blood pool, we once again obtain the whole body matrix equation that is shown in Figure 6 . The coefficients in the body segment matrixes and the right-hand-side column differ from the corresponding coefficients for transient conditions, but the blood pool row, the blood pool column, and the coupling coefficient remain unchanged. The whole body matrix equation in Figure 6 needs to be solved only once, in order to obtain the steady state (or set-point) temperatures. 


\section{$\underline{\text { Control Equations }}$}

The control equations for shivering $S h(\mathrm{~W})$, vasoconstriction $C s(-)$, vasodilation $D l$ $\left(\mathrm{W} \cdot \mathrm{K}^{-1}\right)$, and sweating $S w\left(\mathrm{~g} \cdot \mathrm{min}^{-1}\right)$ are defined as [14]

$$
\begin{aligned}
& S h=10\left[\tanh \left(0.48 \Delta T_{s k, m}+3.62\right)-1\right] \Delta T_{s k, m}-27.9 \Delta T_{h y} \\
& +1.7 \Delta T_{s k, m} \frac{d T_{s k, m}}{d t}-28.6 \\
& C s=35\left[\tanh \left(0.34 \Delta T_{s k, m}+1.07\right)-1\right] \Delta T_{s k, m}+3.9 \Delta T_{s k, m} \frac{d T_{s k, m}}{d t} \\
& D l=21\left[\tanh \left(0.79 \Delta T_{s k, m}-0.70\right)+1\right] \Delta T_{s k, m} \\
& +32\left[\tanh \left(3.29 \Delta T_{h y}-1.46\right)+1\right] \Delta T_{h y} \\
& S w=\left[0.8 \tanh \left(0.59 \Delta T_{s k, m}-0.19\right)+1.2\right] \Delta T_{s k, m} \\
& +\left[5.7 \tanh \left(1.98 \Delta T_{h y}-1.03\right)+6.3\right] \Delta T_{h y}
\end{aligned}
$$

where $\Delta T_{s k, m}(\mathrm{~K})$ is the mean skin temperature error signal, $\Delta T_{h y}(\mathrm{~K})$ is the hypothalamus (head core) error signal, and $d T_{s k, m} / d t\left(\mathrm{~K} \cdot \mathrm{hr}^{-1}\right)$ is the rate of change of the mean skin temperature

$$
\frac{d T_{s k, m}}{d t}=\frac{T_{s k, m}^{(t)}-T_{s k, m}^{(t-1)}}{\Delta t}
$$

The mean skin temperature $T_{s k, m}$ is defined as

$$
T_{s k, m}=\sum_{j}^{s e g}\left[a_{s k, j} \sum_{s}^{\mathrm{sec}} \frac{A_{s k, j s}}{A_{s k, j}} T_{s k, j s}\right]
$$


where $a_{s k, j}$ is the skin sensitivity coefficient of the $j$-th body segment (see Table 12 in Appendix $A$ ), $A_{s k, j}$ is the total skin surface area of the $j$-th body segment, $A_{s k, j s}$ is the skin surface area of sector $s$ in the $j$-th body segment, and $T_{s k, j s}$ is the corresponding local skin temperature.

The $\Delta T_{s k, m} \cdot d T_{s k, m} / d t$ term in the Cs command (Equation ( 77 )) is only activated when mean skin temperatures are decreasing $\left(d T_{s k, m} / d t<0\right)$ and $\Delta T_{s k, m}<0$. For all other conditions, the $\Delta T_{s k, m} \cdot d T_{s k, m} / d t$ term in the $C s$ command is set to zero. The shivering response $S h$ (W) in Equation ( 76 ) has a maximum of $350 \mathrm{~W}$ and is distributed according to

$$
q_{m, s h, j}=\frac{a_{s h, j} S h}{V_{m s c, j}}
$$

where $a_{s h, j}$ is the shivering distribution coefficient of the $j$-th body segment (see Table 12 in Appendix A), $V_{m s c, j}$ is the segmental muscle volume, and $q_{m, s h, j}\left(\mathrm{~W} \cdot \mathrm{m}^{-3}\right)$ is the shivering component of the local volumetric metabolic heat generation rate (Equation ( 14 )). The sweating response $S w\left(\mathrm{~g} \cdot \mathrm{min}^{-1}\right)$ in Equation ( 79 ) has an upper limit of $30 \mathrm{~g} \cdot \mathrm{min}^{-1}$ and is distributed according to

$$
\frac{d m_{s w, s}}{d t}=a_{s w, j} \frac{A_{s k, s}}{A_{s k, j}} S w \cdot 2^{\frac{T_{s k, s}-T_{s k, 0, s}}{10}}
$$

where $a_{s w, j}$ is the sweat distribution coefficient of the $j$-th body segment (see Table 12 in Appendix A), and $d m_{s w, s} / d t\left(\mathrm{~g} \cdot \mathrm{min}^{-1}\right)$ is the local sweat rate for skin sector $s$ in body segment $j$ (used to compute $q_{s w, s}^{\prime \prime}$ in Equation ( 67$)$ ).

The variable blood perfusion in the skin compartment is controlled by the thermoregulatory system according to 


$$
\beta_{s k, s}^{\prime}=\frac{\beta_{s k, 0, s}^{\prime}+a_{d l, j} D l}{1+a_{c s, j} C s \exp \left(-\frac{D l}{80}\right)} \cdot 2^{\frac{T_{s k, s}-T_{s k, 0, s}}{10}}
$$

where $\beta_{s k, s}^{\prime}\left(\mathrm{W} \cdot \mathrm{K}^{-1}\right)$ is the volume weighted blood perfusion rate factor for skin sector $s, a_{d l, j}$ and $a_{c s, j}$ are the vasodilation and vasoconstriction distribution coefficients for the $j$-th body segment (see Table 12 in Appendix A), Cs is the vasoconstriction command defined by Equation ( 77 ), and $D l$ is the vasodilation command defined in Equation ( 78 ).

Since cardiac output is limited, the maximum skin blood flow depends on how much blood is being pumped to working muscles $[129,130]$. In the Fiala model [14], any excessive skin blood flow arising from Equations ( 78 ) and ( 84 ) is trimmed to a threshold $\beta_{s k, \text { max }}^{\prime}\left(\mathrm{W} \cdot \mathrm{K}^{-}\right.$ ${ }^{1}$ ), which depends on the activity level

$$
\beta_{s k \text { max }}^{\prime}=386.9-0.32 \mu H
$$

where $\mu=0.932 \mathrm{~K}^{-1}$ is a proportionality factor and $H(\mathrm{~W})$ is the internal whole body heat load due to exercise (Equation ( 17 )).

\section{Modifications to the Thermoregulatory Model}

In our previous study [131], we identified a problem with the dynamic response of the central blood pool temperature. Whenever there is a change in metabolic rate, there is an abrupt change in the central blood pool temperature. As a result, the model predicts an excessive change (sometimes in the wrong direction) in core temperature when there is a change in metabolic rate. This unphysical behavior is inherent in Stolwijk-based thermoregulatory models and is allegedly due to the assumption of instantaneous blood supply to working muscles [11]. Hence, when there 
is a change in metabolic rate, the required muscle blood flow for a given exercise rate is instantaneously supplied, which results in an unrealistic change in the central blood pool temperature. In reality, the cardiovascular system does not instantaneously respond to changing requirements. Instead, there is an exponential type of increase or decrease of muscle blood flow after a change in the activity level [132]. Therefore, we use the following equation to model the change in muscle blood flow after a change in exercise rate

$$
\Delta \beta_{m s c, w}(t)=\Delta \beta_{m s c, w, i}+\left(\Delta \beta_{m s c, w, t}-\Delta \beta_{m s c, w, i}\right) \cdot\left[1-\exp \left(-\frac{t}{\tau_{m s c}}\right)\right]
$$

where $\Delta \beta_{m s c, w}$ is the delayed muscle blood perfusion rate factor due to work, $t$ is the time that has elapsed since the change in exercise rate, $\Delta \beta_{m s c, w, i}$ is the corresponding initial value before the change in exercise rate, $\Delta \beta_{m s c, w, t}$ is the corresponding steady state target value associated with the new exercise rate, and $\tau_{m s c}$ is the time constant of the muscle blood perfusion response. In our model, we use a $\tau_{m s c}$ of $1 \mathrm{~min}$, which matches with the time constant that is used in the Wissler thermoregulatory model [17]. This time constant is a bit higher than the typical time constant of $45 \mathrm{~s}$ for a sedentary person [132] and the $43 \mathrm{~s}$ time constant that is used in the Tikuisis thermoregulatory model [109].

Another problem that we identified in our previous study [131] is that the skin blood flow (SBF) is excessively reduced at the onset of exercise, as a result of the decreasing LCG water temperature. The excessive reduction in SBF leads to an overly large drop in skin temperature, which in turn inhibits body heat rejection and results in an excessive core temperature rise in the beginning of the exercise period. In order to reduce the magnitude of the vasoconstriction 
response at the onset of exercise, we introduce an exponential delay of the vasoconstriction response $C s$

$$
C s(t)=C s_{i}+\left(C s_{t}-C s_{i}\right) \cdot\left[1-\exp \left(-\frac{t}{\tau_{c s}}\right)\right]
$$

where $C s$ is the delayed vasoconstriction response, $C s_{t}$ is the target vasoconstriction response as computed by Equation ( 77 ), $t$ is the time that has elapsed since the change in target value, $C s_{i}$ is the corresponding initial value, and $\tau_{c s}$ is the time constant of the vasoconstriction response. We use a vasoconstriction time constant of $200 \mathrm{~s}$ in our model. This can be compared with the $173 \mathrm{~s}$ time constant used by Tikuisis et al. [109] and the $60 \mathrm{~s}$ time constant used by Wissler [17] for the skin blood perfusion response.

The vasoconstriction command $C s$ in Fiala's thermoregulatory model is a function of the mean skin temperature error signal $\Delta T_{s k, m}(\mathrm{~K})$ and the rate of change of the mean skin temperature $d T_{s k, m} / d t\left(\mathrm{~K} \cdot \mathrm{hr}^{-1}\right)$ (see Equation $\left.(77)\right)$. In order to offset the excessive vasoconstriction response during conditions of simultaneously increasing core and decreasing skin temperatures, we introduce an additional dependency on the product of the rate of change of hypothalamus temperature $d T_{h y} / d t\left(\mathrm{~K} \cdot \mathrm{hr}^{-1}\right)$ and the hypothalamus error signal $\Delta T_{h y}(\mathrm{~K})$. Our modified vasoconstriction response is therefore

$$
\begin{array}{r}
C s=35\left[\tanh \left(0.34 \Delta T_{s k, m}+1.07\right)-1\right] \Delta T_{s k, m} \\
+b_{s k} \Delta T_{s k, m} \frac{d T_{s k, m}}{d t}+b_{h y} \Delta T_{h y} \frac{d T_{h y}}{d t}
\end{array}
$$

where $b_{s k}$ and $b_{h y}$ are constants to be determined. 


\section{Analytical Solutions to the Bioheat Equation}

Analytical solutions to the bioheat equation are very useful tools for validating the passive system of the thermoregulatory model. In order to ensure that our numerical formulation of the bioheat equation is accurate, we expose individual cylinders and spheres to a variety of different conditions, and compare the model responses to available analytical solutions.

Eberhart [133] presents an analytical solution to the transient Pennes bioheat equation for homogeneous cylinders with convective boundary conditions (see Appendix B). We use this analytical solution to validate our model's tissue temperature response in a homogeneous cylinder for a variety of different time steps and radial node configurations.

Durkee and coworkers [134-136] present analytical solutions to the transient multicompartment Pennes bioheat equation for rectangular, cylindrical, and spherical geometries. With these analytical solutions, we can validate our model predictions for non-homogeneous geometries and ensure that our compartmental boundary conditions are correct. Instead of implementing the rather tedious solution procedure, we use computer software to extract data points from their plots. This data extraction process introduces a small amount of error in the exact analytical solution, but it is practically insignificant for our validation purpose.

\section{Experimental Data}

In order to validate our thermoregulatory model, we benchmark it with the experimental data from Webb and Annis [64]. As explained earlier, they use a whole body liquid cooling garment to remove metabolic heat from individuals during a variety of different exercise programs consisting of grade walking on a treadmill. For our present study, we consider their rectangular type activity schedule where four test subjects exercise on a treadmill for one hour at 
a high and constant metabolic rate of $700 \mathrm{~W}$. This metabolic rate is around eight times higher than the basal metabolic rate of a standard man, and is slightly higher than the $600 \mathrm{~W}$ metabolic rate that is frequently encountered by the astronaut [3]. The exercise period is preceded and followed by rest periods of at least one hour, as depicted in Figure 7.

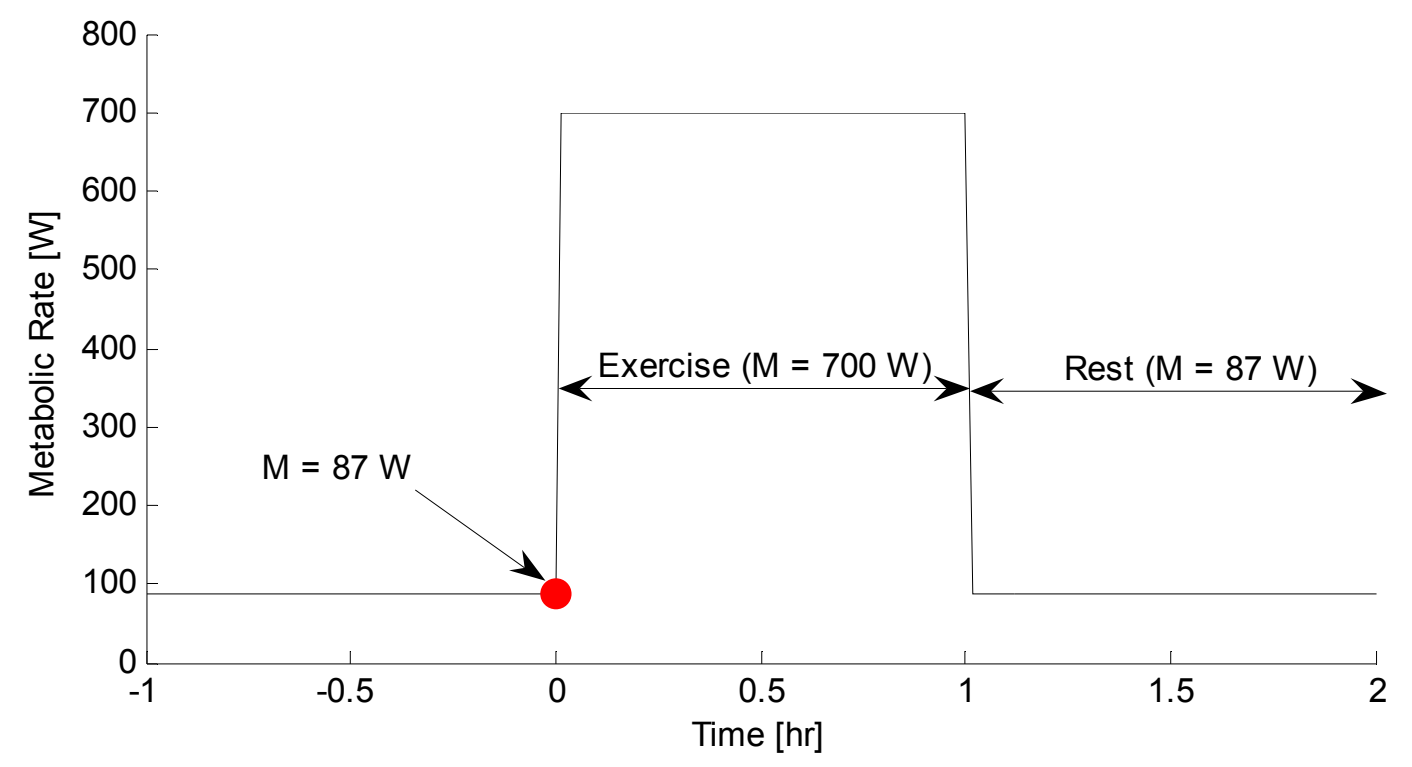

Figure 7: Metabolic rate profile used as input to the model

Figure 8 shows the mean and standard deviation of the LCG inlet water temperature for the four test subjects during the exercise and recovery periods. 


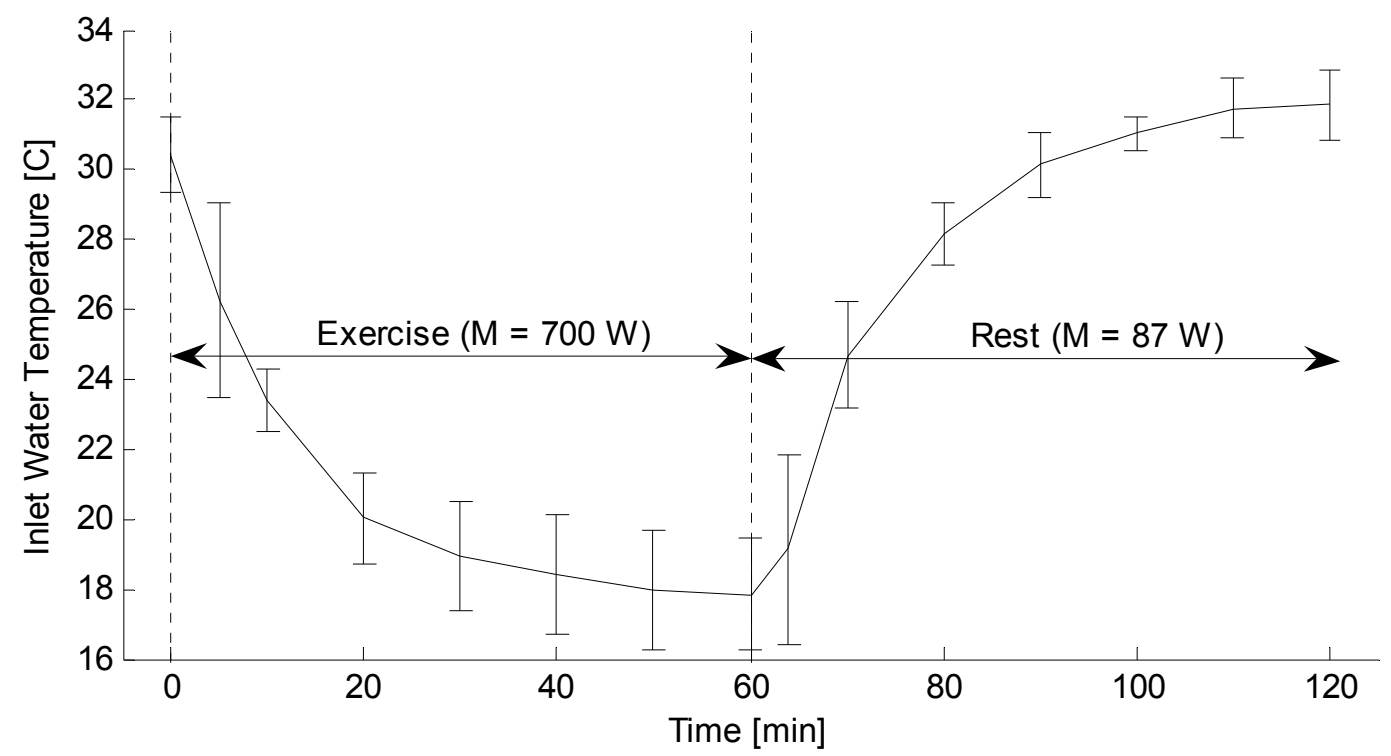

Figure 8: LCG inlet water temperature (mean \pm standard deviation) used as input to the model

Continuous graphs for heat removal rate, coolant inlet temperature, oxygen consumption, rectal temperature, and mean skin temperature are presented. However, the experimental data does not separate heat and work losses. Instead, Webb and Annis [64] provides continuous graphs of the quantity "Q", which includes sensible and latent heat rate losses from the skin, the respiration heat rate loss, and the work rate. Hence, in order to obtain an estimate of the LCG heat removal rate, we need to subtract the work rate and respiration and latent heat rate losses from Webb and Annis' "Q" quantity. By assuming a work efficiency of $20 \%$, a sweat evaporation rate of $83 \mathrm{~g} / \mathrm{h}$, and a respiration heat loss rate according to Equation ( 23 ), we estimate the LCG heat removal rate $Q_{L C G}$ and compute the outlet LCG water temperature $T_{\text {out }}$ according to

$$
T_{\text {out }}=T_{\text {in }}+\frac{Q_{L C G}}{\dot{V}_{\text {water }} \rho_{\text {water }} c_{\text {water }}}
$$


where $T_{\text {in }}$ is the mean of the inlet temperature data in Figure $8, \dot{V}_{\text {water }}$ is the total volumetric LCG water flow rate, $\rho_{\text {water }}$ is the density of water, and $c_{\text {water }}$ is the specific heat of water. The density and specific heat are evaluated at $25^{\circ} \mathrm{C}$.

The mean and standard deviation of the test subjects' body characteristics are; age, $28.3 \pm 11.8$ years; height, $176 \pm 4.8 \mathrm{~cm}$; weight, $71.0 \pm 7.5 \mathrm{~kg}$; and surface area, $1.85 \pm 0.06 \mathrm{~m}^{2}$. The weight and height of the test subjects match well with our model characteristics.

\section{Quantifying Thermal Comfort}

In order to quantify thermal comfort, we use Kuznetz' thermal comfort band (see Figure 1). Body heat storage (BHS) is computed with the following equation

$$
B H S=\sum_{j}^{\text {seg }} \sum_{r}^{\text {nod }} m_{j, r} c_{j, r}\left(T_{j, r}-T_{0, j, r}\right)
$$

where $m$ is the mass, $c$ is the specific heat, $T$ is the actual temperature, and $T_{0}$ is the set-point temperature. The summation indices $j$ and $r$ are body segment and node numbers, respectively. With Kuznetz' thermal comfort band of $\pm 19 \mathrm{~W} \cdot \mathrm{hr}$, Smith et al. [24] suggested that a BHS accuracy of $\pm 6.5 \mathrm{~W} \cdot \mathrm{hr}$ may be tolerable for automatic cooling control development. The absolute BHS error $\varepsilon_{B H S}$ is estimated by

$$
\varepsilon_{B H S}=\sum_{j}^{\operatorname{seg}} \sum_{r}^{\text {nod }} m_{j, r} c_{j, r} \varepsilon_{T, j, r}
$$

where $\varepsilon_{T}$ is the absolute error between the predicted and measured temperatures. Since the experimental data only provides measured rectal and mean skin temperatures, we assign the 
mean skin temperature error to all skin nodes, and the rectal temperature error to all other nodes [24].

\section{Calibration Procedure}

In order to obtain a reasonable agreement between experimental data and our model response, we need to calibrate some model parameters which are not available from the experimental data. In the calibration procedure, we vary these parameters within justifiable limits, study the trends of the results, and identify the optimum parameters that will produce the best fit between measured and simulated responses.

As previously explained, Webb and Annis [64] provides continuous graphs for the quantity "Q", which includes sensible and latent heat rate losses from the skin, respiration heat rate losses, and work rates. Hence, we do not know the work rate throughout the exercise period or the LCG heat removal rate throughout the activity schedule. Because of these unknowns, we introduce the work efficiency $\eta_{w}$ and the overall LCG heat transfer coefficient $U$ as calibration parameters. These calibration parameters are iteratively tuned until we have an optimum fit between measured and simulated tissue temperatures.

The latent heat losses are severely inhibited for the experimental subjects, as indicated by the average sweat rate of $83 \mathrm{~g} / \mathrm{h}$ for the activity schedule. In order to match this evaporation rate, we introduce a maximum allowable sweat evaporation rate $S w_{C A P}$. Any sweat that is produced in excess of $S w_{C A P}$ is discarded by the model and does not contribute to any cooling. The $S w_{C A P}$ is iteratively tuned so that the average sweat evaporation rate matches with the experiment.

The above three calibration parameters $\left(\eta_{w}, U\right.$, and $\left.S w_{C A P}\right)$ are the only calibration parameters for the old thermoregulatory model (Fiala's model without modifications). The 
modifications that we make to the thermoregulatory model introduce additional calibration parameters; the muscle blood flow time constant $\tau_{m s c}$, the vasoconstriction time constant $\tau_{c s}$, and the constants $b_{s k}$ and $b_{h y}$ in the vasoconstriction command (Equation ( 88$)$ ). 


\section{CHAPTER 4 RESULTS}

\section{$\underline{\text { Analytical Validation }}$}

First, we compare the passive model response with Eberhart's [133] exact analytical solution to the bioheat equation for a cylinder with homogeneous properties. The cylinder is initially in thermal equilibrium with a convective environment $\left(U=20 \mathrm{~W} \cdot \mathrm{m}^{-2} \cdot \mathrm{K}^{-1}, T_{L C G}=0^{\circ} \mathrm{C}\right)$. At $t=0 \mathrm{~min}$, the cylinder is perfused with blood $\left(w_{b l}=0.001 \mathrm{~s}^{-1}, T_{b l, a}=37^{\circ} \mathrm{C}, \rho_{b l}=1069 \mathrm{~kg} \cdot \mathrm{m}^{-3}\right.$,

$\left.c_{b l}=3650 \mathrm{~J} \cdot \mathrm{kg}^{-1} \cdot \mathrm{K}^{-1}\right)$ and supplied with a metabolic heat source $\left(q_{m}=500 \mathrm{~W} \cdot \mathrm{m}^{-3}\right)$. As shown in Figure 9, the tissue temperatures initially increase quickly, and thereafter approach the new steady state temperatures asymptotically. We obtain the model response in Figure 9 with a five minute time step and seven radial nodes in a leg cylinder with an outer radius of $5.53 \mathrm{~cm}$. The three radial locations correspond to core $(r=1.56 \mathrm{~cm})$, muscle $(r=4.15 \mathrm{~cm})$, and skin $(r=5.38$ $\mathrm{cm})$. In order to make the cylinder homogeneous, we assign muscle properties $\left(\rho=1085 \mathrm{~kg} \cdot \mathrm{m}^{-3}\right.$, $c=3768 \mathrm{~J} \cdot \mathrm{kg}^{-1} \cdot \mathrm{K}^{-1}, k=0.42 \mathrm{~W} \cdot \mathrm{m}^{-1} \cdot \mathrm{K}^{-1}$ ) to all tissue compartments. The mean absolute tissue temperature errors for the three radial locations are $0.03^{\circ} \mathrm{C}$ at $r=1.56 \mathrm{~cm}, 0.15^{\circ} \mathrm{C}$ at $r=4.15 \mathrm{~cm}$, and $0.34^{\circ} \mathrm{C}$ at $r=5.38 \mathrm{~cm}$, which indicate that the error increases towards the skin surface. The mean absolute temperature error for all seven temperature responses is $0.23^{\circ} \mathrm{C}$. 


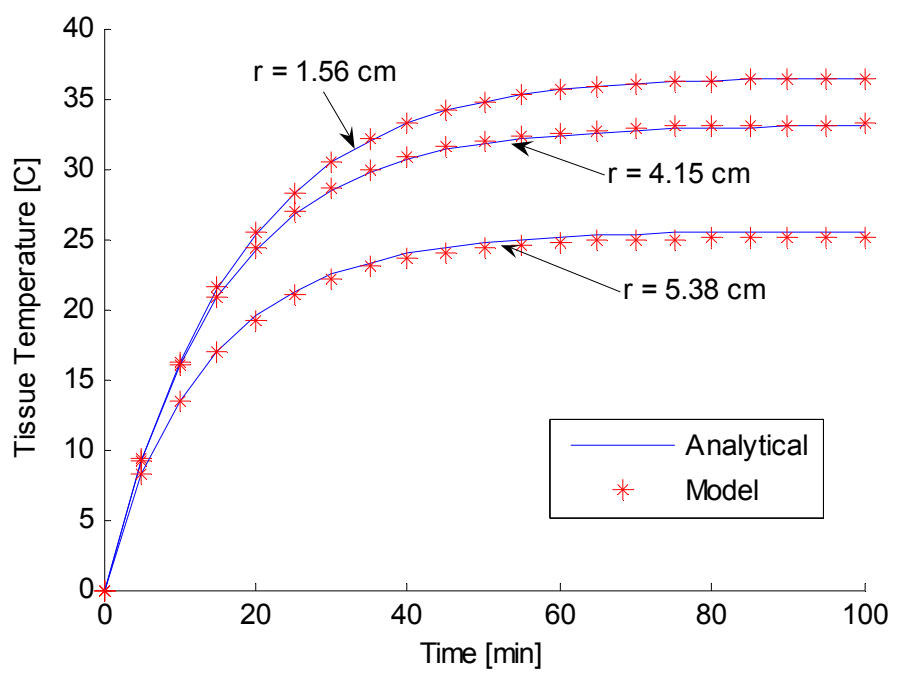

Figure 9: Comparing model response with exact analytically derived temperatures after a sudden supply of blood perfusion and metabolic heat in a homogeneous cylinder

In Figure 10, we investigate model response dependency on time step. The conditions are the same as in Figure 9, but we consider only the core node $(r=1.56 \mathrm{~cm})$, and we include model predictions with 10 min and 20 min time steps. As shown in Figure 10, the model demonstrates excellent stability even for excessively large time steps. The mean absolute errors for the three simulations are $0.03^{\circ} \mathrm{C}, 0.13^{\circ} \mathrm{C}$, and $0.55^{\circ} \mathrm{C}$, respectively, which confirm that the error increases with an increasing time step. 


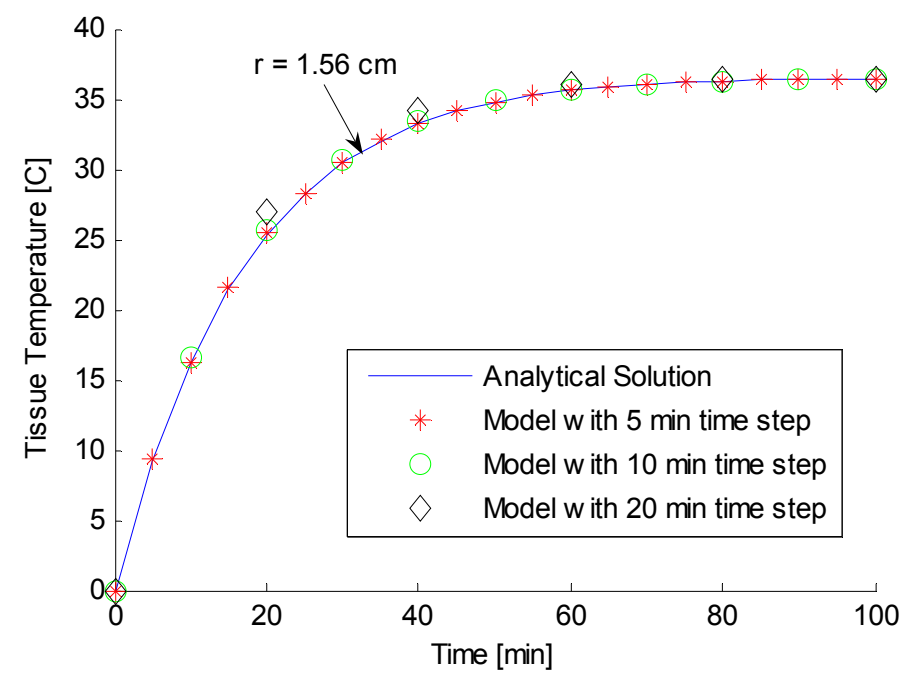

Figure 10: Investigating model response dependency on time step

In Figure 11, we investigate model response dependency on radial node spacing. The conditions are the same as in Figure 9, but we consider only the response at $t=20 \mathrm{~min}$, and we include the model response for a 14-node configuration. Figure 11 shows the radial temperature distributions in the cylinder for the two node configurations, as well as the corresponding exact analytical solution. The mean absolute error is $0.17^{\circ} \mathrm{C}$ for the seven-node configuration and $0.06^{\circ} \mathrm{C}$ for the 14-node configuration, which confirms that the error decreases with an increasing number of nodes. 


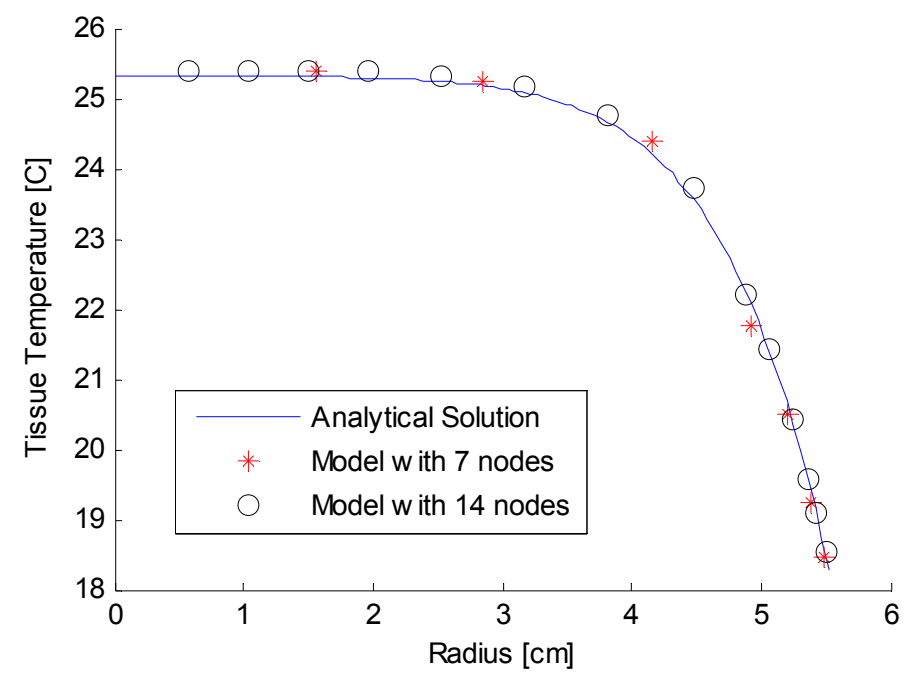

Figure 11: Investigating model response dependency on radial node spacing

Next, we consider the transient temperature response of a sphere consisting of eight physiologically distinct compartments as presented by Durkee and coworkers [136]. The sphere, initially at a uniform temperature of $34^{\circ} \mathrm{C}$, is suddenly exposed to a convective environment at $32^{\circ} \mathrm{C}$, a non-uniform blood perfusion rate, and a non-uniform heat generation rate. The heat generation rate in the skin compartment (C8 in Figure 12), which simulates a therapeutic heat source, is almost 207,000 times higher than the heat generation rates in the other compartments. Figure 12 shows the predicted and the analytically derived radial temperature distributions in the sphere at seven different points in time during the exposure. The therapeutic heat source quickly drives up tissue temperatures in the peripheral compartments while heat slowly diffuses into central regions. For the simulation in Figure 12, we use three to seven compartmental nodes, and the time step varies from $0.01 \mathrm{~s}$ to $100 \mathrm{~s}$. The root mean square (RMS) deviation between the analytical and numerical solutions is $0.12^{\circ} \mathrm{C}$. 


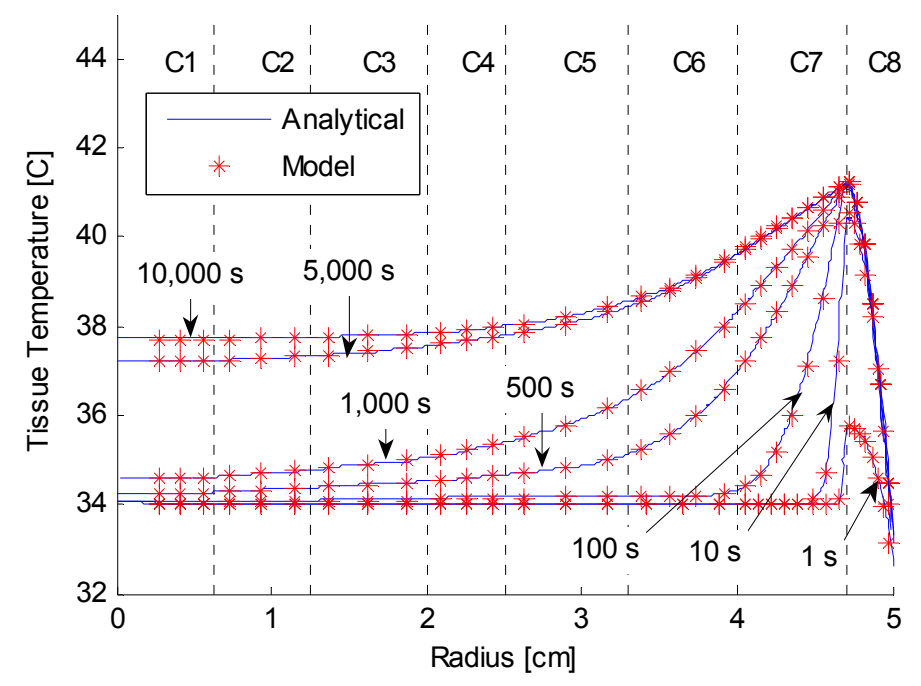

Figure 12: Comparing model response with exact analytically derived temperature profiles in a sphere with eight physiologically distinct compartments

The above analytical validation procedure confirms that we have implemented an accurate and stable numerical representation of the Pennes bioheat equation.

\section{Experimental Validation}

The experimental activity schedule (Figure 7) starts with at least an hour of rest in an attempt to obtain basal metabolic conditions at the onset of the exercise period. Since the thermoregulatory model assumes a basal metabolic state at the beginning of the simulation, we start our simulation at the onset of the exercise period and hence do not simulate the initial rest period that is shown in Figure 7.

Since we assume an initial basal metabolic state, the initial temperature distribution of the model corresponds to the set-point temperature distribution. As discussed earlier, we obtain the set-point temperatures by exposing the thermoregulatory model in basal configuration to a thermally neutral environment and solving for the steady state temperatures. Table 1 summarizes the result of this procedure. The data match well with the corresponding steady state solution 
reported by Fiala et al. [15]. Furthermore, the mean skin temperature matches with the $34.4^{\circ} \mathrm{C}$ mean skin temperature that is obtained when using Fanger's correlation [2] for a sedentary person in thermal comfort with a metabolic rate of $87.1 \mathrm{~W}$ and a skin surface area of $1.86 \mathrm{~m}^{2} . \mathrm{In}$ addition, the hypothalamus temperature matches with the $37.0^{\circ} \mathrm{C}$ oral temperature that is associated with a healthy resting adult human being [26].

Table 1: Set-points obtained when exposing the passive basal model to thermal neutrality

\begin{tabular}{|c|c|c|c|c|c|c|}
\hline $\begin{array}{l}\mathrm{T}_{\text {sk, } \mathrm{m}} \\
\left({ }^{\circ} \mathrm{C}\right)\end{array}$ & $\begin{array}{l}\mathrm{T}_{\text {hy }} \\
\left({ }^{\circ} \mathrm{C}\right)\end{array}$ & $\begin{array}{l}\mathrm{T}_{\mathrm{re}} \\
\left({ }^{\circ} \mathrm{C}\right)\end{array}$ & $\begin{array}{l}\mathrm{T}_{\mathrm{bl}, \mathrm{p}} \\
\left({ }^{\circ} \mathrm{C}\right)\end{array}$ & $\begin{array}{c}\mathrm{T}_{\mathrm{msc}, \mathrm{m}} \\
\left({ }^{\circ} \mathrm{C}\right)\end{array}$ & $\begin{array}{c}\text { SBF } \\
\left(\mathrm{L} \mathrm{min}^{-1}\right)\end{array}$ & $\begin{array}{l}Q_{\text {resp }} \\
(\mathrm{W})\end{array}$ \\
\hline 34.40 & 37.00 & 36.90 & 36.66 & 36.22 & 0.38 & 6.99 \\
\hline
\end{tabular}

\section{Old Model Response}

Without modifications to the Fiala thermoregulatory model, the calibration procedure results in an overall heat transfer coefficient of $16.2 \mathrm{~W} \cdot \mathrm{m}^{-2} \cdot \mathrm{K}^{-1}$. This value is in the low end of the range of heat transfer coefficients $\left(14 \mathrm{~W} \cdot \mathrm{m}^{-2} \cdot \mathrm{K}^{-1}-73 \mathrm{~W} \cdot \mathrm{m}^{-2} \cdot \mathrm{K}^{-1}\right)$ that we found in the literature for comparable studies $[122,124,127]$. The work efficiency $\eta_{w}$ is calibrated to $40 \%$, which corresponds to the maximum value that has been reported in the literature for grade walking on a treadmill [27]. Furthermore, the maximum allowable sweat evaporation rate is set to $1.68 \mathrm{~g} / \mathrm{min}$ in order to match the average evaporation rate of $83 \mathrm{~g} / \mathrm{h}$ that is reported in the experiment. Figure 13 shows the sweat rate and the sweat evaporation rate during the exercise and the subsequent rest period. The sweat that is produced in excess of the calibrated $1.68 \mathrm{~g} / \mathrm{min}$ cap is discarded by the model and does not contribute to any cooling. 


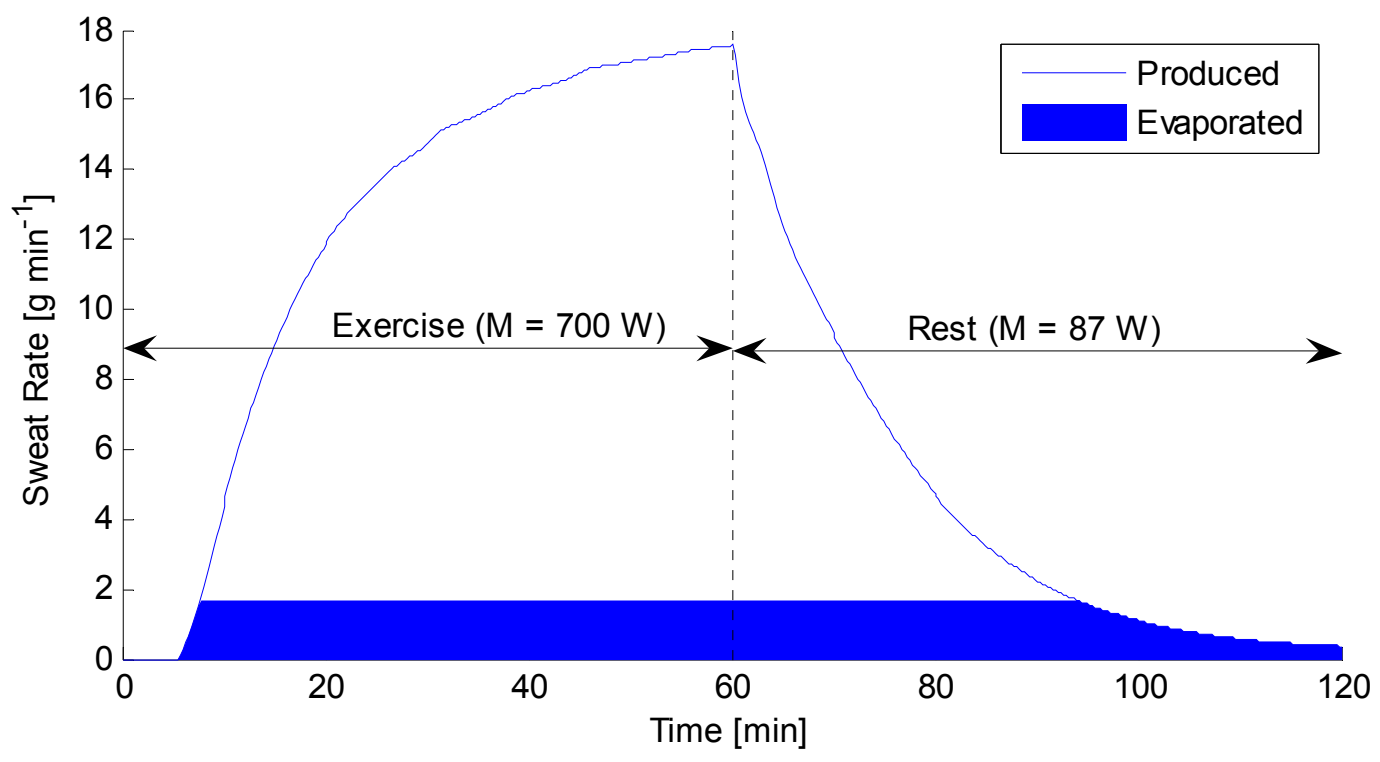

Figure 13: Predicted sweat production rate and sweat evaporation rate during the activity schedule

In Figure 14, we compare the old model's predicted rectal and mean skin temperature responses with the mean and standard deviation of the corresponding experimental data. We also include the $\pm 0.5^{\circ} \mathrm{C}$ and $\pm 2.0^{\circ} \mathrm{C}$ accuracy limits for the rectal and mean skin temperatures, respectively, that Wissler [92] suggests is necessary for useful model predictions. As seen in Figure 14, the predicted rectal and mean skin temperatures are within the recommended accuracy limits at all times throughout the activity schedule, but exceed the standard deviation at the beginning and in the middle of the exercise period as well as in the end of the rest period. The root mean square (RMS) deviation between the model response and the mean experimental group response is $0.16^{\circ} \mathrm{C}$ for the rectal temperature and $0.70^{\circ} \mathrm{C}$ for the mean skin temperature. Fiala et al. [14] reported rectal temperature RMS deviations of $0.10^{\circ} \mathrm{C}-0.18^{\circ} \mathrm{C}$ and mean skin temperature RMS deviations of $1.07^{\circ} \mathrm{C}-1.75^{\circ} \mathrm{C}$ for various exercise exposures in cold air environments. Hence, the accuracy of the Fiala thermoregulatory model translates well from air to LCG environments. 

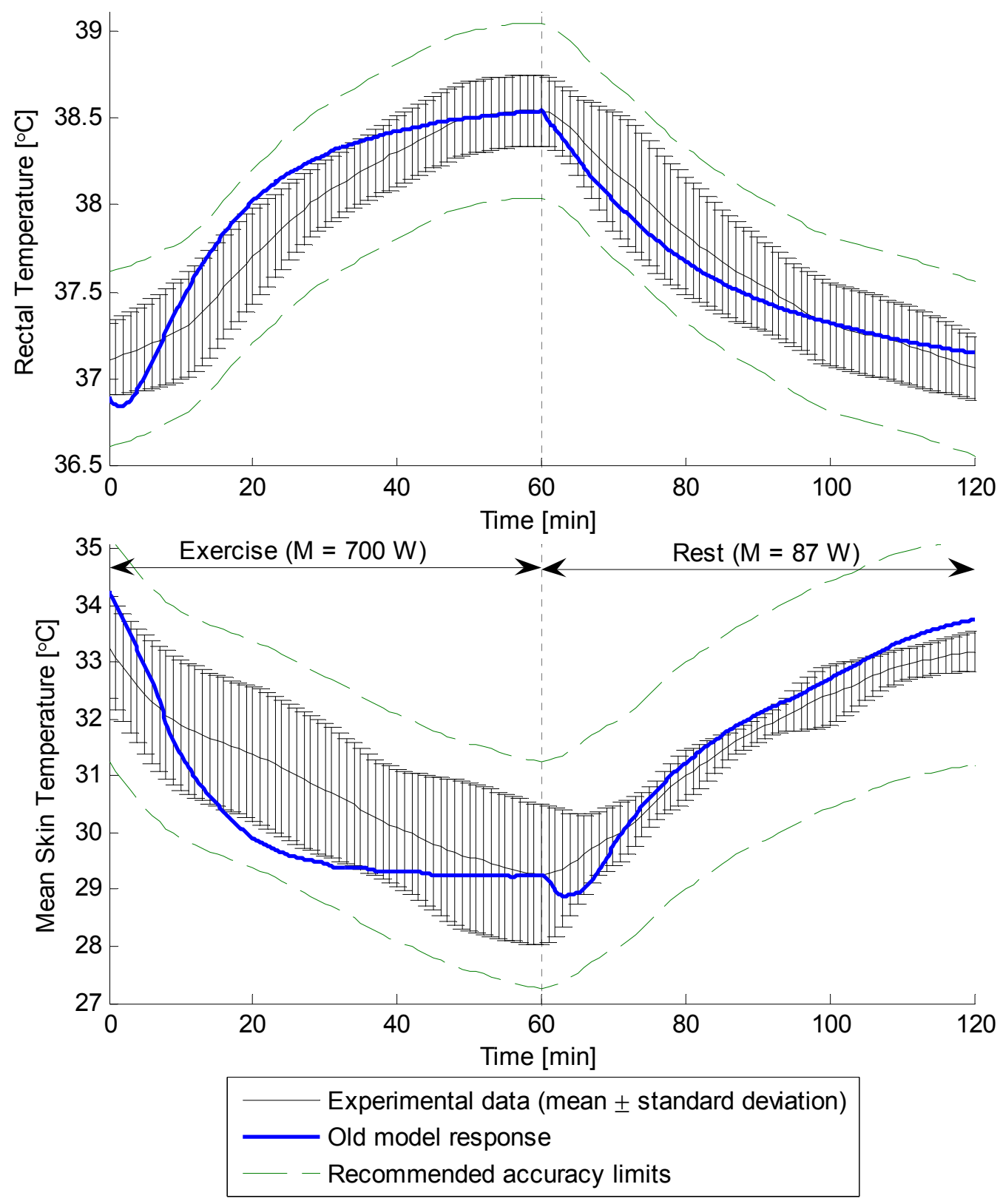

Figure 14: Comparing predicted rectal and mean skin temperature responses with experimental data and recommended accuracy limits

Despite excellent accuracies of the rectal and mean skin temperature responses, it is apparent that some discrepancies exist. The model predicts an initial decrease in rectal temperature during the first minutes following the onset of exercise (see Figure 14), which is not present in the experimental data. As discussed in Modifications to the Thermoregulatory Model, 
this drop is due to the assumption of instantaneous blood supply to working muscles, which results in an unrealistic jump in the central blood pool temperature. This jump is present at the cessation of exercise as well, but it is in the "right direction" and hence not obvious from the rectal temperature response. However, it is evident by the dip in the mean skin temperature at the onset of the rest period (see Figure 14).

Another discrepancy that is apparent in Figure 14 is that the rate of increase of the rectal temperature and the rate of decrease of the mean skin temperature are excessive during the first 20 min of exercise. As discussed in Modifications to the Thermoregulatory Model, this is due to an excessive vasoconstriction response, which reduces skin blood flow and skin temperatures. The reduced skin conductance inhibits body heat rejection, which in combination with the high metabolic heat load, results in an excessive rectal temperature rise.

Figure 15 illustrates how the predicted body heat storage (BHS) changes during the exercise and recovery periods. We also include Kuznetz' steady state comfort band [42] for a $700 \mathrm{~W}$ metabolic rate. As shown, the body heat storage increases quickly in the beginning of the exercise period, and then asymptotically approaches a value of around $52 \mathrm{~W} \cdot \mathrm{h}$. The BHS experiences a similar but decreasing type of response during the rest period. According to the figure, the model predicts a state of thermal comfort during the majority of the exercise period, which matches well with the subjective response from the experimental investigation. 


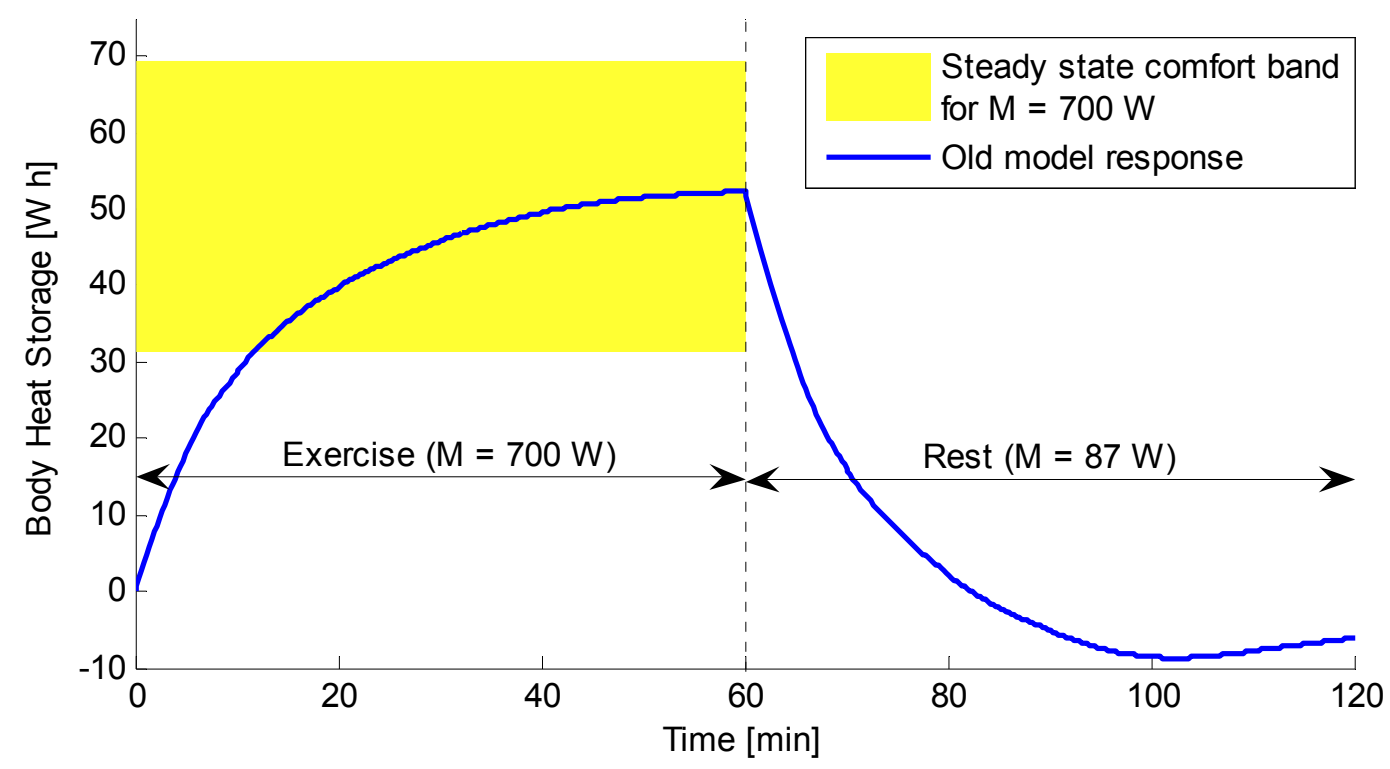

Figure 15: Predicted variation of body heat storage during the activity schedule

Figure 16 illustrates how the old model's absolute BHS error $\left(\varepsilon_{B H S}\right)$ varies during the activity schedule. For comparison purposes, we also include Kuznetz' \pm 19 W'h comfort band [42] and the target accuracy of $\pm 6.5 \mathrm{~W} \cdot \mathrm{h}$ that is required for automatic cooling control development [24]. As shown, $\varepsilon_{B H S}$ exceeds the target accuracy during the majority of the simulation time. During the exercise period, $\varepsilon_{B H S}$ exceeds the $\pm 19 \mathrm{~W} \cdot \mathrm{h}$ comfort band for $19 \mathrm{~min}$, which makes a comfort prediction very questionable. After 20 min of exercise, $\varepsilon_{B H S}$ peaks at 25.2 $\mathrm{W} \cdot \mathrm{h}$ which is almost four times larger than the target accuracy. The mean absolute body heat storage error $\bar{\varepsilon}_{B H S}$ is $12.9 \mathrm{~W} \cdot \mathrm{h}$ for the exercise period, $6.5 \mathrm{~W} \cdot \mathrm{h}$ for the rest period, and $9.7 \mathrm{~W} \cdot \mathrm{h}$ for the combined exercise and rest periods. 


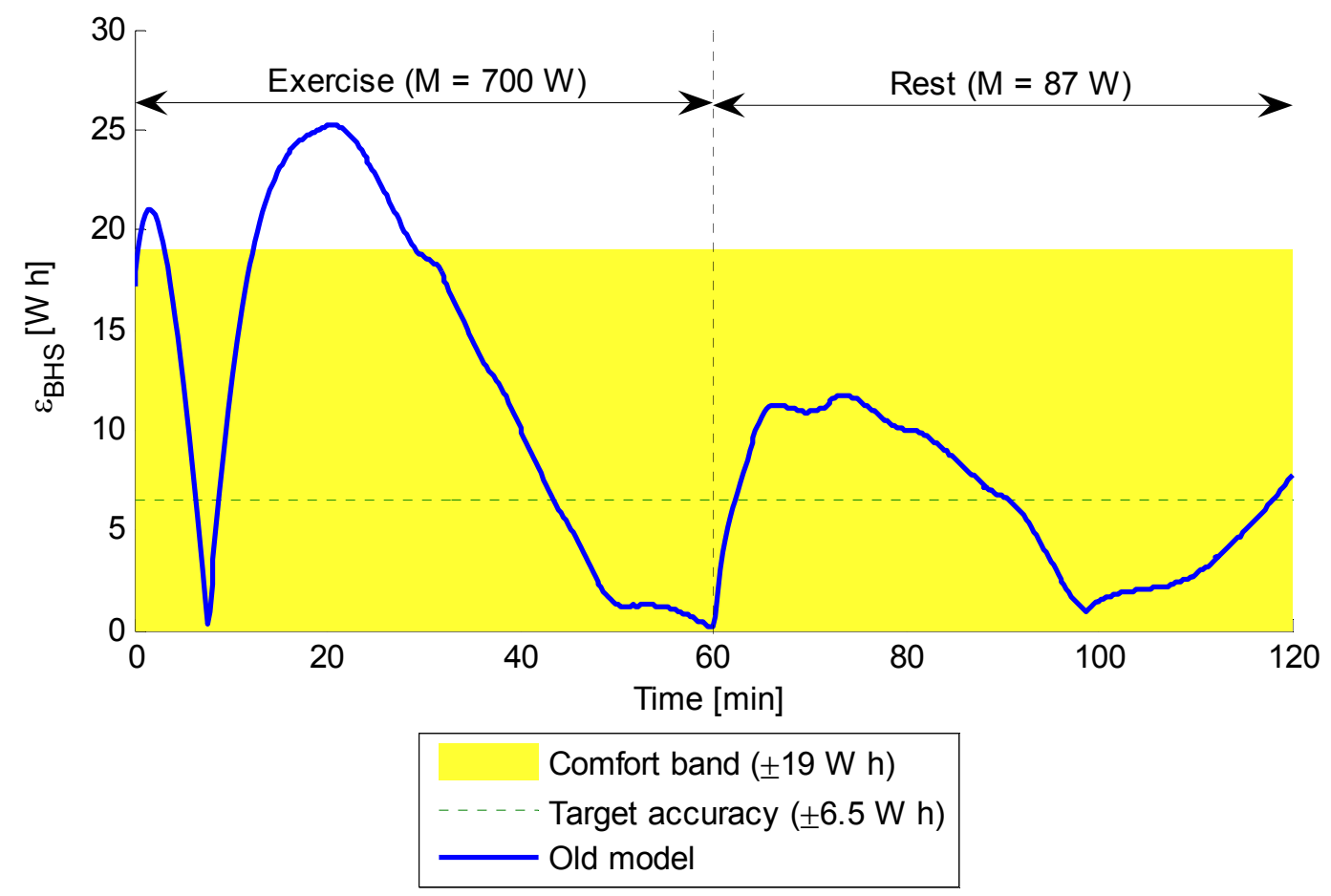

Figure 16: Comparing absolute body heat storage error of the old model with comfort band and target accuracy

The above analysis indicates that the accuracy of the Fiala thermoregulatory model translates well from air to LCG environments, and that the accuracies of rectal and mean skin temperature predictions are within the recommended limits suggested in the literature. However, the model fails to predict body heat storage with the accuracy that is required for automatic LCG cooling control development. The mean absolute BHS error for the exercise period is almost twice as large as the corresponding error for the rest period, and the peak BHS error during the exercise period is almost four times larger than the target accuracy. It is clear that significant improvements are necessary, especially to the exercise response, in order to achieve the target accuracy. 


\section{New Model Response}

\section{$\underline{\text { Exponential Delay of Muscle Blood Flow }}$}

In this section, we will investigate the effect of delaying the blood perfusion to working muscles according to Equation ( 86 ). Figure 17 shows the response of the muscle blood perfusion rate factor due to work $\Delta \beta_{m s c, w}\left(\mathrm{~W} \cdot \mathrm{m}^{-3} \cdot \mathrm{K}^{-1}\right)$ for the old model's step response, the old model with a time constant of $1 \mathrm{~min}$, and the old model with a time constant of $6 \mathrm{~min}$. The $\Delta \beta_{m s c, w}$ response shown in Figure 17 is for the leg segment, and does not include the basal component. With time constants of $1 \mathrm{~min}$ and $6 \mathrm{~min}$, more than 99 percent of the response amplitudes are attained after $5 \mathrm{~min}$ and $30 \mathrm{~min}$, respectively. The $1 \mathrm{~min}$ time constant matches with the time constant that is used in the Wissler thermoregulatory model [17], and is a bit higher than the typical $45 \mathrm{~s}$ time constant of a sedentary person [132]. Clearly, the 6 min time constant can not be justified, but we include it for comparison purposes.

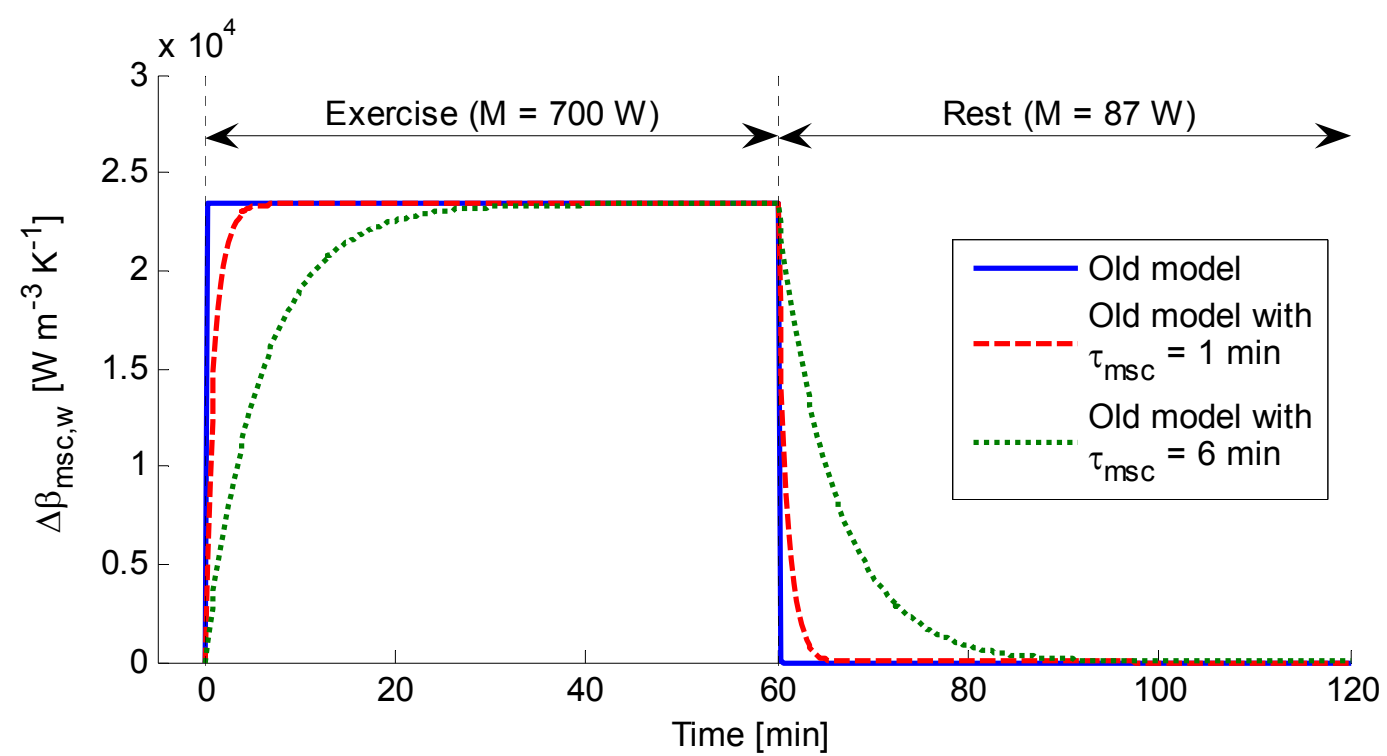

Figure 17: Comparing instantaneous versus exponential blood flow response to working muscles in the leg segment 
Figure 18 shows the corresponding plot for the central blood pool temperature response (Equation ( 22 )). As shown, the old model's step response in muscle blood perfusion results in an abrupt change in $T_{b l, p}$ immediately following a change in metabolic rate. The abrupt change in $T_{b l, p}$ is caused by the sudden change in blood perfusion to activated or deactivated muscles. At the onset of exercise, there is a drop in $T_{b l, p}$ because blood perfusion is suddenly increased in cooler (relative to $T_{b l, p}$ ) muscle tissue. At the cessation of exercise, there is also a drop in $T_{b l, p}$ because blood perfusion is now suddenly decreased in warmer (relative to $T_{b l, p}$ ) muscle tissue. With $\tau_{m s c}=1 \mathrm{~min}$, the magnitude of the initial $T_{b l, p}$ drop is reduced by more than half, and with the fictitious $\tau_{m s c}=6 \mathrm{~min}$, the initial $T_{b l, p}$ drop is almost completely eliminated. It is noticeable that except for the first few minutes following a change in metabolic rate, the three responses in Figure 18 are almost identical. 


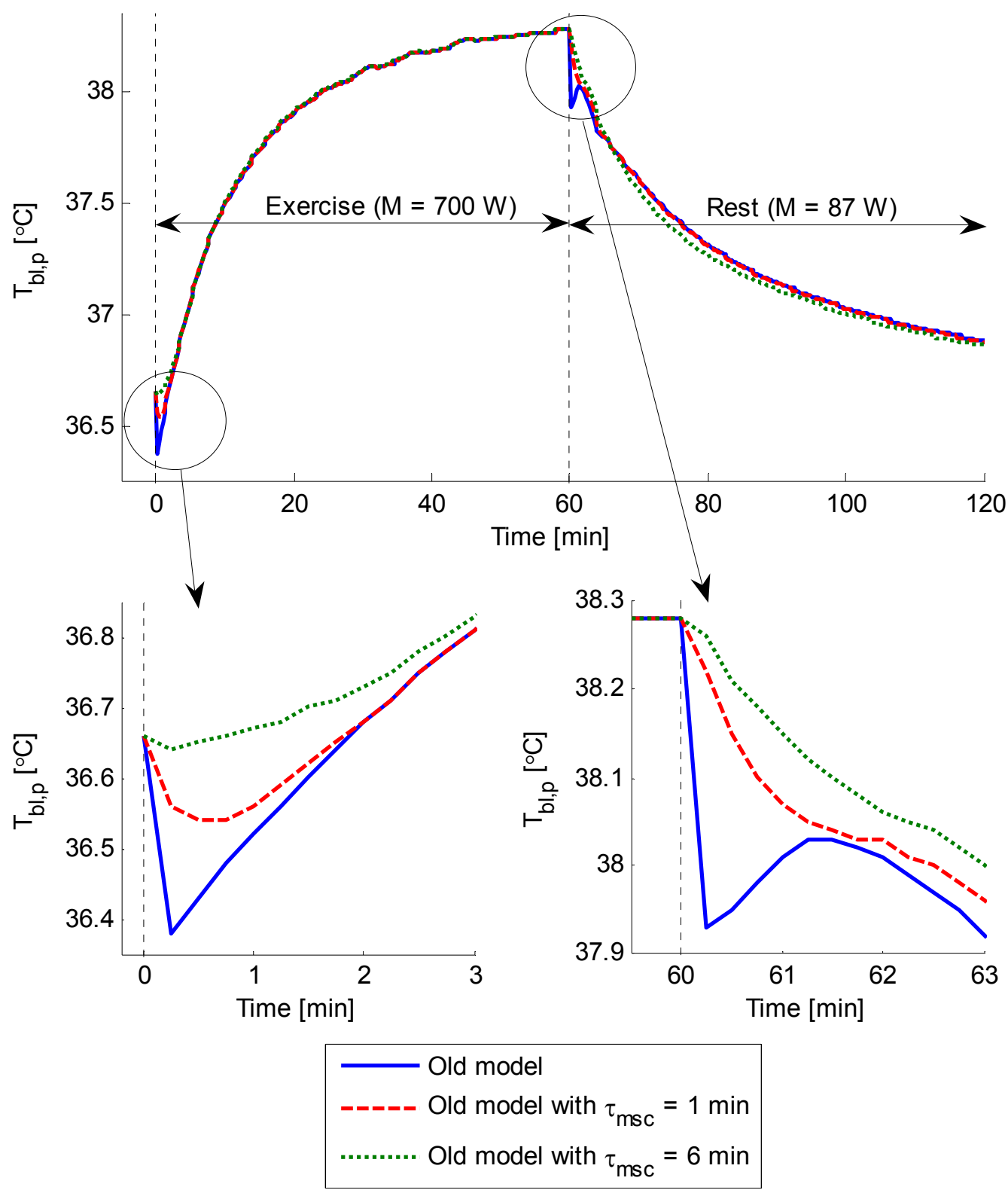

Figure 18: Investigating effect of muscle blood flow delay on blood pool temperature response

In Figure 19 and Figure 20, we see the effect of the muscle blood perfusion delay on the rectal and mean skin temperature responses. The dip in $T_{r e}$ following a change in metabolic rate is due to the corresponding $T_{b l, p}$ dip, but it is smaller in magnitude and longer in duration because of the thermal inertia of the tissue. The dip in $T_{s k, m}$ at the cessation of exercise is caused by the dip in $T_{b l, p}$, which induces a spike in vasoconstriction that further amplify the dip. Similar to the 
$T_{b l, p}$ response, the muscle blood perfusion delay improves the rectal and mean skin temperature responses during a few minutes following a change in metabolic rate. However, except for these few minutes, the muscle blood perfusion delay has an insignificant effect. Clearly, the excessive rise in rectal temperature and the excessive drop in mean skin temperature during the initial 20 min of exercise remain, indicating that this problem is not related to the assumption of instantaneous blood supply to activated or deactivated muscles. With $\tau_{m s c}=1 \mathrm{~min}$, the RMS deviations for the rectal and mean skin temperature responses are reduced by $0.95 \%$ and $0.21 \%$, respectively, which emphasizes the insignificant effect of delaying the blood perfusion response to activated or deactivated muscles. 


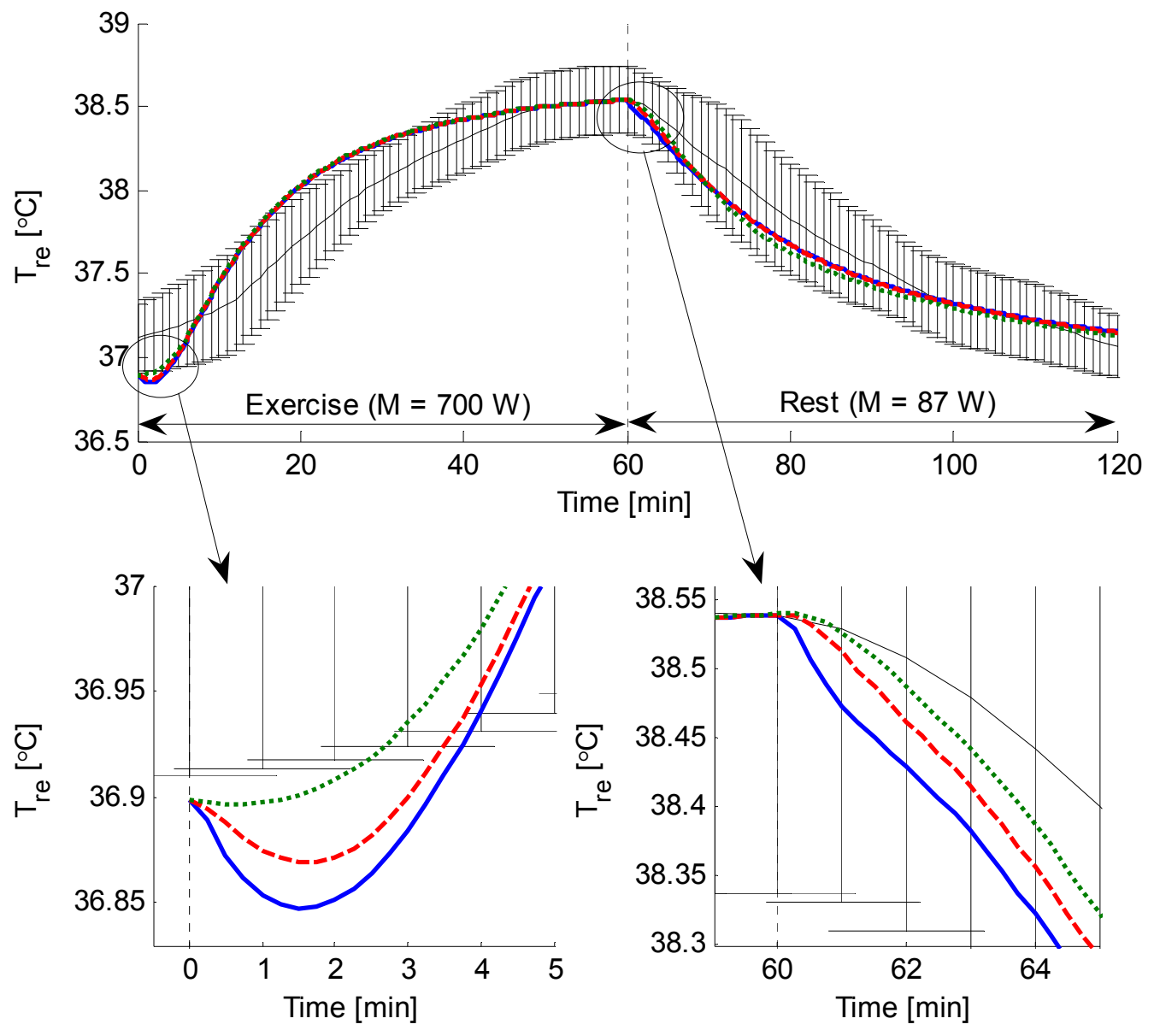

$$
\begin{aligned}
& \text { Experimental data (mean } \pm \text { standard deviation) } \\
& \text { Old model } \\
& \ldots \ldots \text { Old model with } \tau_{\mathrm{msc}}=1 \mathrm{~min} \\
& \ldots . . . . . \text { Old model with } \tau_{\mathrm{msc}}=6 \mathrm{~min}
\end{aligned}
$$

Figure 19: Investigating effect of muscle blood flow delay on rectal temperature response 

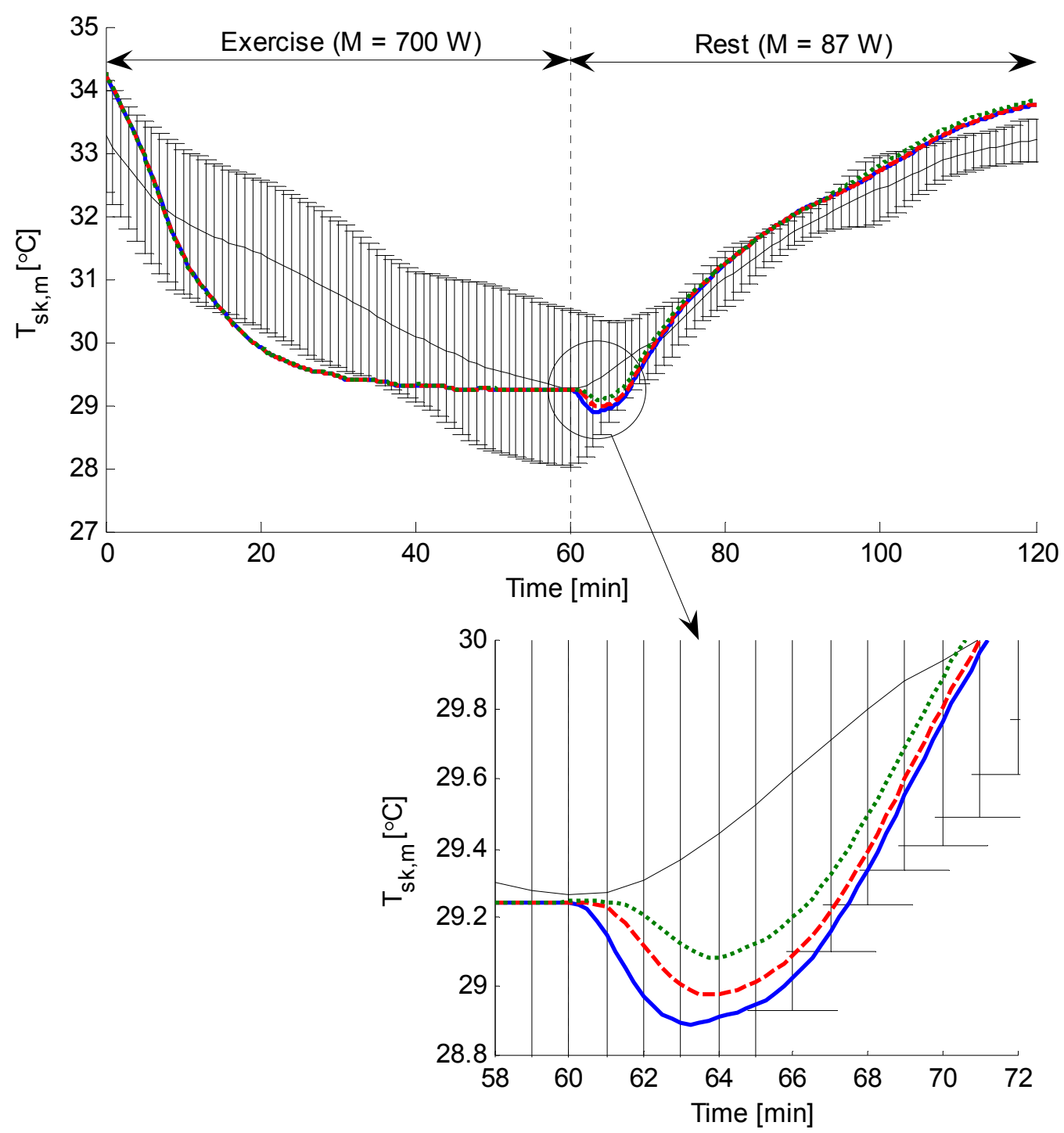

Experimental data (mean \pm standard deviation)
Old model
$\ldots \ldots$........ Old model with $\tau_{\mathrm{msc}}=6 \mathrm{~min}$

Figure 20: Investigating effect of muscle blood flow delay on mean skin temperature response

\section{Exponential Delay of Vasoconstriction}

In this section, we will investigate the effect of delaying the vasoconstriction response according to Equation ( 87 ). Figure 21 shows the vasoconstriction $(C s)$, vasodilation $(D l)$, and 
total skin blood flow (SBF) responses with and without the $C s$ delay. Both models have an initial basal SBF of $0.38 \mathrm{~L} \cdot \mathrm{min}^{-1}$, and experience a sudden drop in SBF at the onset of exercise due to the decreasing LCG water temperature. The fluctuations in the old model's Cs and SBF responses are due to the vasoconstriction dependency on $d T_{s k, m} / d t$ (see Equation ( 77 )). With $\tau_{c s}$ $=200 \mathrm{~s}$, the $C s$ response is delayed and has a smoother appearance, which also leads to a smoother SBF response. The delayed Cs response results in higher skin blood flows during the initial 10 min, which should reduce the excessive initial body heat storage that we experience with the old model. The vasodilation responses for the two cases are practically identical. 

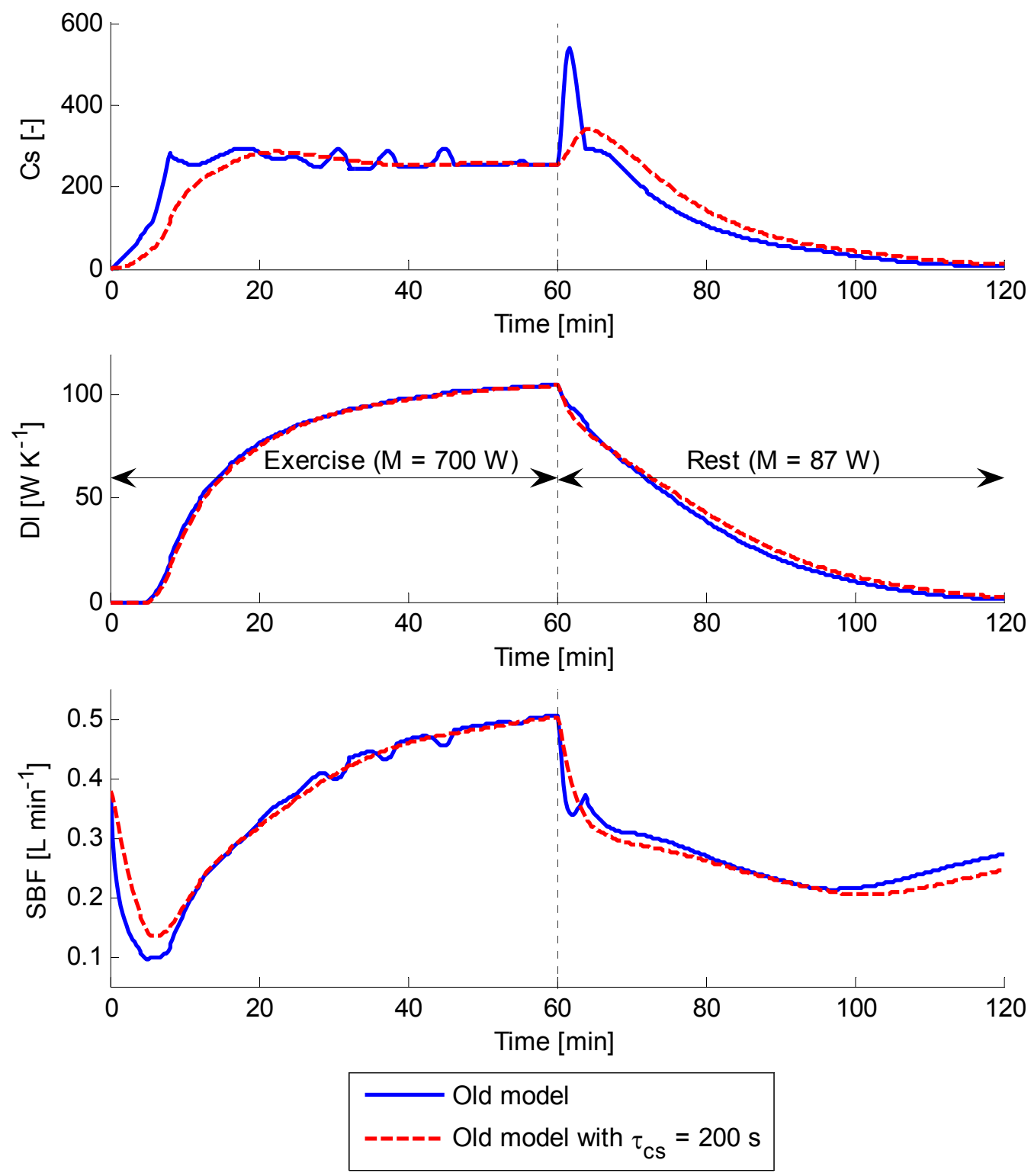

Figure 21: Investigating effect of vasoconstriction delay on vasoconstriction, vasodilation, and skin blood flow responses

In Figure 22, we see the effect of the delayed vasoconstriction response on the rectal and mean skin temperature responses. As shown, the responses are practically identical, which indicates that the vasoconstriction delay has an insignificant effect on our model predictions. We 
could potentially increase the time constant, but this would be difficult to justify since we are already using a relatively large time constant.
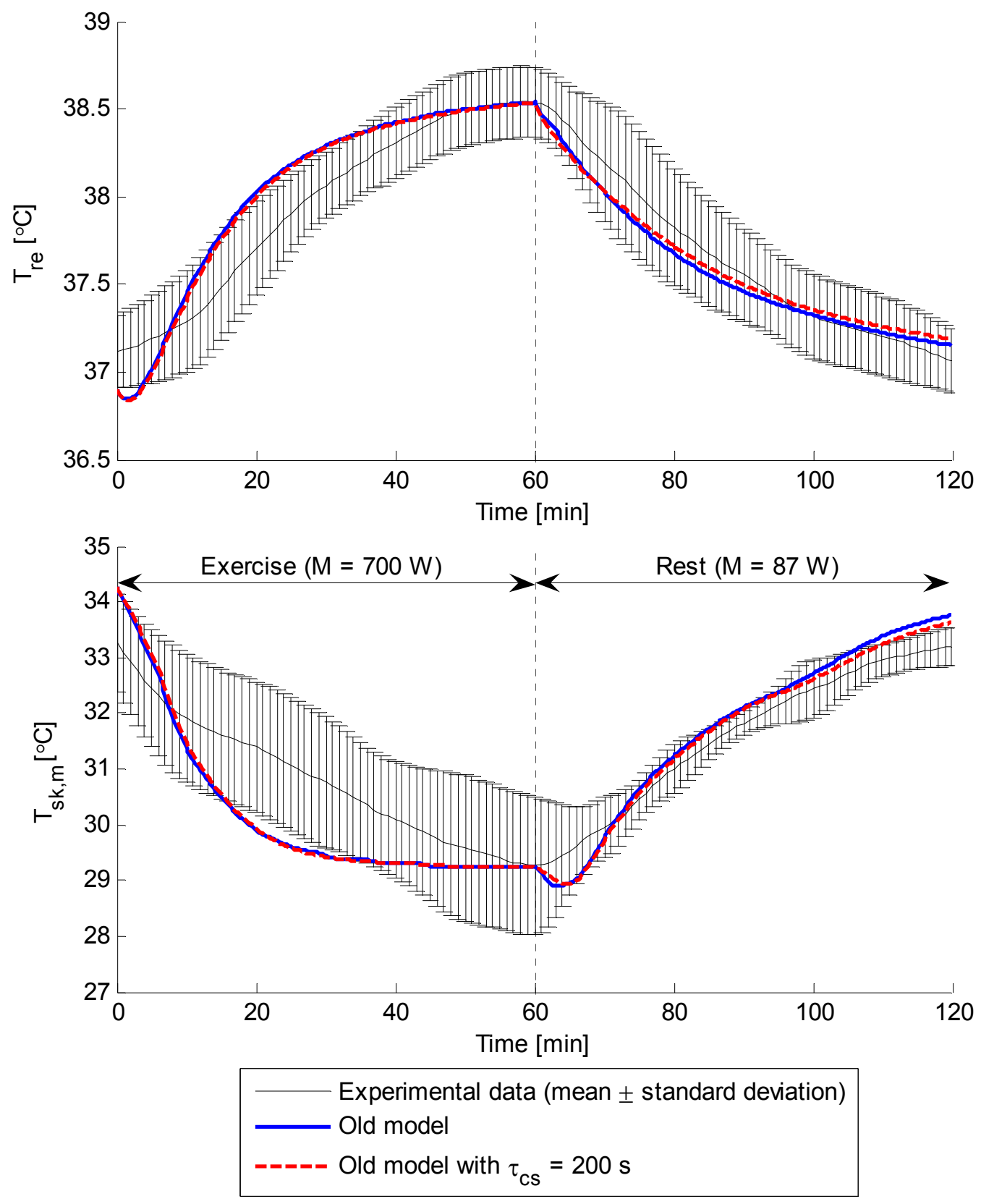

Figure 22: Investigating effect of vasoconstriction delay on rectal and mean skin temperature responses 


\section{Modifying the Vasoconstriction Command}

In this section, we will investigate the effect of including the $\Delta T_{h y} d d T_{h y} / d t$ term in the vasoconstriction command according to Equation ( 88 ). As shown in Table 2, the new $b_{s k}$ and $b_{h y}$ coefficients in the vasoconstriction command result in slightly different calibration parameters. The new $b_{h y}$ coefficient, which governs the $\Delta T_{h y} d T_{h y} / d t$ dependency, is only activated during conditions of increasing hypothalamus temperature $\left(d T_{h y} / d t>0\right)$, decreasing mean skin temperature $\left(d T_{s k, m} / d t<0\right)$, and positive hypothalamus error signals $\left(\Delta T_{h y}>0\right)$. For all other conditions, the $b_{h y}$ coefficient is set to zero. The new model formulation also includes a $\tau_{m s c}$ of $1 \mathrm{~min}$ and a $\tau_{c s}$ of $200 \mathrm{~s}$. Even though we have shown that these parameters do not have a significant impact on the model predictions, we include them because $\tau_{m s c}$ improves the response slightly when there is a change in metabolic rate and $\tau_{c s}$ removes some unwanted fluctuations in the skin blood flow.

Table 2: Calibration parameters of the old and the new models

\begin{tabular}{llllll} 
Model & $\eta_{\mathrm{w}}(\%)$ & $\mathrm{U}\left(\mathrm{W} \mathrm{m}^{-2} \mathrm{~K}^{-1}\right)$ & $\mathrm{Sw}_{\mathrm{CAP}}\left(\mathrm{g} \mathrm{min}^{-1}\right)$ & $\mathrm{b}_{\mathrm{sk}}\left(\mathrm{h} \mathrm{K}^{-2}\right)$ & $\mathrm{b}_{\text {hy }}\left(\mathrm{h} \mathrm{K}^{-2}\right)$ \\
\hline Old & 40.1 & 16.22 & 1.675 & 3.9 & 0 \\
New & 36.9 & 16.675 & 1.646 & -0.7 & -19.5 \\
\hline
\end{tabular}

Figure 23 shows the vasoconstriction $(C s)$, vasodilation $(D l)$, and total skin blood flow (SBF) responses for the old and new models. The new model's $C s$ dependency on $\Delta T_{h y} \cdot d T_{h y} / d t$ significantly delays the $C s$ response during the exercise period, which leads to an increased SBF response during the initial $30 \mathrm{~min}$ of exercise. The increased SBF should reduce the excessive initial body heat storage that we experience with the old model. Because of the different thermal response of the new model, the vasodilation response is delayed a bit during the exercise period 
as well. During the rest period when $T_{h y}$ is decreasing and $T_{s k, m}$ is increasing, the $b_{s k}$ and $b_{h y}$ coefficients in both models are turned off, which results in identical Cs commands. Therefore, the two model responses are quite similar during the rest period. The differences are due to the exponential delays of the muscle blood perfusion $\left(\tau_{m s c}\right)$ and the vasoconstriction response $\left(\tau_{c s}\right)$.
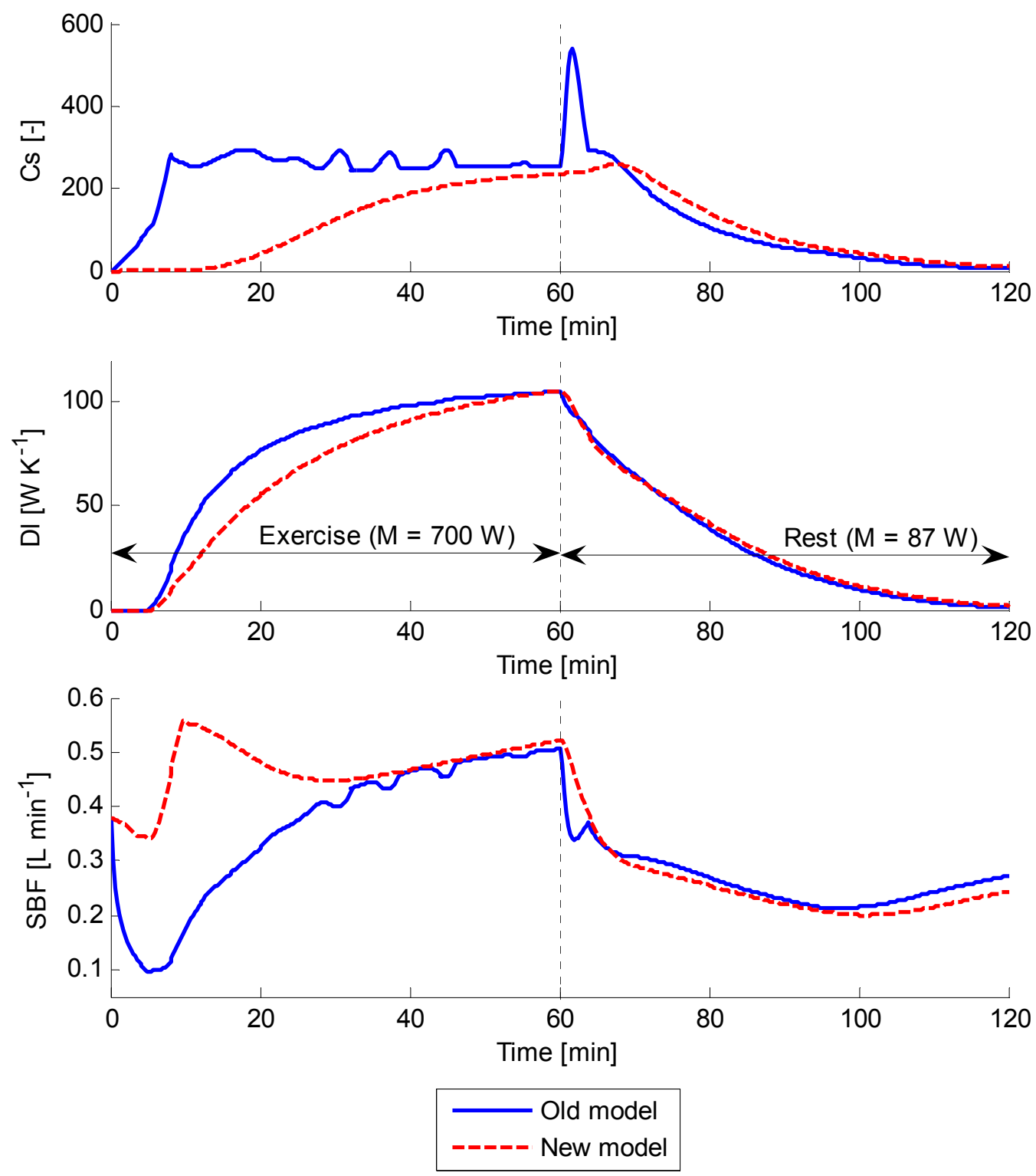

Figure 23: Investigating effect of new vasoconstriction command on vasoconstriction, vasodilation, and skin blood flow responses 
Figure 24 shows the rectal and mean skin temperature responses for the old and new models as well as the mean and standard deviation of the corresponding experimental data. As shown, the new $\Delta T_{h y} \cdot d T_{h y} / d t$ term in the vasoconstriction command improves the $T_{r e}$ and $T_{s k, m}$ responses significantly during the exercise period. The higher SBF of the new model during the initial 20 min of exercise, results in higher skin temperatures which enhances heat rejection rates and decreases the initial rise of the rectal temperature. The significantly improved temperature predictions suggest that the new $\Delta T_{h y} \cdot d T_{h y} / d t$ term in the vasoconstriction command is important during conditions of simultaneously increasing core and decreasing skin temperatures. Such a scenario of simultaneous internal heat stress and external cold stress is common for exercising subjects in cooling garment environments. 

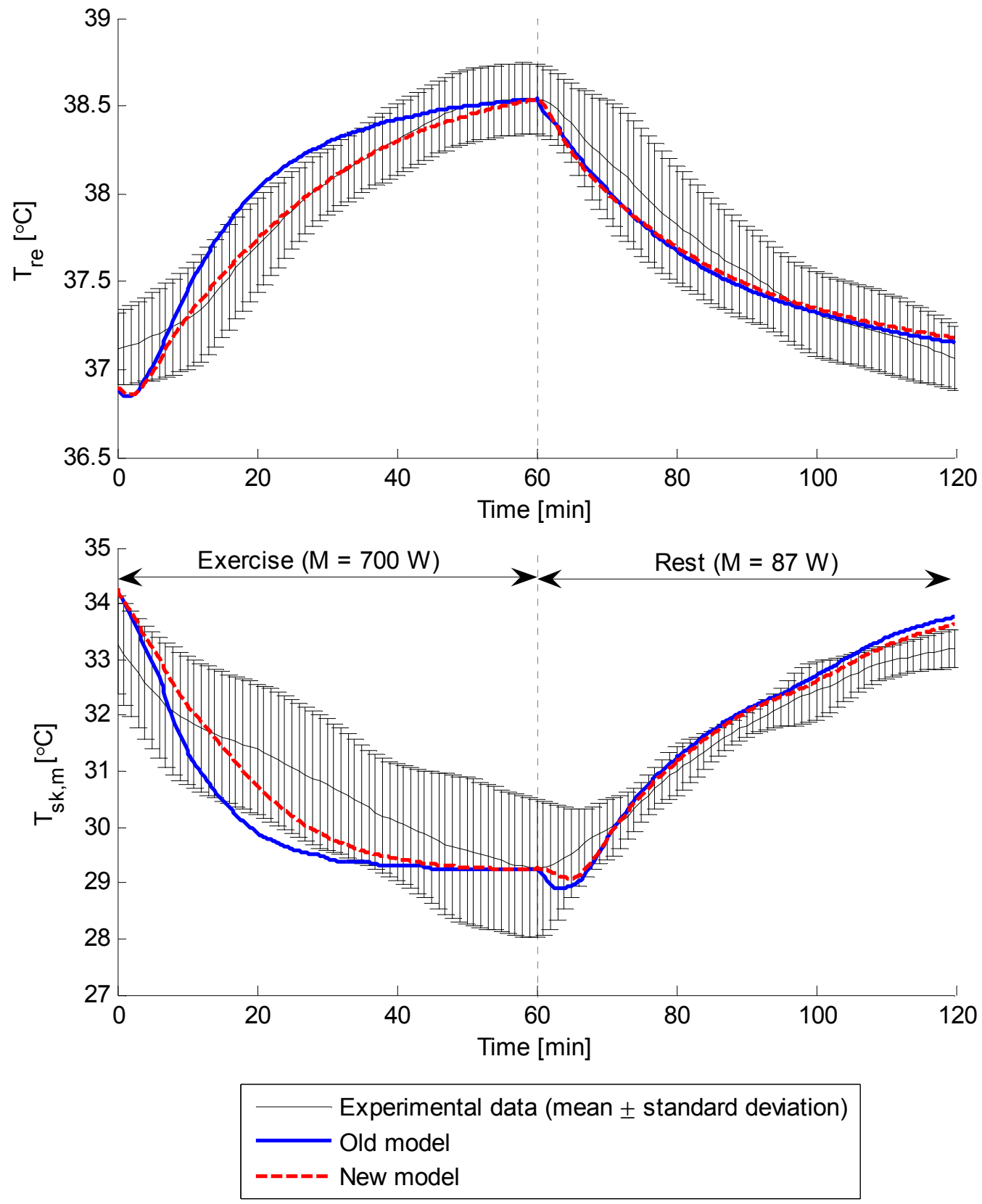

Figure 24: Investigating effect of new vasoconstriction command on rectal and mean skin temperature responses

Table 3 and Table 4 summarize the relative changes in RMS deviations for the different activity periods. As seen in Table 3 , the new model's $T_{r e}$ RMS deviation decreases from $0.16^{\circ} \mathrm{C}$ to $0.10^{\circ} \mathrm{C}$, which corresponds to a $39 \%$ reduction. The RMS deviation for the exercise period is 
reduced by $56 \%$ while the RMS deviation for the rest period is practically unchanged. As seen in Table 4, the new model's $T_{s k, m}$ RMS deviation decreases from $0.70^{\circ} \mathrm{C}$ to $0.48^{\circ} \mathrm{C}$, which corresponds to a $32 \%$ reduction. The RMS deviations for the exercise and rest periods are reduced by $33 \%$ and $27 \%$, respectively. As summarized in Table 5, the new RMS deviations of $0.10^{\circ} \mathrm{C}$ for the rectal temperature prediction and $0.48^{\circ} \mathrm{C}$ for the mean skin temperature prediction are excellent when considering that Fiala et al. [14] reported RMS deviations of $0.10^{\circ} \mathrm{C}-0.18^{\circ} \mathrm{C}$ for rectal temperatures and $1.07^{\circ} \mathrm{C}-1.75^{\circ} \mathrm{C}$ for mean skin temperatures for various exercise exposures in cold air environments.

Table 3: Comparing old and new rectal temperature RMS deviations for the different activity periods

\begin{tabular}{llll} 
& \multicolumn{2}{l}{$\mathrm{T}_{\mathrm{re}} \mathrm{RMS}$ Deviation $\left({ }^{\circ} \mathrm{C}\right)$} & \\
\cline { 2 - 3 } Activity Period & Old Model & New Model & Change \\
\hline Exercise & 0.20 & 0.09 & $-56 \%$ \\
Rest & 0.10 & 0.11 & $0 \%$ \\
Total & 0.16 & 0.10 & $-39 \%$ \\
\hline
\end{tabular}

Table 4: Comparing old and new mean skin temperature RMS deviations for the different activity periods

\begin{tabular}{llll} 
& \multicolumn{2}{l}{$\mathrm{T}_{\mathrm{sk}, \mathrm{m}} \mathrm{RMS}$ Deviation $\left({ }^{\circ} \mathrm{C}\right)$} & \multicolumn{1}{l}{ Change } \\
\cline { 2 - 3 } Activity Period & Old Model & New Model & $-33 \%$ \\
\hline Exercise & 0.93 & 0.62 & $-27 \%$ \\
Rest & 0.35 & 0.26 & $-32 \%$ \\
Total & 0.70 & 0.48 & \\
\hline
\end{tabular}


Table 5: Comparing root mean square deviations between measured and predicted temperatures of the Fiala, the old, and the new models

\begin{tabular}{llll}
\multirow{2}{*}{ Model } & Exposure Type & \multicolumn{2}{l}{$\mathrm{RMS}$ Deviation $\left({ }^{\circ} \mathrm{C}\right)$} \\
\cline { 3 - 4 } Fiala & $\begin{array}{l}\text { Exercise in various cold } \\
\text { air environments }\end{array}$ & $0.10-0.18$ & $1.07-1.75$ \\
Old & $\begin{array}{l}\text { Exercise in LCG } \\
\text { environment }\end{array}$ & 0.16 & 0.70 \\
New & $\begin{array}{l}\text { Exercise in LCG } \\
\text { environment }\end{array}$ & 0.10 & 0.48 \\
\hline
\end{tabular}

Figure 25 shows how the predicted absolute body heat storage error $\varepsilon_{B H S}$ varies during the exercise and rest periods. For comparison purposes, we also include Kuznetz' \pm 19 W·h comfort band [42] and the target accuracy of $\pm 6.5 \mathrm{~W} \cdot \mathrm{h}$ that is required for automatic cooling control development [24]. As shown in Figure 25, the new model significantly reduces the $\varepsilon_{B H S}$ during the exercise period. Except for the initial $7.75 \mathrm{~min}$, the new $\varepsilon_{B H S}$ stays within the $\pm 6.5 \mathrm{~W} \cdot \mathrm{h}$ target accuracy during the exercise period. As expected from the temperature predictions in Figure 24, the new $\varepsilon_{B H S}$ during the rest period is similar to the old $\varepsilon_{B H S}$, which exceeds the target accuracy during a significant portion of the rest period, but stays within the comfort band. As sown in Table 6 , the new mean absolute body heat storage error $\bar{\varepsilon}_{B H S}$ during the exercise and rest periods are $5.2 \mathrm{~W} \cdot \mathrm{h}$ and $6.3 \mathrm{~W} \cdot \mathrm{h}$, respectively, which correspond to reductions of $59 \%$ and $3 \%$, respectively. The new $\bar{\varepsilon}_{B H S}$ for the entire activity schedule is $5.8 \mathrm{~W} \cdot \mathrm{h}$, which corresponds to a $40 \%$ reduction compared to the old $\bar{\varepsilon}_{B H S}$. 


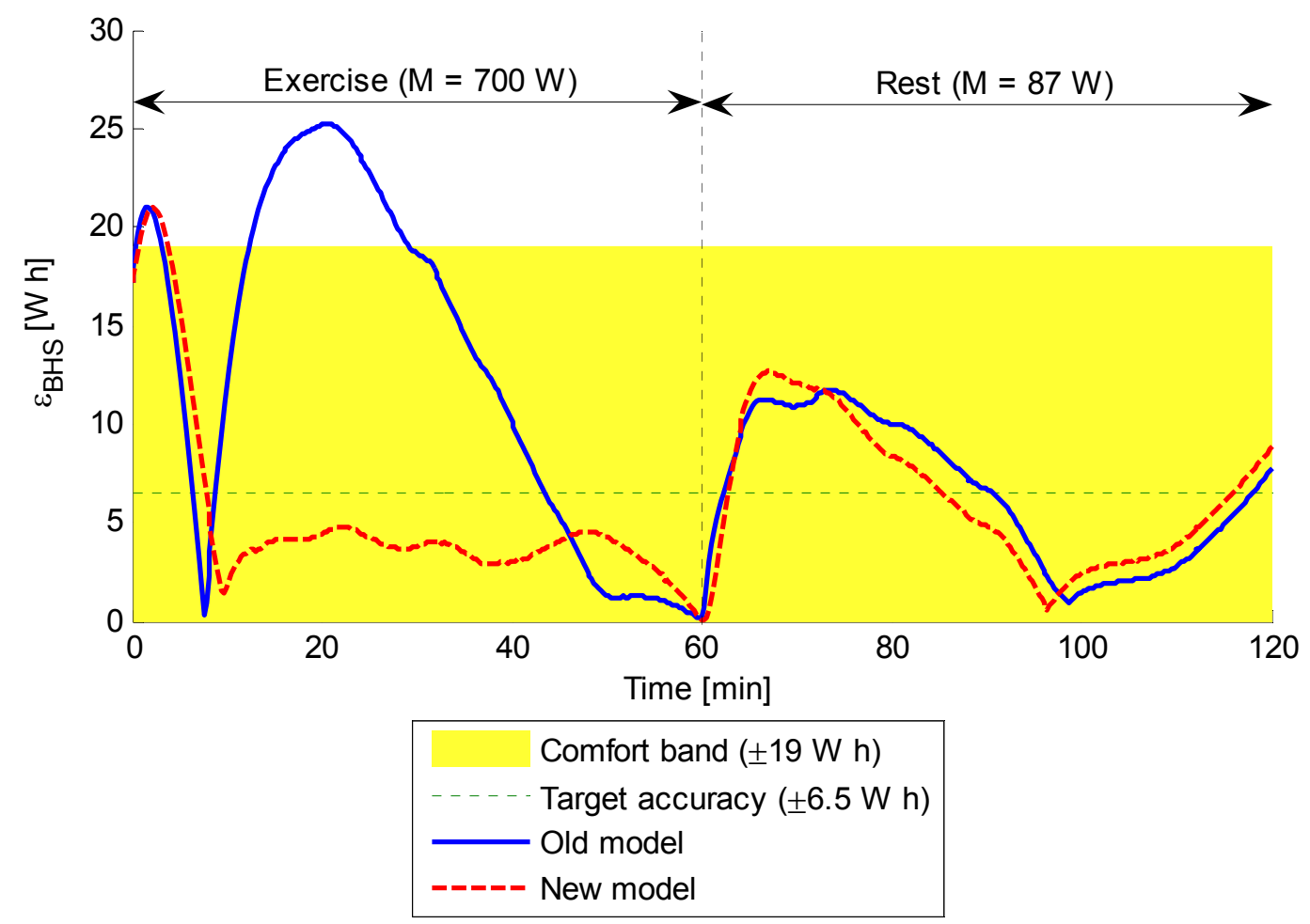

Figure 25: Comparing absolute body heat storage errors of the old and new models with comfort band and target accuracy

Table 6: Comparing old and new mean absolute BHS errors for the different activity periods Mean absolute BHS error ( $\mathrm{W} h$ )

\begin{tabular}{llll}
\cline { 2 - 3 } Activity Period & Old Model & New Model & Change \\
\hline Exercise & 12.9 & 5.2 & $-59 \%$ \\
Rest & 6.5 & 6.3 & $-3 \%$ \\
Total & 9.7 & 5.8 & $-40 \%$ \\
\hline
\end{tabular}

It is apparent from the above analysis that the new thermoregulatory model, despite its state-of-the-art rectal and mean skin temperature predictions, does not satisfy the target BHS accuracy during the entire simulation time. However, $\varepsilon_{B H S}$ is within the target accuracy during a significant period of the simulation time, and it appears that with some additional improvements 
it may be possible to achieve the desired accuracy that is needed for the automatic cooling control development.

First, it is apparent from the above analysis that the set-points of the thermoregulatory model do not match well with the initial conditions of the test subjects. As seen in Figure 24 and Figure 25, relatively large errors are already present at the beginning of the simulation. These errors can probably be reduced by tuning the geometry of the model so that surface area, weight, and especially the fat content match with the experimental subjects.

Second, modifications to the central blood pool formulation are necessary to improve the response following a change in metabolic rate. As shown in this study, delaying the blood flow to activated or deactivated muscles does not significantly improve the central blood pool temperature dynamics. The current central blood pool formulation assumes instantaneous mixing of blood from all tissue nodes, and it is apparent that $T_{b l, p}$ changes too quickly whenever there is a change in metabolic rate. Accounting for blood circulation time would increase the thermal inertia of the central blood pool, which may improve model predictions.

Third, the LCG boundary condition formulation can be improved. We apply the inlet coolant temperature to all skin nodes, and hence do not account for the increasing coolant temperature along the flow path. Our model's coolant temperature is therefore lower than the corresponding experimental coolant temperature. The effect of this simplification may be counteracted somewhat by the calibrated overall heat transfer coefficient $U$, which probably is lower than the actual experimental value. Furthermore, the overall heat transfer coefficient does not account for any transient variations due to moisture absorption in the LCG or any regional variations. 


\section{Investigating Dependency on Work Efficiency and LCG Water Temperature}

The above analysis suggests that the vasoconstriction dependency on $\Delta T_{h y} \cdot d T_{h y} / d t$ is important during conditions of increasing core and decreasing skin temperatures. Can this new dependency just be a result of the simplifying assumptions that we make when formulating the model? In this section, we will investigate the model response dependency on the work efficiency and the LCG water temperature.

\section{Assuming a $20 \%$ Instead of a $40 \%$ Work Efficiency}

The work efficiencies in the old and new thermoregulatory models are calibrated to be $40 \%$ and $37 \%$, respectively. As mentioned earlier, these efficiencies are within the maximum work efficiency of $40 \%$ that has been reported for grade walking on a treadmill [27], but we can not confirm the work efficiency with the experiment because it was not reported. What if the actual work efficiency in the experiment is significantly different from what we use in our simulation? Would a significantly different work efficiency invalidate our new $\Delta T_{h y} \cdot d T_{h y} / d t$ dependency in the vasoconstriction command? To answer this question, we run the old and new models with $20 \%$ work efficiencies.

Table 7 shows the modified calibration parameters for the old and new models with $20 \%$ work efficiencies. The remaining calibration parameters of the new model are unchanged $\left(\tau_{m s c}=\right.$ $1 \mathrm{~min}, \tau_{c s}=200 \mathrm{~s}, b_{s k}=-0.7 \mathrm{~h} \cdot \mathrm{K}^{-2}$ ). Because of the decreased work efficiencies (or increased heat loads), we need to increase the overall LCG heat transfer coefficients in order to optimize the agreements between measured and simulated temperature responses. In addition, the absolute value of the new model's $b_{h y}$ coefficient needs to be increased in order to optimize the response of the new model. 
Table 7: Modified calibration parameters of the old and the new models with $20 \%$ work efficiencies

\begin{tabular}{|c|c|c|c|}
\hline Model & $U\left(\mathrm{~W} \mathrm{~m}{ }^{-2} \mathrm{~K}^{-1}\right)$ & $S w_{C A P}\left(g \min ^{-1}\right)$ & $b_{\text {hy }}\left(\mathrm{h} \mathrm{K}^{-2}\right)$ \\
\hline Old with $\eta_{w}=20 \%$ & 22.55 & 1.54 & N.A. \\
\hline New with $\eta_{w}=20 \%$ & 21.43 & 1.69 & -78.0 \\
\hline
\end{tabular}

Figure 26 shows the rectal and mean skin temperature responses of the old and new models with $20 \%$ work efficiencies. As shown, the new model's response is significantly better than the old model's response. The rectal temperature response of the old model severely overshoots the measured response, while the mean skin temperature of the old model is excessively reduced in the beginning of the exercise period. Clearly, we are not able to obtain a reasonable agreement between measured and simulated temperature responses with the old model using a $20 \%$ work efficiency. On the other hand, when we use a $20 \%$ work efficiency in the new model, we are able to obtain a reasonable agreement, although the responses are more irregular than when we use a $37 \%$ work efficiency. 

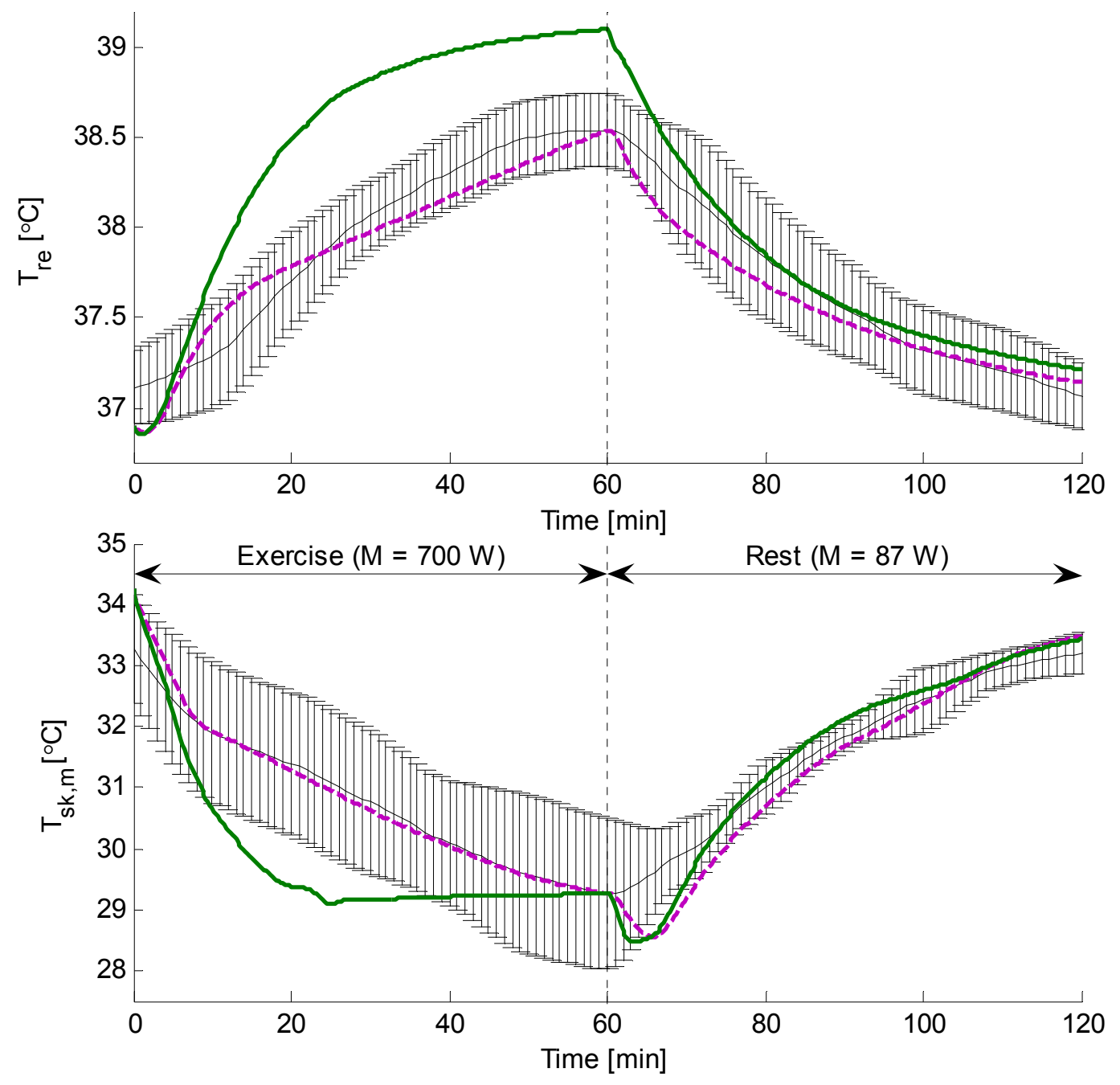

Experimental data (mean \pm standard deviation)
Old model with $\eta_{w}=20 \%$
----- New model with $\eta_{w}=20 \%$

Figure 26: Rectal and mean skin temperature responses of the old and new models with $20 \%$ work efficiencies

Table 8 further emphasizes how much better the new model performs than the old model when using $20 \%$ work efficiencies. The mean absolute BHS errors for the exercise period are $40.2 \mathrm{~W} \cdot \mathrm{h}$ and $7.8 \mathrm{~W} \cdot \mathrm{h}$ for the old and new models, respectively. The corresponding errors for the combined exercise and rest periods are $23.8 \mathrm{~W} \cdot \mathrm{h}$ and $7.3 \mathrm{~W} \cdot \mathrm{h}$ for the old and new models, 
respectively. Hence, the new model reduces $\bar{\varepsilon}_{B H S}$ by $81 \%$ for the exercise period and by $69 \%$ for the total activity schedule.

Table 8: Comparing old and new mean absolute BHS errors for the different activity periods when using $20 \%$ work efficiencies

\begin{tabular}{llll} 
& \multicolumn{2}{c}{ Mean absolute BHS error (W h) } \\
\cline { 2 - 3 } Activity Period & Old Model & New Model & Change \\
\hline Exercise & 40.2 & 7.8 & $-81 \%$ \\
Rest & 7.4 & 6.8 & $-8 \%$ \\
Total & 23.8 & 7.3 & $-69 \%$ \\
\hline
\end{tabular}

The above analysis answers the question that we asked in the beginning of this section. Even if the actual and the calibrated work efficiencies differ significantly, it does not invalidate our new $\Delta T_{h y} \cdot d T_{h y} / d t$ dependency in the vasoconstriction command. In fact, even though the new model's $\bar{\varepsilon}_{B H S}$ is larger with a $20 \%$ than with a $37 \%$ work efficiency, the relative error reduction (new versus old model) is greater when using 20\% work efficiencies. Clearly, the new vasoconstriction command significantly reduces errors regardless of what work efficiency we use.

\section{Using Average Instead of Inlet LCG Water Temperature}

Another potential concern is that we apply the inlet water temperature to all skin nodes in the convective boundary condition (Equation ( 60 )), and hence do not account for the increasing coolant temperature along the flow path within the LCG. We are therefore exposing our model to an environment that is colder than the actual environment seen by the experimental subjects. Could this be the reason why our model's vasoconstriction response is excessive at the beginning 
of the exercise? If that is true, our new $\Delta T_{h y} \cdot d T_{h y} / d t$ dependency in the vasoconstriction command could potentially be invalidated by simply using a more accurate LCG coolant temperature. In order to find the answer to the above question, we run the old model with the average instead of the inlet water temperature in the convective boundary condition (Equation ( 60 )).

Figure 27 shows inlet, outlet, and average LCG water temperatures throughout the activity schedule. The inlet temperature is the mean of the measured inlet temperatures in Figure 8, and the outlet temperature is estimated from Equation ( 89 ). As shown in Table 9, the calibration parameters change slightly when we run the simulation with the average instead of the inlet water temperature. The overall LCG heat transfer coefficient and the sweat rate cap are increased while the work efficiency is decreased slightly.

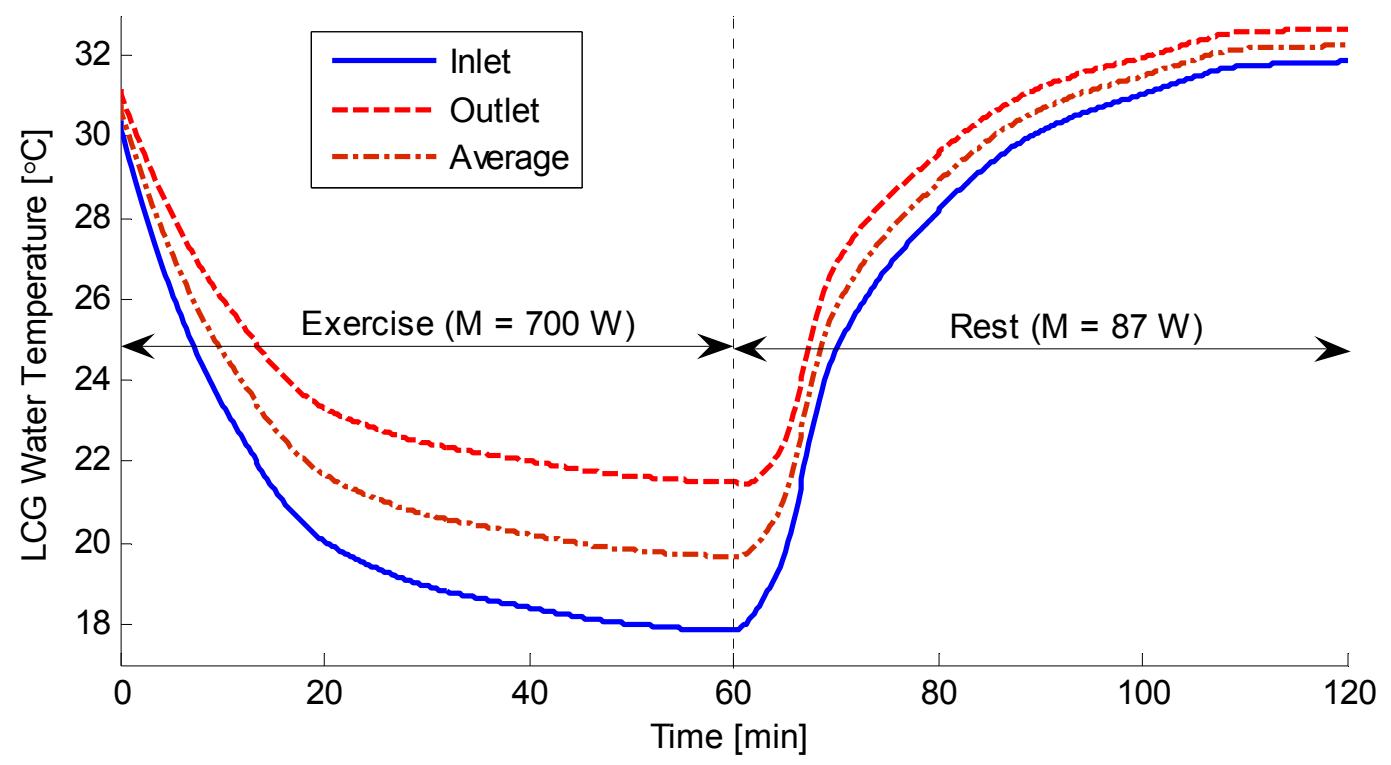

Figure 27: Inlet, outlet, and average LCG water temperatures during the activity schedule 
Table 9: Calibration parameters of the old model when using inlet and average LCG water temperatures

\begin{tabular}{lccc} 
Model & $\eta_{\mathrm{w}}(\%)$ & $\mathrm{U}\left(\mathrm{W} \mathrm{m}^{-2} \mathrm{~K}^{-1}\right)$ & $\mathrm{Sw}_{\mathrm{CAP}}\left(\mathrm{g} \mathrm{min}^{-1}\right)$ \\
\hline $\begin{array}{l}\text { Old with } \mathrm{T}_{\mathrm{LCG}}=\text { inlet water } \\
\text { temperature }\end{array}$ & 40.1 & 16.22 & 1.675 \\
$\begin{array}{l}\text { Old with } \mathrm{T}_{\mathrm{LCG}}=\text { average } \\
\text { water temperature }\end{array}$ & 39.7 & 19.50 & 1.680 \\
\hline
\end{tabular}

Figure 28 shows the rectal and mean skin temperature responses of the old model, when we use the inlet and average LCG water temperatures in the skin boundary condition (Equation ( 60 )). As shown, the response with the average LCG water temperature is practically identical to the response with the inlet LCG water temperature. Hence, the effect of the increased water temperature is cancelled by the modified calibration parameters in Table 9. This answers the question that we asked in the beginning of this section. The excessive vasoconstriction response of the old model is not caused by the simplified skin boundary condition. Hence, the $\Delta T_{h y} \cdot d T_{h y} / d t$ dependency in our new vasoconstriction command is important whether we use the inlet or average LCG coolant temperature. 

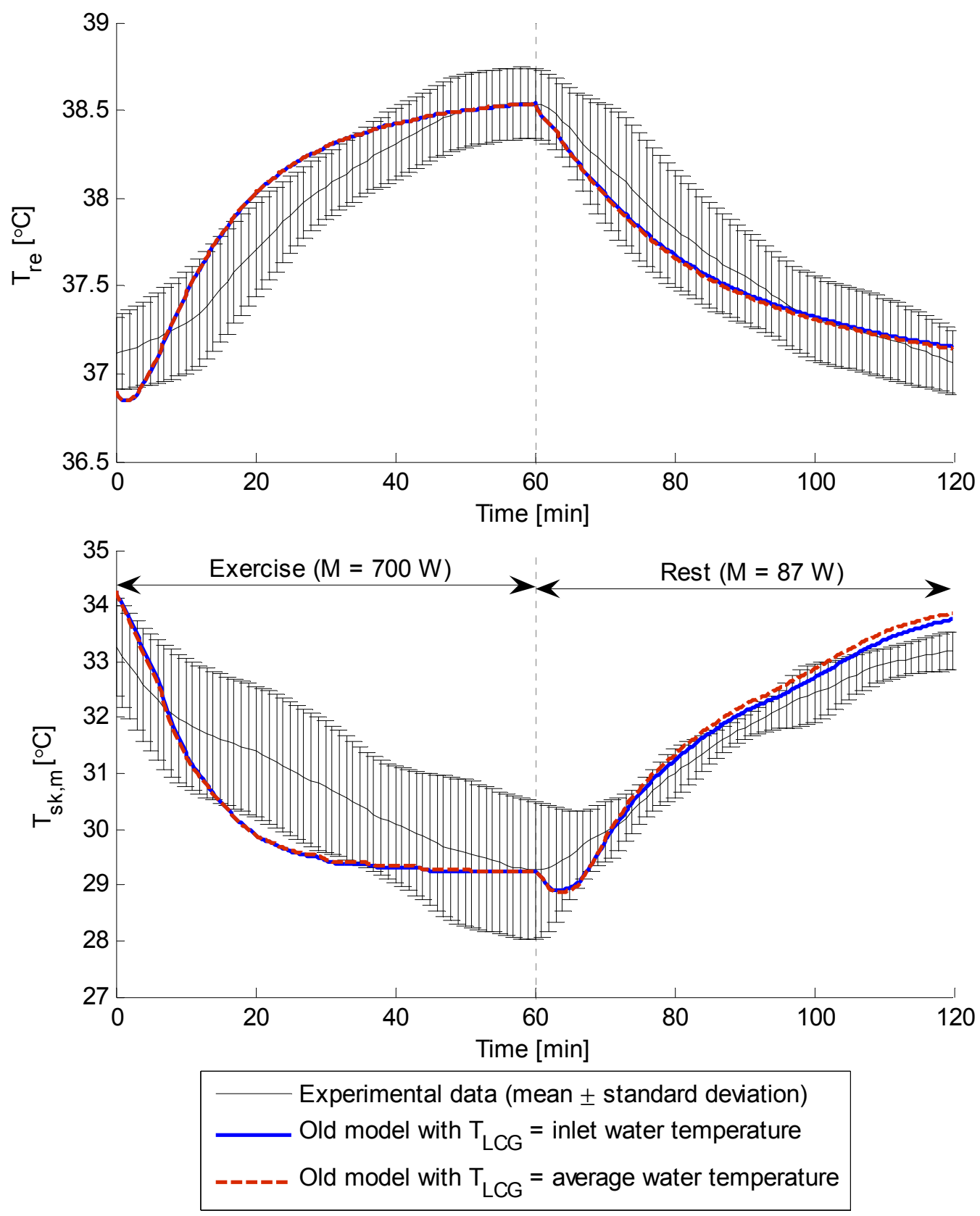

Figure 28: Rectal and mean skin temperature responses of the old model when using inlet and average LCG water temperatures 


\section{CHAPTER 5 CONCLUSIONS AND RECOMMENDATIONS}

In order to find out if state-of-the-art thermoregulatory models are accurate enough for the development of automatic LCG cooling control, we implement the Fiala thermoregulatory model with an LCG environment. The Fiala thermoregulatory model has previously shown stateof-the-art predictive abilities in air environment. After implementing the Fiala thermoregulatory model, we validate the numerical formulation with analytical solutions to the bioheat equation, and find our model to be accurate and stable with a variety of different grid configurations. The thermoregulatory model predictions are then compared with experimental data where individuals, equipped with an LCG, exercise according to a $700 \mathrm{~W}$ rectangular type activity schedule. The root mean square (RMS) deviation between the model response and the mean experimental group response is $0.16^{\circ} \mathrm{C}$ for the rectal temperature and $0.70^{\circ} \mathrm{C}$ for the mean skin temperature. Fiala et al. [14] reported rectal temperature RMS deviations of $0.10^{\circ} \mathrm{C}-0.18^{\circ} \mathrm{C}$ and mean skin temperature RMS deviations of $1.07^{\circ} \mathrm{C}-1.75^{\circ} \mathrm{C}$ for various exercise exposures in cold air environments. Hence, the accuracy of the Fiala thermoregulatory model translates well from air to LCG environments. However, with a mean absolute body heat storage error $\bar{\varepsilon}_{B H S}$ of $9.7 \mathrm{~W} \cdot \mathrm{h}$, the model fails to satisfy the $\pm 6.5 \mathrm{~W} \cdot \mathrm{h}$ accuracy that is required for the automatic LCG cooling control development. Errors are especially large during the exercise period where the maximum $\varepsilon_{B H S}$ is almost four times larger than the target accuracy.

In an effort to achieve the target body heat storage accuracy, we modify the blood flow dynamics of the Fiala thermoregulatory model. Instead of using step responses to changing requirements, we introduce exponential responses to the muscle blood flow and the vasoconstriction command. We find that such modifications have an insignificant effect on 
temperature predictions. However, a new vasoconstriction dependency, i.e. the rate of change of hypothalamus temperature weighted by the hypothalamus error signal $\left(\Delta T_{h y} \cdot d T_{h y} / d t\right)$, proves to be an important signal that governs the thermoregulatory response during conditions of simultaneously increasing core and decreasing skin temperatures, which is a common scenario in LCG environments. With the new $\Delta T_{h y} \cdot d T_{h y} / d t$ dependency in the vasoconstriction command, the $\bar{\varepsilon}_{B H S}$ for the exercise period is reduced by $59 \%$ (from $12.9 \mathrm{~W} \cdot \mathrm{h}$ to $5.2 \mathrm{~W} \cdot \mathrm{h}$ ). The $\bar{\varepsilon}_{B H S}$ for the total activity schedule is reduced by $40 \%$ (from $9.7 \mathrm{~W} \cdot \mathrm{h}$ to $5.8 \mathrm{~W} \cdot \mathrm{h}$ ). Even though the new $\bar{\varepsilon}_{B H S}$ of $5.8 \mathrm{~W} \cdot \mathrm{h}$ is within the target accuracy of $\pm 6.5 \mathrm{~W} \cdot \mathrm{h}$, additional model improvements are necessary for $\varepsilon_{B H S}$ to stay within the target accuracy during the entire activity schedule.

First, the set-points of the thermoregulatory model do not match well with the initial conditions of the test subjects. Therefore, relatively large errors are already present at the beginning of the simulation. These initial errors can probably be reduced by tuning the geometry of the model so that surface area, weight, and especially the fat content match with the experimental subjects.

Second, modifications to the central blood pool formulation are necessary to improve the response following a change in metabolic rate. As shown in this study, delaying the blood flow to activated or deactivated muscles does not significantly improve the central blood pool temperature dynamics. The current central blood pool formulation assumes instantaneous mixing of blood from all tissue nodes, and it is apparent that $T_{b l, p}$ changes too quickly whenever there is a change in metabolic rate. Accounting for blood circulation time would increase the thermal inertia of the central blood pool, which may improve model predictions. 
Third, the LCG boundary condition formulation can be improved. We use a constant overall LCG heat transfer coefficient and hence do not account for any regional or transient variations due to moisture absorption in the LCG. Furthermore, we assume a uniform LCG water temperature and hence do not account for the increasing water temperature along the flow path. In order to validate a more complex boundary condition formulation, we need more detailed measurements of the actual experimental boundary conditions.

Finally, the thermoregulatory model needs to be validated with various exercise schedules and with experimental data from other sources. With the above improvements, it seems possible to achieve the strict body heat storage accuracy that is needed for automatic LCG cooling control development. 
APPENDIX A

THERMOREGULATORY MODEL PARAMETERS 
Table 10: Geometric data of the human body model [15]

\begin{tabular}{|c|c|c|c|c|c|c|c|}
\hline Segment & Shape & $\mathrm{L}(\mathrm{cm})$ & Sector & Angle $\left({ }^{\circ}\right)$ & Tissue & $\mathrm{N}$ & $r_{o}(\mathrm{~cm})$ \\
\hline \multirow[t]{4}{*}{$\overline{\text { Head }}$} & Partial Sphere & N.A. & Forehead & 10 & Brain & 5 & 8.60 \\
\hline & & & Head & 170 & Bone & 2 & 10.05 \\
\hline & & & & & Fat & 2 & 10.20 \\
\hline & & & & & Skin & 4 & 10.40 \\
\hline \multirow[t]{5}{*}{ Face } & Partial Cylinder & 9.84 & & 210 & Muscle & 1 & 2.68 \\
\hline & & & & & Bone & 1 & 5.42 \\
\hline & & & & & Muscle & 1 & 6.80 \\
\hline & & & & & Fat & 2 & 7.60 \\
\hline & & & & & Skin & 2 & 7.80 \\
\hline \multirow[t]{4}{*}{ Neck } & Cylinder & 8.42 & Anterior & 180 & Bone & 1 & 1.90 \\
\hline & & & Posterior & 180 & Muscle & 4 & 5.46 \\
\hline & & & & & Fat & 2 & 5.56 \\
\hline & & & & & Skin & 4 & 5.67 \\
\hline \multirow[t]{4}{*}{ Shoulders } & Partial Cylinder & 32.00 & & 130 & Bone & 1 & 3.70 \\
\hline & & & & & Muscle & 2 & 3.90 \\
\hline & & & & & Fat & 2 & 4.40 \\
\hline & & & & & Skin & 2 & 4.60 \\
\hline \multirow[t]{5}{*}{ Thorax } & Cylinder & 30.60 & Anterior & 150 & Lung & 1 & 7.73 \\
\hline & & & Posterior & 150 & Bone & 3 & 8.91 \\
\hline & & & Inferior & 60 & Muscle & 3 & 12.34 \\
\hline & & & & & Fat & 6 & 12.68 \\
\hline & & & & & Skin & 6 & 12.90 \\
\hline \multirow[t]{5}{*}{ Abdomen } & Cylinder & 55.20 & Anterior & 150 & Viscera & 1 & 7.85 \\
\hline & & & Posterior & 150 & Bone & 3 & 8.34 \\
\hline & & & Inferior & 60 & Muscle & 3 & 10.90 \\
\hline & & & & & Fat & 6 & 12.44 \\
\hline & & & & & Skin & 6 & 12.60 \\
\hline \multirow[t]{4}{*}{ Arms } & Cylinder & 127.40 & Anterior & 135 & Bone & 1 & 1.53 \\
\hline & & & Posterior & 135 & Muscle & 3 & 3.43 \\
\hline & & & Inferior & 90 & Fat & 6 & 4.01 \\
\hline & & & & & Skin & 6 & 4.18 \\
\hline \multirow[t]{4}{*}{ Hands } & Cylinder & 62.00 & Back & 180 & Bone & 1 & 0.70 \\
\hline & & & Palm & 180 & Muscle & 2 & 1.74 \\
\hline & & & & & Fat & 2 & 2.04 \\
\hline & & & & & Skin & 4 & 2.26 \\
\hline \multirow[t]{4}{*}{ Legs } & Cylinder & 139.00 & Anterior & 150 & Bone & 1 & 2.20 \\
\hline & & & Posterior & 150 & Muscle & 6 & 4.80 \\
\hline & & & Inferior & 60 & Fat & 6 & 5.33 \\
\hline & & & & & Skin & 6 & 5.53 \\
\hline \multirow[t]{4}{*}{ Feet } & Cylinder & 48.00 & Instep & 180 & Bone & 1 & 2.00 \\
\hline & & & Sole & 180 & Muscle & 2 & 2.50 \\
\hline & & & & & Fat & 4 & 3.26 \\
\hline & & & & & Skin & 4 & 3.50 \\
\hline
\end{tabular}

Definitions: L, length; $N$, number of nodes; $r_{0}$, outer compartment radius. 
Table 11: Thermophysical properties of tissue [15]

\begin{tabular}{|c|c|c|c|c|c|c|c|}
\hline Segment & $\begin{array}{c}h_{x} \\
\left(W^{-1}\right)\end{array}$ & Tissue & $\left(\mathrm{W} \mathrm{m}^{-1} \mathrm{~K}^{-1}\right)$ & $\begin{array}{c}\rho \\
\left(\mathrm{kg} \mathrm{m}^{-3}\right)\end{array}$ & $\begin{array}{c}\mathrm{C} \\
\left(\mathrm{J} \mathrm{kg}^{-1} \mathrm{~K}^{-1}\right)\end{array}$ & $\begin{array}{c}\mathrm{w}_{\mathrm{bl}, 0} \\
\left(\mathrm{~L} \mathrm{~s}^{-1} \mathrm{~m}^{-3}\right) \\
\end{array}$ & $\begin{array}{c}\mathrm{q}_{\mathrm{m}, 0} \\
\left(\mathrm{~W} \mathrm{~m}^{-3}\right)\end{array}$ \\
\hline \multirow[t]{4}{*}{ Head } & 0.00 & Brain & 0.49 & 1080 & 3850 & 10.1320 & 13400 \\
\hline & & Bone & 1.16 & 1500 & 1591 & 0.0000 & 0 \\
\hline & & Fat & 0.16 & 850 & 2300 & 0.0036 & 58 \\
\hline & & Skin & 0.47 & 1085 & 3680 & 5.4800 & 368 \\
\hline \multirow[t]{5}{*}{ Face } & 0.00 & Muscle & 0.42 & 1085 & 3768 & 0.5380 & 684 \\
\hline & & Bone & 1.16 & 1500 & 1591 & 0.0000 & 0 \\
\hline & & Muscle & 0.42 & 1085 & 3768 & 0.5380 & 684 \\
\hline & & Fat & 0.16 & 850 & 2300 & 0.0036 & 58 \\
\hline & & Skin & 0.47 & 1085 & 3680 & 11.1700 & 368 \\
\hline \multirow[t]{4}{*}{ Neck } & 0.00 & Bone & 0.75 & 1357 & 1700 & 0.0000 & 0 \\
\hline & & Muscle & 0.42 & 1085 & 3768 & 0.5380 & 684 \\
\hline & & Fat & 0.16 & 850 & 2300 & 0.0036 & 58 \\
\hline & & Skin & 0.47 & 1085 & 3680 & 6.8000 & 368 \\
\hline \multirow[t]{4}{*}{ Shoulders } & 0.80 & Bone & 0.75 & 1357 & 1700 & 0.0000 & 0 \\
\hline & & Muscle & 0.42 & 1085 & 3768 & 0.5380 & 684 \\
\hline & & Fat & 0.16 & 850 & 2300 & 0.0036 & 58 \\
\hline & & Skin & 0.47 & 1085 & 3680 & 1.0100 & 368 \\
\hline \multirow[t]{5}{*}{ Thorax } & 0.00 & Lung & 0.28 & 550 & 3718 & $\mathrm{CO}$ & 600 \\
\hline & & Bone & 0.75 & 1357 & 1700 & 0.0000 & 0 \\
\hline & & Muscle & 0.42 & 1085 & 3768 & 0.5380 & 684 \\
\hline & & Fat & 0.16 & 850 & 2300 & 0.0036 & 58 \\
\hline & & Skin & 0.47 & 1085 & 3680 & 1.5800 & 368 \\
\hline \multirow[t]{5}{*}{ Abdomen } & 0.00 & Viscera & 0.53 & 1000 & 3697 & 4.3100 & 4100 \\
\hline & & Bone & 0.75 & 1357 & 1700 & 0.0000 & 0 \\
\hline & & Muscle & 0.42 & 1085 & 3768 & 0.5380 & 684 \\
\hline & & Fat & 0.16 & 850 & 2300 & 0.0036 & 58 \\
\hline & & Skin & 0.47 & 1085 & 3680 & 1.4400 & 368 \\
\hline \multirow[t]{4}{*}{ Arms } & 4.13 & Bone & 0.75 & 1357 & 1700 & 0.0000 & 0 \\
\hline & & Muscle & 0.42 & 1085 & 3768 & 0.5380 & 684 \\
\hline & & Fat & 0.16 & 850 & 2300 & 0.0036 & 58 \\
\hline & & Skin & 0.47 & 1085 & 3680 & 1.1000 & 368 \\
\hline \multirow[t]{4}{*}{ Hands } & 0.57 & Bone & 0.75 & 1357 & 1700 & 0.0000 & 0 \\
\hline & & Muscle & 0.42 & 1085 & 3768 & 0.5380 & 684 \\
\hline & & Fat & 0.16 & 850 & 2300 & 0.0036 & 58 \\
\hline & & Skin & 0.47 & 1085 & 3680 & 4.5400 & 368 \\
\hline \multirow[t]{4}{*}{ Legs } & 6.90 & Bone & 0.75 & 1357 & 1700 & 0.0000 & 0 \\
\hline & & Muscle & 0.42 & 1085 & 3768 & 0.5380 & 684 \\
\hline & & Fat & 0.16 & 850 & 2300 & 0.0036 & 58 \\
\hline & & Skin & 0.47 & 1085 & 3680 & 1.0500 & 368 \\
\hline \multirow[t]{4}{*}{ Feet } & 3.40 & Bone & 0.75 & 1357 & 1700 & 0.0000 & 0 \\
\hline & & Muscle & 0.42 & 1085 & 3768 & 0.5380 & 684 \\
\hline & & Fat & 0.16 & 850 & 2300 & 0.0036 & 58 \\
\hline & & Skin & 0.47 & 1085 & 3680 & 1.5000 & 368 \\
\hline Blood & & & & 1069 & 3650 & & \\
\hline
\end{tabular}

Definitions: $h_{x}$, countercurrent heat exchange coefficient; $k$, thermal conductivity; $\rho$, density; $c$, specific heat; $\mathrm{w}_{\mathrm{bl}, 0}$, basal blood perfusion; $\mathrm{q}_{\mathrm{m}, 0}$, basal metabolic heat generation. 
Table 12: Distribution coefficients [14, 15]

\begin{tabular}{|c|c|c|c|c|c|c|c|}
\hline \multirow[b]{2}{*}{ Segment } & \multirow[b]{2}{*}{$a_{s k}$} & \multicolumn{2}{|c|}{$a_{m, w}$} & \multirow[b]{2}{*}{$a_{\mathrm{sw}}$} & \multirow[b]{2}{*}{$a_{d l}$} & \multirow[b]{2}{*}{$a_{c s}$} & \multirow[b]{2}{*}{$a_{\text {sh }}$} \\
\hline & & Sed & Stnd & & & & \\
\hline Head & 0.0835 & 0.00 & 0.00 & 0.095 & 0.055 & 0.0300 & 0.0000 \\
\hline Face & 0.0418 & 0.00 & 0.00 & 0.054 & 0.046 & 0.0330 & 0.0020 \\
\hline Neck & 0.0417 & 0.03 & 0.01 & 0.042 & 0.031 & 0.0250 & 0.0020 \\
\hline Shoulders & 0.0300 & 0.05 & 0.02 & 0.037 & 0.020 & 0.0100 & 0.0002 \\
\hline Thorax & 0.1290 & 0.12 & 0.07 & 0.101 & 0.141 & 0.0005 & 0.6305 \\
\hline Abdomen & 0.1210 & 0.46 & 0.20 & 0.181 & 0.161 & 0.0205 & 0.2400 \\
\hline Arms & 0.1800 & 0.19 & 0.08 & 0.133 & 0.095 & 0.1945 & 0.0400 \\
\hline Hands & 0.0900 & 0.02 & 0.01 & 0.049 & 0.121 & 0.1100 & 0.0020 \\
\hline Legs & 0.2080 & 0.11 & 0.60 & 0.261 & 0.230 & 0.2000 & 0.0813 \\
\hline Feet & 0.0750 & 0.02 & 0.01 & 0.047 & 0.100 & 0.3765 & 0.0020 \\
\hline
\end{tabular}

Definitions: $a_{s k}$, skin sensitivity coefficient; $a_{m, w}$, workload distribution coefficient; Sed, sedentary activity; Stnd, standing activity; $a_{s w}$, distribution coefficient for sweating; $a_{d l}$, distribution coefficient for vasodilation; $a_{\mathrm{cs}}$, distribution coefficient for vasoconstriction; $a_{\text {sh }}$, distribution coefficient for shivering. 
APPENDIX B

AN ANALYTICAL SOLUTION TO PENNES' BIOHEAT EQUATION 
The analytical solution to the transient Pennes bioheat equation for homogeneous cylindrical geometries with convective boundary conditions is given by [133]

$$
\frac{T-T_{i}}{T_{b l, \text { mod }}-T_{i}}=1-\frac{B i I_{0}(\sqrt{\Phi} R)}{\sqrt{\Phi} I_{1}(\sqrt{\Phi})+B i I_{0}(\sqrt{\Phi})}-2 \Phi B i \sum_{n=1}^{\infty} \frac{J_{0}\left(u_{n} R\right) \exp \left[-\frac{\alpha t}{r_{o}^{2}}\left(u_{n}^{2}+\Phi\right)\right]}{\left(u_{n}^{2}+\Phi\right)\left(u_{n}^{2}+B i^{2}\right) J_{0}\left(u_{n}\right)}
$$

where

$$
\begin{gathered}
R=\frac{r}{r_{o}} \\
\alpha=\frac{k}{\rho c} \\
B i=\frac{h r_{o}}{k} \\
T_{b l, \bmod }=T_{b l}+\frac{q_{m}}{\rho_{b l} c_{b l} w_{b l}} \\
\Phi=\frac{r_{o}^{2} \rho_{b l} c_{b l} w_{b l}}{k}
\end{gathered}
$$

where $r$ is the actual radius, $r_{o}$ is the outer cylinder radius, $k$ is the thermal conductivity of the tissue, $\rho$ is the density of the tissue, $c$ is the specific heat of the tissue, $h$ is the heat transfer coefficient, $T_{b l}$ is the blood temperature, $q_{m}$ is the volumetric metabolic heat generation rate, $\rho_{b l}$ is the blood density, $c_{b l}$ is the blood specific heat, and $w_{b l}$ is the blood perfusion rate. The remaining parameters in Equation ( 92 ) are; $T$, actual tissue temperature at location $r ; T_{i}$, initial tissue 
temperature at location $r ; I_{0}$, modified Bessel function of the first kind and zero order; $I_{l}$, modified Bessel function of the first kind and first order; $J_{0}$, Bessel function of the first kind and zero order; and $t$, time. Finally, the parameter $u_{n}$ is the $n$-th root of the transcendental equation

$$
u_{n} J_{1}\left(u_{n}\right)-B i J_{0}\left(u_{n}\right)=0
$$

where $J_{l}$ is the Bessel function of the first kind and first order. 


\section{REFERENCES}

[1] Webb, P., S.J. Troutman, and J.F. Annis, Automatic cooling in water cooled space suits. Aerospace Med., 1970. 41(3): p. 269-277.

[2] Fanger, P.O., Thermal comfort: Analysis and applications in environmental engineering. 1970, Copenhagen: Danish Technical Press.

[3] Flouris, A.D. and S.S. Cheung, Design and control optimization of microclimate liquid cooling systems underneath protective clothing. Annals of Biomedical Engineering, 2006. 34(3): p. 359-372.

[4] Smith, L.F., S.S. Nair, and J.B. Miles, Evaluating human thermal models for advanced portable life support system control development. Transactions of the Society of Automotive Engineers, Journal of Aerospace, 1993. 102: p. 1193-1203.

[5] Tikuisis, P. Functional modeling in human thermoregulation to thermal stress. in Proceedings of the 9th International Conference on Environmental Ergonomics. 2000. Dortmund, Germany.

[6] Werner, J., Thermoregulatory models: Recent research, current applications and future development. Scand. J. Work Environ. Health, 1989. 15: p. 34-46.

[7] Salloum, M., N. Ghaddar, and K. Ghali, A new transient bioheat model of the human body and its integration to clothing models. International Journal of Thermal Sciences, 2007. 46(4): p. 371-384.

[8] Huizenga, C., Z. Hui, and E. Arens, A model of human physiology and comfort for assessing complex thermal environments. Building and Environment, 2001. 36(6): p. 691-699.

[9] Wolf, M.B. and R.P. Garner, Simulation of human thermoregulation during water immersion: Application to an aircraft cabin water-spray system. Annals of Biomedical Engineering, 1997. 25(4): p. 620-634.

[10] Tikuisis, P., R.R. Gonzalez, and K.B. Pandolf, Thermoregulatory model for immersion of humans in cold water. Journal of Applied Physiology, 1988. 64(2): p. 719-727.

[11] Stolwijk, J.A.J. and J.D. Hardy, Control of body temperature, in Handbook of physiology - reaction to environmental agents, D.H.K. Lee, Editor. 1977. p. 45-68.

[12] Montgomery, L.D., A model of heat transfer in immersed man. Annals of Biomedical Engineering, 1974. 2(1): p. 19-46. 
[13] Gagge, A.P., A two node model of human temperature regulation in FORTRAN, in Bioastronautics Data Book, NASA SP-3006, J.F. Parker and V.R. West, Editors. 1973: Washington D.C. p. 142-148.

[14] Fiala, D., K.J. Lomas, and M. Stohrer, Computer prediction of human thermoregulatory and temperature responses to a wide range of environmental conditions. Int. J. Biometeorol., 2001. 45: p. 143-159.

[15] Fiala, D., K.J. Lomas, and M. Stohrer, A computer model of human thermoregulation for a wide range of environmental conditions: The passive system. J. Appl. Physiol., 1999. 87: p. 1957-1972.

[16] Werner, J. and P. Webb, A six-cylindrical model of human thermoregulation for general use on personal computers. Ann. Physiol. Anthrop., 1993. 12(3): p. 123-134.

[17] Wissler, E.H., Mathematical simulation of human thermal behavior using whole body models, in Heat transfer in medicine and biology, A. Shitzer and R.C. Eberhart, Editors. 1985, Plenum Press, New York. p. 325-373.

[18] Gordon, R.G., R.B. Roemer, and S.M. Horvath, A mathematical model of the human temperature regulatory system - Transient cold exposure response. IEEE Transactions on Biomedical Engineering, 1976. BME-23(6): p. 434-444.

[19] Qi, Y., A new two-dimensional human thermal model and study of heat transfer in living tissue. 1994, Ph.D. dissertation, The University of Texas: Austin.

[20] Mungcharoen, T. and E.H. Wissler. A new two-dimensional human thermal model. in AIChE Symposium Series. 1989. Philadelphia, PA, USA.

[21] Kuznetz, L.H., A two-dimensional transient mathematical model of human thermoregulation. American Journal of Physiology, 1979. 237(5): p. R266-R277.

[22] Smith, C.E., A transient three-dimensional model of the human thermal system. 1991, Ph.D. dissertation, Kansas State University: Manhattan.

[23] Werner, J. and M. Buse, Three-dimensional simulation of cold and warm defense in man, in Environmental Ergonomics, I.B. Mekjavic, E.W. Banister, and J.B. Morrison, Editors. 1988, Taylor and Francis: New York. p. 286-296.

[24] Smith, L.F., J.D. French, S.S. Nair, J.B. Miles, and B.W. Webbon, Evaluation of human thermal models for EVA applications. Transactions of the Society of Automotive Engineers, J. Commercial Veh., 1996. 105(1): p. 698-706. 
[25] French, J.D., A.D. Viswanath, S.S. Nair, J.B. Miles, and C. Lin, Parameter values and assumptions in human thermal modeling for EVA applications. Transactions of the Society of Automotive Engineers, Journal of Aerospace, 1997. 106(1): p. 579-586.

[26] Ganong, W.F., Review of Medical Physiology. 2005, New York: McGraw-Hill Medical.

[27] Manier, L., T. Johnson, S.S. Nair, and J.B. Miles. A review of muscular efficiency studies for different exercises. in 31st International Conference on Environmental Systems. 2001. Orlando, FL.

[28] Stainsby, W.N., L.B. Gladden, J.K. Barclay, and B.A. Wilson, Exercise efficiency: validity of base-line subtractions. Journal of Applied Physiology, 1980. 48(3): p. 518522.

[29] Nunneley, S.A., Water cooled garments: A review. Space Life Sciences, 1970. 2: p. 335360 .

[30] Hemingway, A. and D.G. Stuart, Shivering in man and animals, in Temperature, its measurement and control in science and industry, J.D. Hardy, Editor. 1963, Reinhold Publishing Corporation: New York. p. 407-427.

[31] ASHRAE, ASHRAE handbook \& product directory - 1977 fundamentals. 1977, New York: American Society of Heating, Refrigeration, and Air-Conditioning Engineers.

[32] Leithead, C.S. and A.R. Lind, Heat stress and heat disorders. 1964, Philadelphia: F.A. Davis.

[33] Ladell, W.S.S., Thermal sweating. Brit. Med. Bull., 1945. 3: p. 175.

[34] Nadel, E.R., A brief overview..., in Problems with temperature regulation during exercise, E.R. Nadel, Editor. 1977, Academic Press Inc.

[35] Webb, P., The physiology of heat regulation. American J of Phys, 1995. 268: p. R838R850.

[36] Kerslake, D., An estimate of the preferred skin temperature distribution in man, in FPRC Memo 213, Flying Personnel Research Committee, RAF Institute of Aviation Medicine. 1964: Farnborough.

[37] Saltin, B. and L. Hermansen, Esophageal, rectal, and muscle temperature during exercise. J. Appl. Physiol., 1966. 21: p. 1757-1762.

[38] ASHRAE, Thermal comfort conditions, ASHRAE Standard 55-66. 1966, New York: American Society of Heating, Refrigeration, and Air-Conditioning Engineers. 
[39] Hensen, J.L.M., Literature review on thermal comfort in transient conditions. Building and Environment, 1990. 25(4): p. 309-316.

[40] Fanger, P.O., Calculation of thermal comfort: Introduction of basic comfort equation. ASHRAE Transactions, 1967. 73(Part 2): p. 2051.

[41] Pisacane, V.L., L.H. Kuznetz, J.S. Logan, J.B. Clark, and E.H. Wissler, Thermoregulatory models of space shuttle and space station activities. Aviat Space Environ Med, 2007. 78(4, Suppl.): p. A48-A55.

[42] Kuznetz, L.H., Control of thermal balance by a liquid circulating garment based on a mathematical representation of the human thermoregulatory system. 1975, Ph.D. dissertation, University of California, Berkeley.

[43] Veghte, J.H., Efficacy of pressure suit cooling systems in hot environments. Aerospace Medicine, 1965. 36: p. 964-967.

[44] Kelly, G.F., D.O. Coons, and W.R. Carpentier, Medical aspects of Gemini extravehicular activities. Aerospace Medicine, 1968. 39: p. 611-615.

[45] Chambers, A.B., Controlling thermal comfort in the EVA space suit. ASHRAE Journal, 1970. 12(March): p. 33-38.

[46] Wortz, E.C., D.K. Edwards, and T.J. Harrington, New techniques in pressure suit cooling. Aerospace Medicine, 1964. 35: p. 978-984.

[47] Roth, E.M., Bioenergetics of space suits for lunar exploration. NASA SP-84, 1966.

[48] Harrington, T.J., D.K. Edwards, and E.C. Wortz, Metabolic rates in pressurized pressure suits. Aerospace Medicine, 1965. 36: p. 825-830.

[49] Burton, D.R., Performance of water conditioned suits. Aerospace Medicine, 1966. 37: p. 500-504.

[50] Billingham, J., Heat exchange between man and his environment on the surface of the moon. J. British Interplanetary Soc., 1959. 17: p. 297-300.

[51] Burton, D.R. and L. Collier, The development of water conditioned suits, in Tech. Note ME-400. 1964, Royal Aircraft Establishment: Farnborough.

[52] Jennings, D.C., Water-cooled space suit. J. Spacecraft, 1966. 3: p. 1251-1256.

[53] Short, B.D., The effect of coolant flow rates on the performance of the liquid conditioned coverall, in Technical Report No. 76171. 1976, Royal Aircraft Establishment. 
[54] London, R.C. A review of work in the United Kingdom on water cooling suits. in Proceedings of the Symposium on Individual Cooling. 1969. Kansas State University.

[55] Burton, D.R. Engineering aspects of personal conditioning. in Proceedings of the Symposium on Individual Cooling, AD 694 130. 1969. Kansas State University.

[56] Hensel, H., Neural processes in thermoregulation. Physiol. Rev., 1973. 53: p. 948-1017.

[57] Harrison, M.H. and A.J. Belyavin, Operational characteristics of liquid-conditioning suits. Aviat. Space Environ. Med., 1978. 49(8): p. 994-1003.

[58] Shvartz, E., M. Aldjem, J. Ben-Mordechai, and Y. Shapiro, Objective approach to a design of a whole-body, water-cooled suit. Aerospace Medicine, 1974. 45(7): p. 711-715.

[59] Shitzer, A., J.C. Chato, and B.A. Hertig, Thermal protective garment using independent regional control of coolant temperature. Aerospace Medicine, 1973. 44(1): p. 49-59.

[60] Webb, P., J.F. Annis, and S.J. Troutman, Human calorimetry with a water-cooled garment. J. Appl. Physiol., 1972. 32(3): p. 412-418.

[61] Shvartz, E., Efficiency and effectiveness of different water cooled suits-a review. Aerospace Medicine, 1972. 43(5): p. 488-491.

[62] Kuznetz, L.H., Automatic control of human thermal comfort by a liquid-cooled garment. J. Biomech. Eng. Trans. ASME, 1980. 102(2): p. 155-161.

[63] Smith, L.F., A.B. Campbell, S.S. Nair, J.B. Miles, and B.W. Webbon, Issues in the development of automatic thermal control for portable life support systems, in 24th International Conference on Environmental Systems and 5th European Symposium on Space Environmental Control Systems. 1994: Friedrichshafen, Germany.

[64] Webb, P. and J.F. Annis, Bio-thermal responses to varied work programs in men kept thermally neutral by water cooled clothing, in NASA CR-739. 1967: Washington, D.C.: Nat. Aeronaut. Space Admin.

[65] Shvartz, E. and D. Benor, Total body cooling in warm environments. J. Appl. Physiol., 1971. 31(1): p. 24-27.

[66] Waligora, J.M. and E.L. Michel, Application of conductive cooling for working men in a thermally isolated environment. Aerospace Medicine, 1968. 39: p. 485-487.

[67] Cohen, J.B., J.R. Allan, and P.J. Sowood, Effect of head or neck cooling used with a liquid-conditioned vest during simulated aircraft sorties. Aviat. Space Environ. Med., 1989. 60: p. 315-320. 
[68] Nag, P.K., C.K. Pradhan, A. Nag, S.P. Ashtekar, and H. Desai, Efficacy of a water-cooled garment for auxiliary body cooling in heat. Ergonomics, 1998. 41: p. 179-187.

[69] Vallerand, A.L., R.D. Michas, J. Frim, and K.N. Ackles, Heat balance of subjects wearing protective clothing with a liquid- or air-cooled vest. Aviat. Space Environ. Med., 1991. 62: p. 383-391.

[70] van Rensburg, A.J., D. Mitchell, W.H. van der Walt, and N.B. Strydom, Physiological reactions of men using microclimate cooling in hot humid environments. Brit. J. Industr. Med., 1972. 29: p. 387-393.

[71] Kaufman, W.C. and J.C. Pittman, A simple liquid transport cooling system for aircrew members. Aerospace Medicine, 1966. 37: p. 1239-1243.

[72] McLellan, T.M., J. Frim, and D.G. Bell, Efficacy of air and liquid cooling during light and heavy exercise while wearing NBC clothing. Aviat. Space Environ. Med., 1999. 70: p. $802-811$.

[73] Gold, A.J. and A. Zornitzer, Effect of partial body cooling on man excercising in a hot, dry environment. Aerospace Medicine, 1968. 39: p. 944-946.

[74] Shvartz, E., Effect of a cooling hood on physiological responses to work in a hot environment. J. Appl. Physiol., 1970. 29: p. 36-39.

[75] Nunneley, S.A. and R.J. Maldonado, Head and/or torso cooling during simulated cockpit heat stress. Aviat. Space Environ. Med., 1983. 54(6): p. 496-499.

[76] Kissen, A.T., W.C. Summers, W.J. Buehring, M. Alexander, and D.C. Smedley, Head and neck cooling by air, water, or air plus water in hyperthermia. Aviat. Space Environ. Med., 1976. 47(3 ): p. 265-271.

[77] Williams, B.A. and A. Shitzer, Modular liquid-cooled helmet liner for thermal comfort. Aerospace Medicine, 1974. 45(9): p. 1030-1036.

[78] Nunneley, S.A., S.J. Troutman, Jr., and P. Webb, Head cooling in work and heat stress. Aerospace Medicine, 1971. 42(1): p. 64-68.

[79] Kissen, A.T., J.F. Hall, Jr., and F.K. Klemm, Physiological responses to cooling the head and neck versus the trunk and leg areas in severe hyperthermic exposure. Aerospace Medicine, 1971. 42: p. 882-888.

[80] Morales, V. and S. Konz, The physiological effect of a water-cooled hood in a heat stress environment. ASHRAE Transactions, 1968. 74(II): p. 236-249. 
[81] Xu, X., M. Hexamer, and J. Werner, Multi-loop control of liquid cooling garment systems. Ergonomics, 1999. 42(2): p. 282-298.

[82] Crocker, J.F., P. Webb, and D.C. Jennings, Metabolic heat balances in working men wearing liquid cooled sealed clothing, in AIAA-NASA Third Manned Spaceflight Meeting. 1964, AIAA Publication CP-10. p. 111-117.

[83] Clifford, J.M., Regional heat loss in man in a state of thermal comfort. FPRC/1261. 1961: Flying Personnel Research Committee, RAF Institute of Aviation Medicine, Farnborough.

[84] Froese, G. and A.C. Burton, Heat losses from the human head. J. Applied Physiol., 1957. 10: p. 235-241.

[85] Stolwijk, J.A.J., Mathematical model of thermoregulation, in Physiological and behavioral temperature regulation, J.D. Hardy, A.P. Gagge, and J.A.J. Stolwijk, Editors. 1970, Charles C. Thomas: Springfield, Illinois. p. 703-721.

[86] Pennes, H.H., Analysis of tissue and arterial blood temperatures in the resting human forearm. Journal of Applied Physiology, 1948. 1: p. 93-121.

[87] Charny, C.K., Mathematical models of bioheat transfer, in Bioengineering heat transfer Advances in heat transfer, Y.I. Cho, Editor. 1992, Academic Press, Inc.: San Diego. p. $19-155$.

[88] Weinbaum, S. and L.M. Jiji, A new simplified bioheat equation for the effect of blood flow on local average tissue temperature. ASME J. Biomech. Eng., 1985. 107: p. 131139.

[89] Charny, C.K., S. Weinbaum, and R.L. Levin, An evaluation of the Weinbaum-Jiji bioheat equation for normal and hyperthermic conditions. ASME J. Biomech. Eng., 1990. 112: p. 80-87.

[90] Havenith, G., Individualized model of human thermoregulation for the simulation of heat stress response. J. Appl. Physiol., 2001. 90: p. 1943-1954.

[91] Werner, J. Computer modeling of physiological responses: trends for the future. in Proceedings of the 7th ICEE. 1994. Freund, London.

[92] Wissler, E.H., A review of human thermal models, in Environmental Ergonomics, I.B. Mekjavic, E.W. Banister, and J.B. Morrison, Editors. 1988, Taylor \& Francis: New York. p. 267-285.

[93] Houdas, Y., Modeling of heat transfer in man, in Bioengineering, Thermal Physiology and Comfort, K. Cena and J.A. Clark, Editors. 1981, Elsevier: Amsterdam. p. 111-120. 
[94] Hwang, C.L. and S.A. Konz, Engineering model of the human thermoregulatory systemA review. IEEE Trans. Biomed. Eng., 1977. 24: p. 309-325.

[95] Hardy, J.D., Models of temperature regulation - A review, in Essays on temperature regulation, J. Bligh and R.E. Moore, Editors. 1972, Amsterdam: North Holland Pub. Co.; New York, American Elsevier. p. 163-186.

[96] Fan, L.T., F.T. Hsu, and C.L. Hwang, A review on mathematical models of the human thermal system. IEEE Trans. Biomed. Eng., 1971. 18: p. 218-234.

[97] Burton, A.C., The application of the theory of heat flow to the study of energy metabolism. J. Nutr., 1934. 7: p. 497.

[98] Wyndham, C.H. and A.R. Atkins. An approach to the solution of the human biothermal problem with the aid of an analogue computer. in Proc. 3rd Internat. Conf. Med. Electron. 1960. London.

[99] Wissler, E.H., Steady-state temperature distribution in man. J. Appl. Physiol., 1961. 16: p. 734-740.

[100] Wissler, E.H., An analysis of factors affecting temperature levels in the nude human, in Temperature - Its measurements and control in science and industry, J.D. Hardy, Editor. 1963, Reinhold: New York. p. 603-612.

[101] Wissler, E.H., A mathematical model of the human thermal system. Bull. Math. Biophys., 1964. 26: p. 147-166.

[102] Crosbie, R.J., J.D. Hardy, and E. Fessenden, Electrical analog simulation of temperature regulation in man, in Temperature - its measurement and control in science and industry, J.D. Hardy, Editor. 1963, Reinhold: New York. p. 627-635.

[103] Wyndham, C.H. and A.R. Atkins, A physiological scheme and mathematical model of thermoregulation in man. Pflügers Archiv, 1968. 303: p. 14-30.

[104] Gagge, A.P., J.A.J. Stolwijk, and Y. Nishi, An effective temperature scale based on a simple model of human physiological regulatory response. ASHRAE Transactions, 1971. 77(1): p. 247-262.

[105] Fanger, P.O., Thermal comfort, analysis and applications in engineering. 1982, New York: McGraw Hill.

[106] Stolwijk, J.A.J. and J.D. Hardy, Temperature regulation in man - A theoretical study. Pflügers Archiv, 1966. 291: p. 129-162. 
[107] Haslam, R.A. and K.C. Parsons, A comparison of models for predicting human response to hot and cold environments. Ergonomics, 1987. 30(11): p. 1599-1614.

[108] Tikuisis, P., Prediction of the thermoregulatory response for clothed immersion in cold water. European Journal of Applied Physiology, 1989. 59: p. 334-341.

[109] Tikuisis, P., R.R. Gonzalez, and K.B. Pandolf, Prediction of human thermoregulatory responses and endurance time in water at 20 and $24^{\circ} \mathrm{C}$. Aviat. Space Environ. Med., 1988. 59: p. 742-748.

[110] Tikuisis, P. and R. Gonzalez, Rational considerations for modeling human thermoregulation during cold water immersion. ASHRAE Transactions, 1988. 94(DA88-16-3): p. 10.

[111] Xu, X. and J. Werner, A dynamic model of the human/clothing/environment-system. Applied Human Science, 1997. 16(2): p. 61-75.

[112] Fiala, D., Dynamic simulation of human heat transfer and thermal comfort. 1998, Ph.D. dissertation, De Montfort University: Leicester, UK.

[113] Schuh, H., Differenzenverfahren zum berechnen von temperatur-ausgleichsvorgängen bei eindimensionaler wärmeströmung in einfachen und zusammengesetzten körpern. Forschung auf dem Gebiete des Ingenieurwesens. 1957, Düsseldorf, Germany, VDIVerlag, 23, p. 1-37.

[114] Salloum, M., H. Ghaddar, and K. Ghali. A new transient bio-heat model of the human body. in Proceedings of the ASME Summer Heat Transfer Conference. 2005. San Francisco, CA, United States.

[115] Werner, J. and M. Buse, Temperature profiles with respect to inhomogeneity and geometry of the human body. Journal of Applied Physiology, 1988. 65(3): p. 1110-1118.

[116] Mungcharoen, T., A two-dimensional human thermal model for execution on a parallel processor. 1989, Ph.D. dissertation, The University of Texas: Austin, TX.

[117] Takemori, T., T. Nakajima, and Y. Shoji, A fundamental model of the human thermal system for prediction of thermal comfort. Heat Transfer - Japanese Research, 1995. 24(2): p. 147-165.

[118] Fu, G., A transient 3-D mathematical thermal model for the clothed human. 1995, Ph.D. dissertation, Kansas State University: Manhattan.

[119] Buchberg, H. and C.B. Harrah, Conduction cooling of the human body - a biothermal analysis, in Thermal problems in biotechnology. 1968, American Society of Mechanical Engineers. p. 82-95. 
[120] Shitzer, A., J.C. Chato, and B.A. Hertig, Removal of metabolic heat from man working in a protective suit, in Second Conference on Portable Life Support Systems, NASA SP-302. 1972. p. 265-281.

[121] Shitzer, A., J.C. Chato, and B.A. Hertig, A study of the thermal behavior of living biological tissue with application to thermal control of protective suits. 1971, Technical Report No. ME-TR-207, Department of Mechanical and Industrial Engineering, University of Illinois at Urbana-Champaign: Urbana, Ill.

[122] Wissler, E.H., Simulation of fluid-cooled or heated garments that allow man to function in hostile environments. Chem. Eng. Sci., 1986. 41(6): p. 1689-1698.

[123] Xiugan, Y. and S. Bin, A new two-dimensional "man-WCV" mathematical model of the human thermoregulation. Chinese Journal of Aeronautics, 1990. 3(4): p. 266-276.

[124] Nyberg, K.L., K.R. Diller, and E.H. Wissler. Modeling of human thermal regulation for liquid cooling garment applications. in ASME HTD, 355, p. 119-126. 1997. Dallas, TX, USA.

[125] Nyberg, K.L., K.R. Diller, and E.H. Wissler, Model of human/liquid cooling garment interaction for space suit automatic thermal control. J. Biomech. Eng. Trans. ASME, 2001. 123: p. 114-120.

[126] Nyberg, K.L., Design and evaluation of automatic control for human/liquid cooling garment thermal interaction. 1998, Ph.D. dissertation, The University of Texas at Austin.

[127] Xu, X., L.G. Berglund, S.N. Cheuvront, T.L. Endrusick, and M.A. Kolka, Model of human thermoregulation for intermittent regional cooling. Aviat. Space Environ. Med., 2004. 75(12): p. 1065-1069.

[128] Pu, Z., A dynamic model of the human/cooling system/clothing/environment system. 2005, Ph.D. dissertation, University of Central Florida: Orlando, FL.

[129] Rowell, L.B., Human cardiovascular adjustments to exercise and thermal stress. Physiol. Rev., 1974. 54: p. 75-159.

[130] Johnson, J.L., L.B. Rowell, and G.L. Brengelmann, Modification of the skin blood flow body temperature relationship by upright exercise. J Appl Physiol, 1974. 37: p. 880-886.

[131] Westin, J.K., J.S. Kapat, and L.C. Chow. Evaluating a thermoregulatory model for cooling garment applications with transient metabolic rates. in Proceedings of the ASME Summer Heat Transfer Conference. 2008. Jacksonville, Florida USA. 
[132] Jones, A.M. and D.C. Poole, Oxygen uptake kinetics in sport, exercise and medicine. 2005, London; New York: Routledge. 405.

[133] Eberhart, R.C., Thermal models of single organs, in Heat transfer in medicine and biology - Analysis and applications, A. Shitzer and R.C. Eberhart, Editors. 1985, Plenum: New York. p. 279-284.

[134] Durkee Jr., J.W., and P.P. Antich, Characterization of bioheat transport using an exact solution to the cylindrical geometry, multi-region, time-dependent bioheat equation. Phys. Med. Biol., 1991. 36(10): p. 1377-1406.

[135] Durkee Jr., J.W., P.P. Antich, and C.E. Lee, Exact solutions to the multiregion timedependent bioheat equation I: Solution development. Phys. Med. Biol., 1990. 35(7): p. 847-867.

[136] Durkee Jr., J.W., P.P. Antich, and C.E. Lee, Exact solutions to the multiregion timedependent bioheat equation II: Numerical evaluation of the solution. Phys. Med. Biol., 1990. 35(7): p. 869-889. 